\title{
Improved Roof Stabilization Technologies
}

\author{
Topical Report \\ January 1998
}

\author{
By: \\ M. A. Ebadian
}

Work Performed Under Contract No.: DE-FG21-95EW55094

For

U.S. Department of Energy

Office of Fossil Energy

Federal Energy Technology Center

P.O. Box 880

Morgantown, West Virginia 26507-0880
RECEIVED

OCT 201998

Q.STI

By

Florida International University

Hemispheric Center for Environmental Technology (HCET)

Center for Engineering \& Applied Sciences

10555 West Flagler Street

EAS-2100

Miami, Florida 33174 


\section{Disclaimer}

This report was prepared as an account of work sponsored by an agency of the United States Government. Neither the United States Government nor any agency thereof, nor any of their employees, makes any warranty, express or implied, or assumes any legal liability or responsibility for the accuracy, completeness, or usefulness of any information, apparatus, product, or process disclosed, or represents that its use would not infringe privately owed rights. Reference herein to any specific commercial product, process, or service by trade name, trademark, manufacturer, or otherwise does not necessarily constitute or imply its endorsement, recommendation, or favoring by the United States Government or any agency thereof. The views and opinions of authors expressed herein do not necessarily state or reflect those of the United States Government or any agency thereof. 


\section{DISCLAIMER}

\section{Portions of this document may be illegible electronic image products. Images are produced from the best available original document.}


LIST OF TABLES

LIST OF FIGURES $\mathrm{v}$

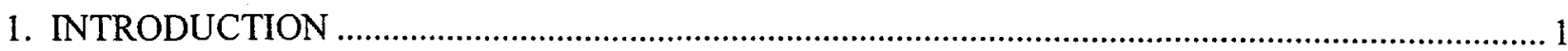

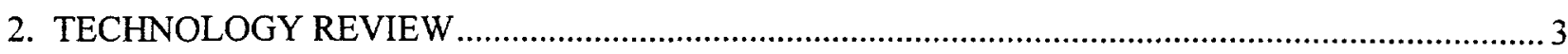

2.1 REVIEWS OF EXISTING MAINTENANCE METHODS ON ROOF SYSTEMS

2.2 INTERPRETATION OF THE PRESENT METHOD AND EXISTING METHODS 4

3. DETERMINISTIC ANALYSIS OF ROOF STRUCTURES ........................................................ 7

3.1 BASIC PRINCIPLES OF FINITE ELEMENT METHOD(FEM) ..................................... 7

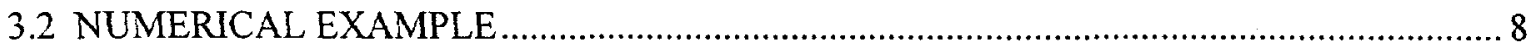

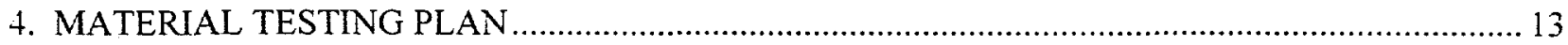

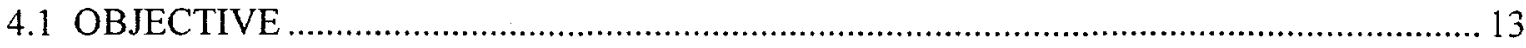

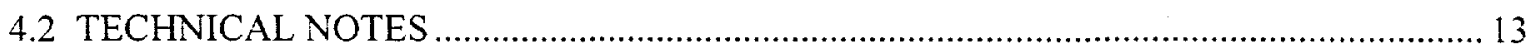

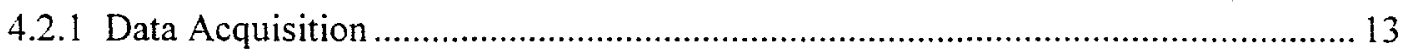

4.2.2 Data Processing ......................................................................................... 14

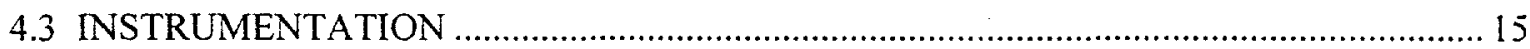

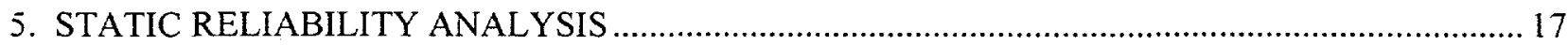

5.1 BASIC PRINCIPLES OF STOCHASTIC FINITE ELEMENT METHOD

(SFEM) .17

5.1.1 Discretization of Random Field...................................................................... 17

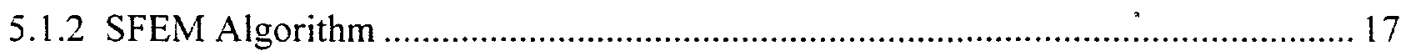

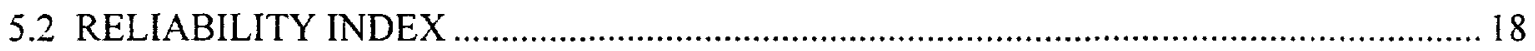

5.3 STABILITY AND STRENGTH ANALYSIS BASED ON SFEM ……………………..... 19

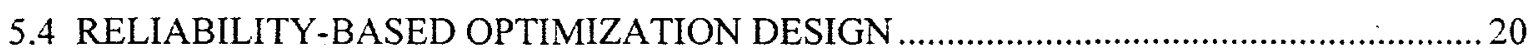

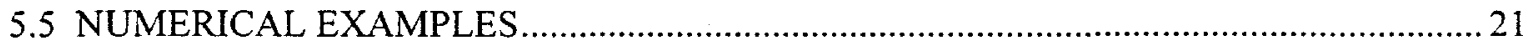

5.5.1 The Stability and Strength Limit State ................................................................. 21

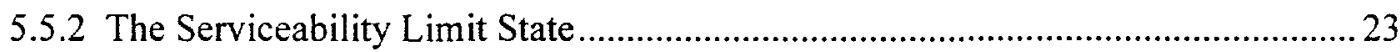

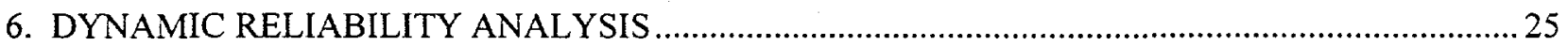

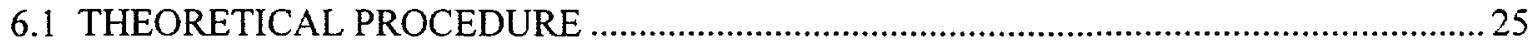

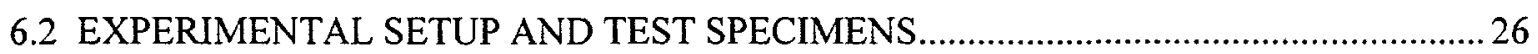

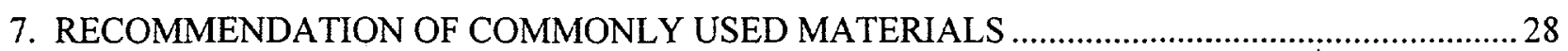

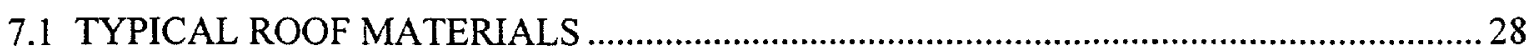

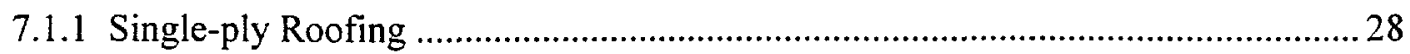

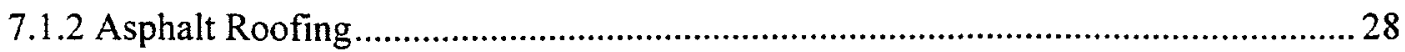




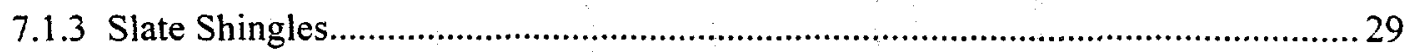

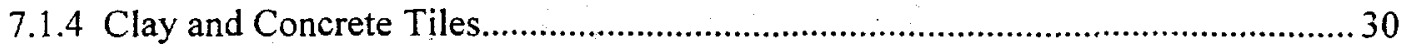

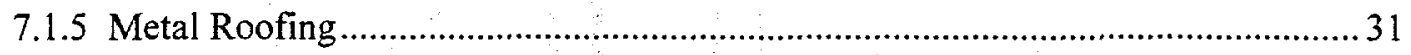

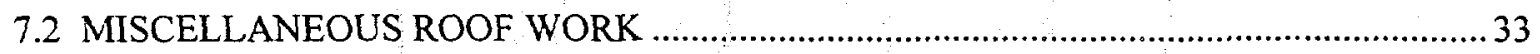

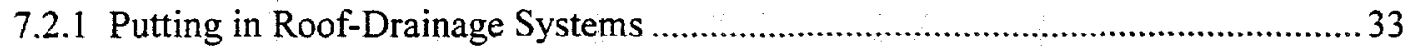

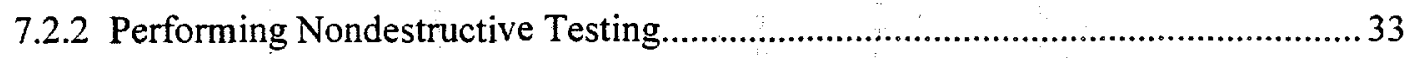

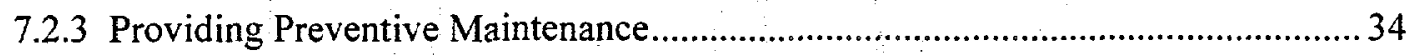

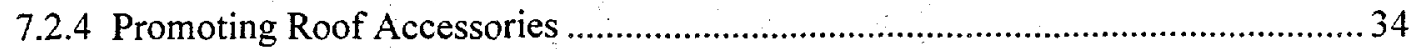

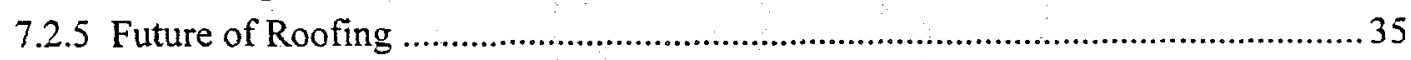

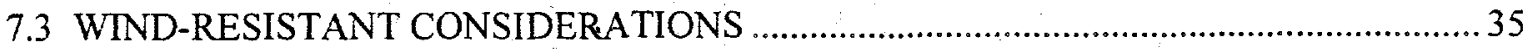

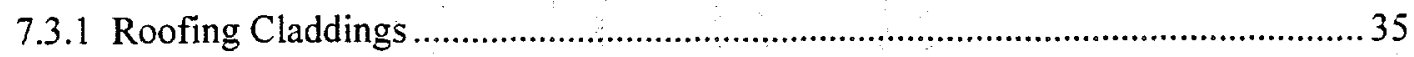

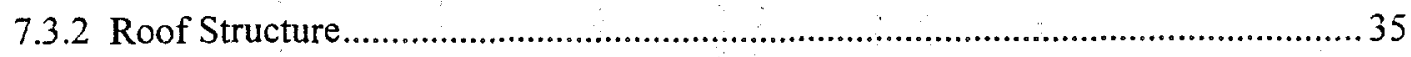

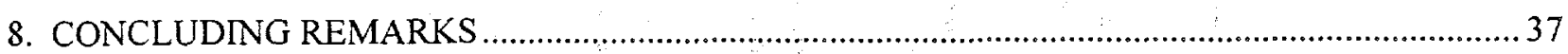

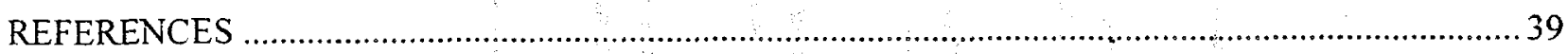

\section{LIST OF TABLES}

Table 1. Existing Programs for the Maintenance of Roof Systems ...........................................3

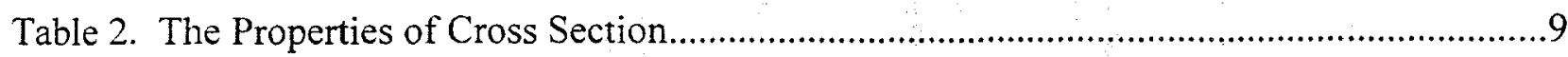

Table 3. The Solved Displacement at Each Node.................................................................10

Table 4. The Solved Deterministic Forces of Steel Members ...............................................12

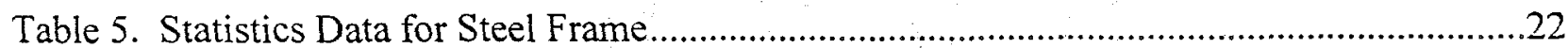

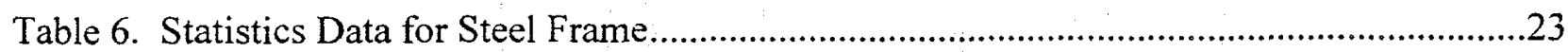




\section{LIST OF FIGURES}

Figure 1. One roof with problems at Savannah River Site. ................................................2

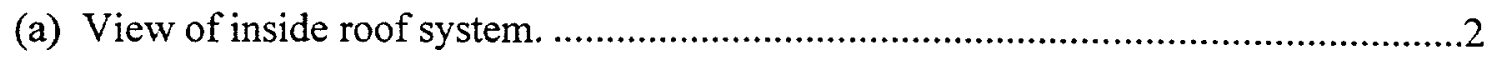

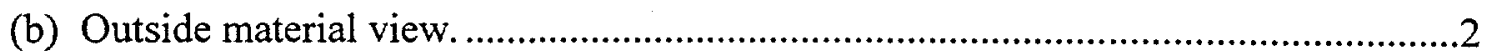

Figure 2. A flowchart for the static deterministic FEM analysis........................................... 7

Figure 3. A steel frame designed by LRFD method. ......................................................

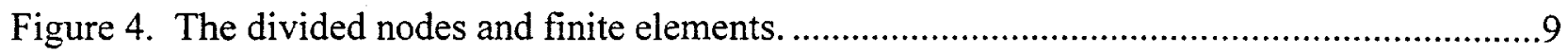

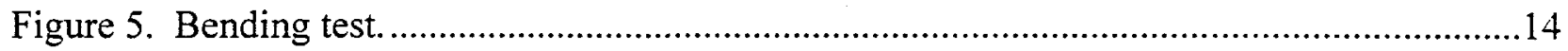

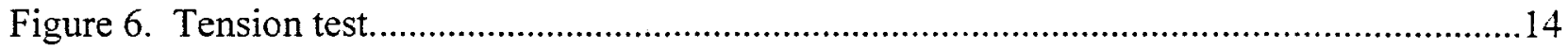

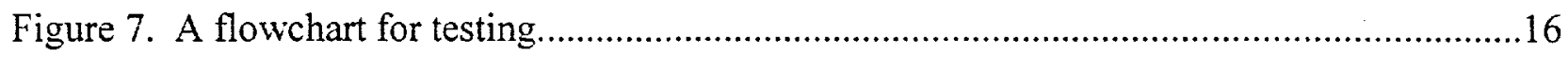

Figure 8. A steel frame with random stiffness and uniform load. .......................................22

Figure 9. Reliability index versus coefficient of correlation .............................................22

Figure 10. Safety probability versus coefficient of correlation $a$.........................................23

Figure 11. Reliability index $\beta$ versus coefficient of correlation $a$. .........................................24

Figure 12. Safety probability versus coefficient of correlation $a$.........................................24

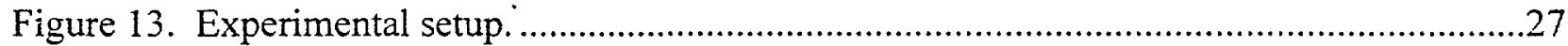

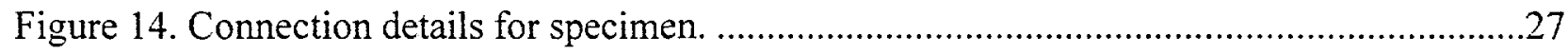

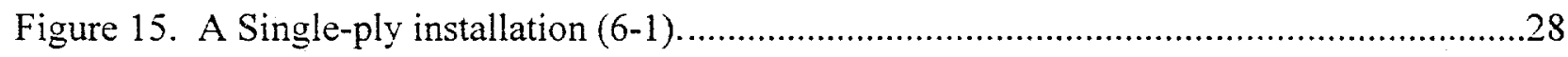

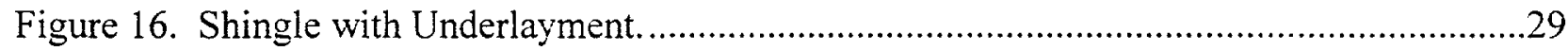

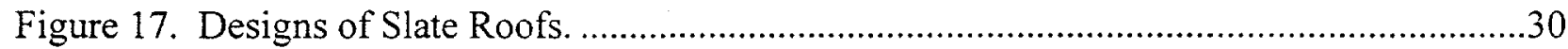

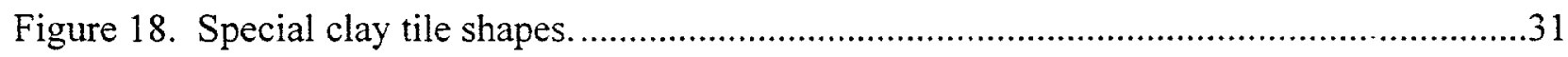

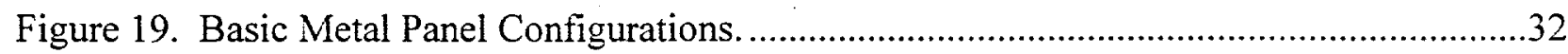

Figure 20. Creating a slope/subassembly system roof frame ...............................................33

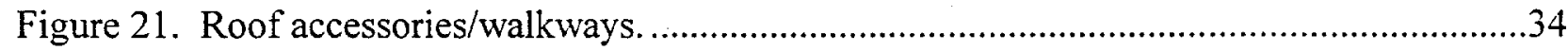




\subsection{INTRODUCTION}

Decontamination and decommissioning (D\&D) activities require that personnel have access to all areas of structures, some of which are more than 40 years old. In many cases, these structures have remained in a standby condition for up to 10 years; few preventative maintenance activities have been performed on them because of lack of funding or a defined future plan of action. This situation has led to deteriorated building conditions, resulting in potential personnel safety hazards. In addition, leaky roofs allow water to enter the buildings, which can cause the spread of contamination and increase building deterioration, worsening the already unsafe working conditions. To ensure worker safety and facilitate building dismantlement, the assessment of roof stabilization techniques applicable to U.S. Department of Energy (DOE) structures has become an important issue.

Many DOE remediation sites have performed roof repair and roof replacement to stabilize facilities prior to performing D\&D activities. This project will review the decision criteria used by these DOE sites, along with the type of repair system used for each different roof type. Based on this information, along with data gathered from roofing experts, a decision-making tool will be generated to help decision makers select the proper roof repair systems. Where appropriate, innovative technologies will be reviewed and applied to the decision-making tool to determine the applicability of these innovative technologies. Based on the results, applied research and development will be conducted to develop a methodology to repair these existing roof systems, and to protect the D\&D worker in a cost-efficient manner.

A trip by DOE and the Hemispheric Center for Environmental Technology at Florida international University (FIU-HCET) to the Savannah River Site (SRS) found that SRS spends about $\$ 3.5$ million per year to replace about $160,000 \mathrm{ft}^{2}$ of roof. They spend about $\$ 250,000$ per year to repair about $20,000 \mathrm{ft}^{2}$ of roof. Typical roofs with severe leaking problems are shown in Figure 1. Developing new technologies is necessary to enhance structural stability and to improve existing material properties of roof systems.

During fiscal year 1997 (FY97), a comprehensive reliability-based model for the structural stabilization analysis of roof system in complex structures was developed. The model consists of three major components: a material testing method, a deterministic structural computer model, and a reliability computer model. Using this model, static stability analyses, static reliability analyses, reliability-based optimization, and probabilistic analyses of roof structures can be implemented. Given site-specific needs, this model recommends the most appropriate roof

stabilization system. This model will give not only an accurate evaluation of the existing roof system in complex structures, but it will also be a reliable method to aid the decision-making process.

This final report includes in its appendix a Users' Manual for the Program of Deterministic and Reliability Analysis of Roof Structures. 


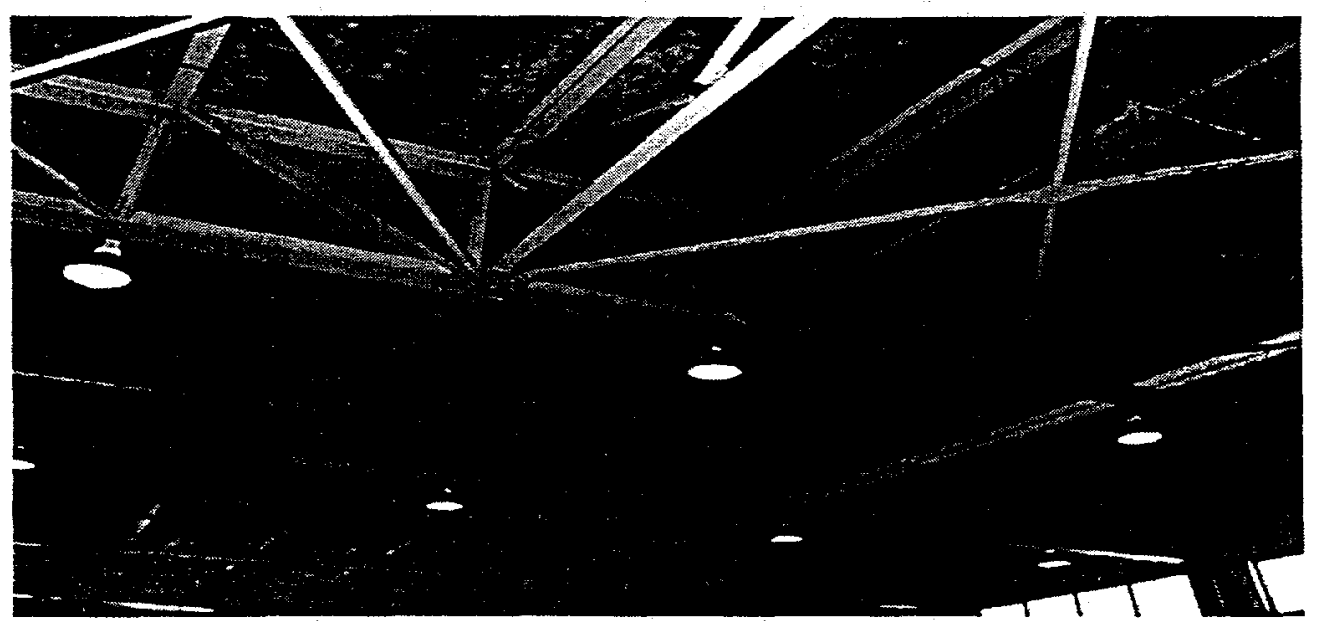

(a) View of inside roof system.

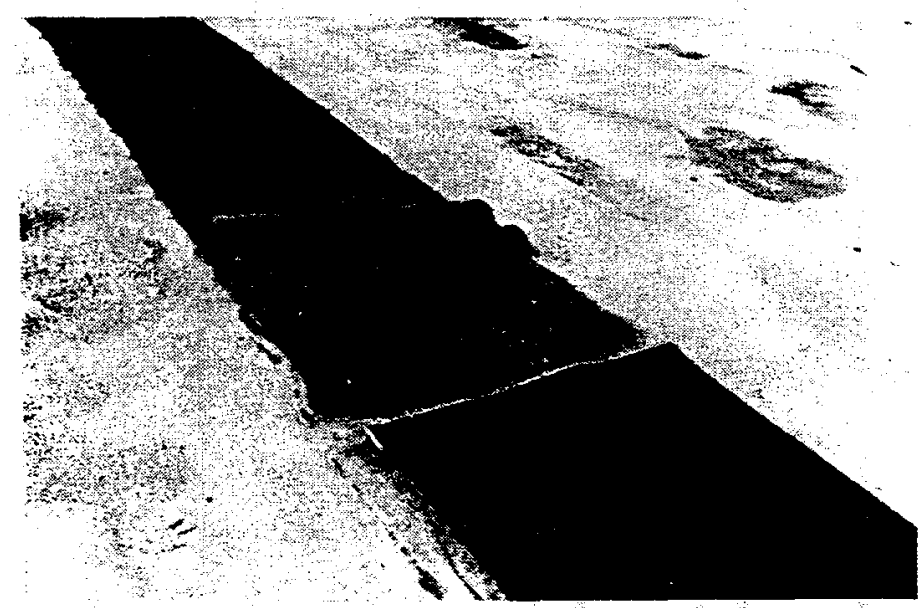

(b) Outside material view.

Figure 1. One roof with problems at Savannah River Site. 


\subsection{TECHNOLOGY REVIEW}

An extensive survey of existing technologies and research activities in the field of improved roof stabilization technologies is summarized in the following sections.

\subsection{REVIEWS OF EXISTING MAINTENANCE METHODS ON ROOF SYSTEMS}

Nowadays, several approaches have been used to evaluate roof systems, such as ROOFER, Hanford Jacobs Engineering Roofing Analytical Model-FACEDATA, and the Air Force Roof Management Program. The major functions of the three programs are listed in Table 1. All of them are information-based, decision-making management systems.

Table 1.

Existing Programs for the Maintenance of Roof Systems

\begin{tabular}{|c|c|c|c|}
\hline Program & ROOFER & FACEDATA & $\begin{array}{c}\text { Air Force Roof Management } \\
\text { Program }\end{array}$ \\
\hline Developer & $\begin{array}{l}\text { U.S. Army Construction } \\
\text { Engineering Research } \\
\text { Laboratory (USACERL) }\end{array}$ & Hanford Jacobs Engineering & U.S. Air Force \\
\hline Objective & $\begin{array}{l}\text { Provide the user with a cost- } \\
\text { effective program for } \\
\text { managing built-up and single- } \\
\text { ply membrane roofs. }\end{array}$ & $\begin{array}{l}\text { Provide a statistical projection } \\
\text { of the remaining life of the } \\
\text { roof structure. }\end{array}$ & $\begin{array}{l}\text { Provide technical standards and } \\
\text { general guidance for construction, } \\
\text { inspection, maintenance, and } \\
\text { repair for all types of roof } \\
\text { systems, reducing the life cycle } \\
\text { cost of Air Force building roofs, } \\
\text { and improving the effectiveness of } \\
\text { Air Force personnel in performing } \\
\text { these cost-reduction activities. }\end{array}$ \\
\hline Functions & $\begin{array}{l}\text { By visual inspection, it } \\
\text { identifies membrane and } \\
\text { flashing problems and an } \\
\text { aerial infrared (IR) roof scan } \\
\text { to locate areas of wet roof } \\
\text { insulation, and evaluates if it } \\
\text { is more cost effective to make } \\
\text { repairs or to replace the entire } \\
\text { roof. }\end{array}$ & $\begin{array}{l}\text { It calculates the return on } \\
\text { investment (ROI) achieved if } \\
\text { repairs and replacements are } \\
\text { performed and the additional } \\
\text { costs incurred if repairs and } \\
\text { replacements are delayed. }\end{array}$ & $\begin{array}{l}\text { It develops and maintains useful } \\
\text { information on topics such as } \\
\text { instructions for performing } \\
\text { inspections; roof system selection } \\
\text { guidance; energy conservation } \\
\text { techniques; construction details; } \\
\text { instructions for contracting for } \\
\text { construction and inspection; and } \\
\text { establishment of base-wide } \\
\text { maintenance programs. }\end{array}$ \\
\hline \begin{tabular}{|l|} 
Years of \\
development
\end{tabular} & 10 & - & - \\
\hline
\end{tabular}




\subsection{INTERPRETATION OF THE PRESENT METHOD AND EXISTING METHODS}

Since December 1996, we have been performing a reliability-based research plan entitled "Improved Roof Stabilization Technologies" for the roof systems of existing DOE buildings. The objective of this plan is to perform a structural reliability analysis of existing roof structures with severe problems and recommend the best possible roof structures for future buildings.

Although the FIU-HCET's "Improved Roof Stabilization Technologies" has the same general goal as that of ROOFER, Hanford Jacobs Engineering Roofing Analytical ModelFACEDATA, and Air Force Roof Management Program, its approach differs in that it involves. the development of a reliability-based model for structural stabilization analysis of roof systems. This model will have four major components:

- Material testing methods-These methods will be developed to obtain the required material information about existing roof structures for the reliability analysis.

- Deterministic analysis model-The well-known finite element method (FEM) will be used to establish a computer model for deterministic structural analysis. This FEM model is nonlinear and three dimensional.

- Static reliability-based analysis model-The stochastic finite element method (SFEM) will be able to perform the following analyses:

* Static stability-Determination of the buckling loads and the most significant parameters that affect the buckling of the roof system

* Static reliability-Determination of the reliability index under a prescribed limit state, which represents the safety or failure probability

* Reliability-based optimizations-Optimization of the design of roof systems according to objective function, such as weight, cost, or safety/failure probability

- Fatigue reliability analysis model-Use of a cumulative damage mechanism in fatigue reliability to determine the remaining life of existing roof structures.

The proposed FIU-HCET study emphasizes the stability safety of whole structures and is based on structural reliability analysis models. Statistical data on component properties, such as modulus of elasticity, section area, moment of inertia, etc., are obtained from numerous field tests at the job site. Thus, the test measures real conditions of every component of existing roof systems. The aim of the FIU-HCET model is to optimize the design of roof systems on the basis of weight, cost, or stability of the structure.

The U.S. Army Center for Public Works (USACPW) provides oversight and assistance on the U.S. Army Roofing Maintenance Management System, or ROOFER, to Army installations, Corps of Engineers Districts, and Army Reserves. ROOFER is an automated engineered management system (EMS) that provides the user with a cost-effective program for managing built-up and single-ply membrane roofs. ROOFER was developed by USACERL, with technical assistance provided by the U.S. Army Cold Regions Research and Engineering Laboratory (USACRREL), the U.S. Navy, the U.S. Air Force, two civilian consultants, and USACPW. The Windows-based ROOFER program is installed in a laptop computer to collect inspection data 
and includes a program-generated 10-year budget and the geographical information system (GIS).

ROOFER provides the user with the following benefits:

- Inventory of roof assets

- Development of detailed roof plans

- Detection of roof defects using:

* a visual inspection to identify membrane and flashing problems,

* an aerial IR roof scan to locate areas of wet roof insulation.

- Development of:

* condition indices for flashings (PCI), membrane (MCI), insulation ( $\mathrm{ICI})$, and overall roof condition $(\mathrm{RCI})$

* network analysis reports to summarize the findings and develop a 10-year budget program

* project analysis evaluation to determine if it is more cost-effective to accomplish the repairs or to replace the entire roof

* work requests to document the recommended action.

- Development of installation database and summary reports.

ROOFER is a convenient tool to manage a roof system. However, the operation of ROOFER depends on a very large number of data collected from various job sites. Furthermore, a visual inspection may not always reveal hidden structural damages; a defect may cause safety risks to workers.

Hanford Jacobs Engineering's FACEDATA is an analytical model that uses the information provided by the inspectors to determine the repairs necessary to maximize the extension of the Actuarial Projection of Service Life (APSL), a statistical projection of the remaining life of the roof structure. Pricing can be adjusted for radiologically contaminated areas (RCA), where additional costs will be incurred. The program calculates the ROI achieved if repairs and replacements are performed and the additional costs incurred if repairs and replacements are delayed. FACEDATA also has the capability to find less-than-optimum solutions if budgetary constraints exist.

The purpose of the Air Force Roof Management Program is to provide technical standards and general guidance for construction, inspection, maintenance, and repair for all types of roof systems. The goal of the program is to reduce the life-cycle cost of Air Force building roofs, and improve the effectiveness of Air Force personnel in performing these cost-reduction activities. The major function of this program is to develop and maintain useful information on topics such as instructions for performing inspections; roof system selection guidance; energy conservation techniques; construction details; instructions for contracting construction and inspections; and establishment of base-wide maintenance programs. 
Each program provides distinctive advantages over the others and all achieve improvements in roof structures. The FIU-HCET model's unique approach evaluates existing roof structures by performing field tests and mechanics analysis, rather than by processing collected data from the whole job-sites, thus providing a substantially cost-effective alternative.

The first phase of the FIU-HCET project will concentrate on the interior of a structure. In contrast to the other models, it evaluates every specific roof from the view of structural strength and stability. The goal in the second phase is to improve the exterior membrane portion of the structure. In the second phase, the other programs will be considered for inclusion into the FIUHCET model, thus achieving the development of a comprehensive model that includes the interior structural analysis, exterior top material, maintenance, and inspection. 


\subsection{DETERMINISTIC ANALYSIS OF ROOF STRUCTURES}

The most widely used numerical method, FEM, has a high accuracy in structural analysis. The present study uses FEM to solve the static displacement of roof structures under dead load and various live loads and a computer program uses Fortran language to analyze the roof structure.

\subsection{BASIC PRINCIPLES FEM}

A basic procedure for the FEM program, which is used to compute the static displacement of roof structures under dead load and various live loads, has been worked out, as shown in Figure 2. For a detailed interpretation of the FEM program one can refer to Bickford, 1990 and Martin and Carey, 1973.

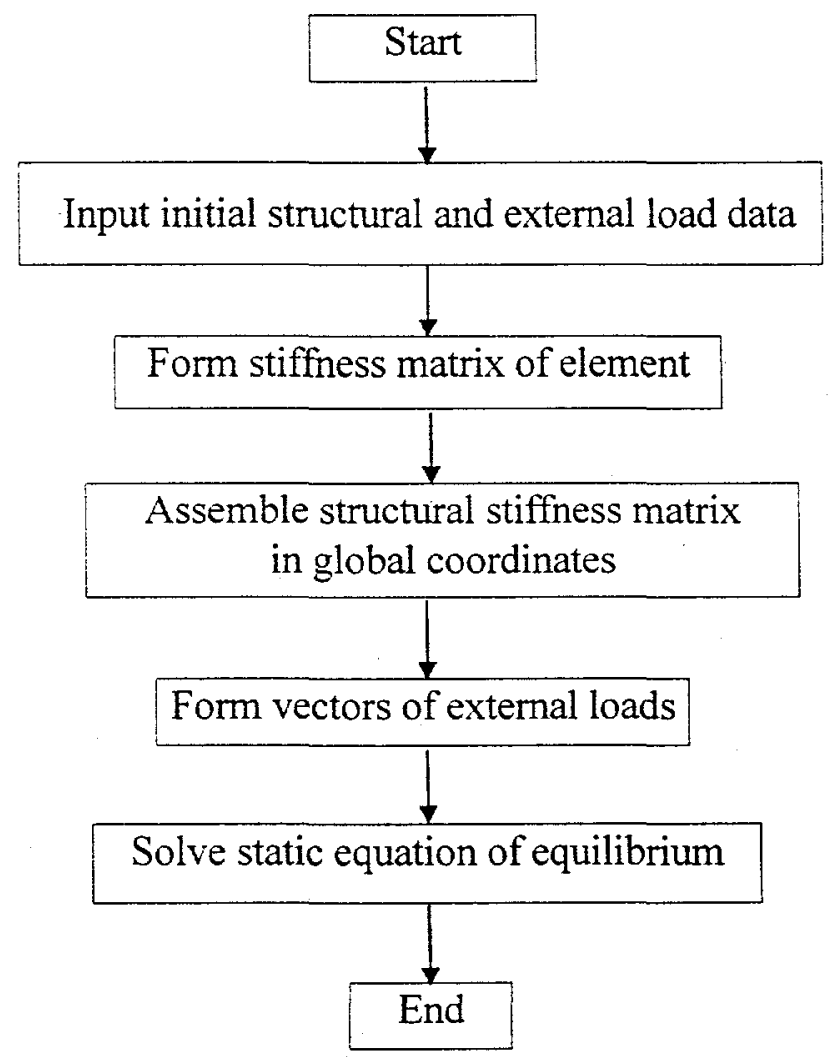

Figure 2. A flowchart for the static deterministic FEM analysis. 


\subsection{NUMERICAL EXAMPLE}

As a numerical example, a steel frame with a roof structure like the one shown in Figure 3 . is calculated by using the FORTRAN program developed in the project. Dividing of nodes and finite elements is shown in Figure 4. This plane steel frame example is designed according to the load and resistance factor design (LRFD) specifications (Tamboli, 1997). The analytical results are in accordance with those in Tamboli; 1997.

The section properties of this frame are shown in Table 2. The deterministic displacements at each node and the deterministic forces of steel members under dead load and live loads are shown in Tables 3 and 4, respectively.

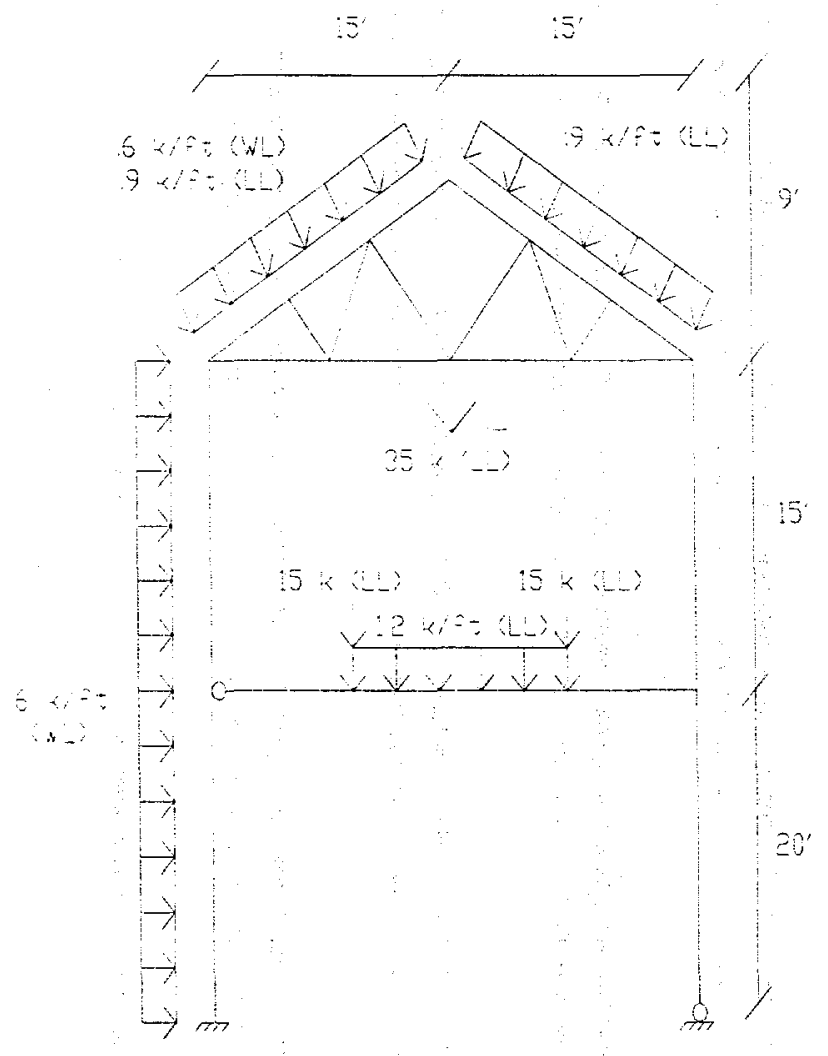

Note: LL: Live Load

WL: Wind Load

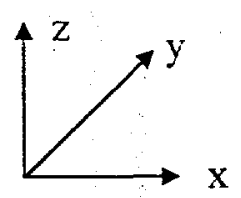

Figure 3. A steel frame designed by LRFD method. 


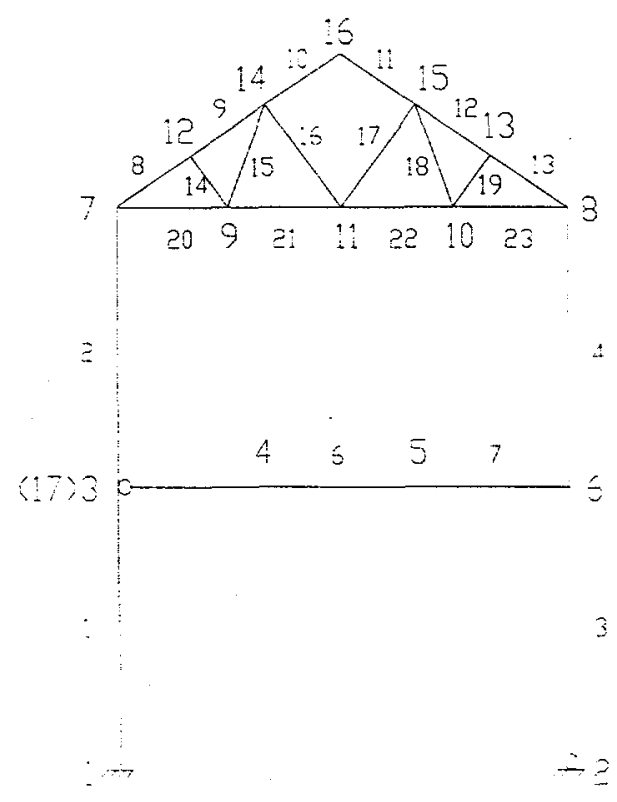

Note: Large size number represents the number of nodes;

Small size number represents the number of elements.

Figure 4. The divided nodes and finite elements.

Table 2.

The Properties of Cross Section

\begin{tabular}{|c|c|c|c|c|c|c|c|c|c|}
\hline Element No. & $\begin{array}{c}A_{x} \\
\left(\text { in. }^{2}\right) \\
\end{array}$ & $\begin{array}{c}\boldsymbol{A}_{y} \\
\text { (in.) } \\
\end{array}$ & $\begin{array}{c}A_{z} \\
\text { (in. }{ }^{2} \text { ) }\end{array}$ & $\begin{array}{c}I_{x} \\
\text { (in.) }\end{array}$ & $\begin{array}{c}I_{y} \\
\left.\text { (in. }{ }^{2}\right)\end{array}$ & $\begin{array}{c}I_{z} \\
\text { (in.) }\end{array}$ & $\begin{array}{c}E \\
\left(\text { in. }^{2}\right)\end{array}$ & $\begin{array}{c}\mu \\
\left.\text { (in. }{ }^{2}\right)\end{array}$ & $\begin{array}{c}\rho \\
\left(\text { in. }{ }^{2}\right)\end{array}$ \\
\hline $1,3,4$ & 26.5 & 6.17 & 13.75 & 4.06 & 362.0 & 999.0 & $.29 \times 10^{5}$ & 0.3 & $.283 \times 10^{-3}$ \\
\hline 2 & 14.4 & 3.39 & 7.47 & 1.39 & 93.40 & 272.0 & $.29 \times 10^{5}$ & 0.3 & $.283 \times 10^{-3}$ \\
\hline $5,6,7$ & 14.7 & 7.92 & 4.66 & 1.14 & 24.90 & 984.0 & $.29 \times 10^{5}$ & 0.3 & $.283 \times 10^{-3}$ \\
\hline $8,9,10,11,12,13$ & 10.3 & 5.31 & 3.4 & 0.51 & 15.30 & 510.0 & $.29 \times 10^{5}$ & 0.3 & $.283 \times 10^{-3}$ \\
\hline $\begin{array}{c}14,15,16,17,18,19,20 \\
21,22,23\end{array}$ & 1.9 & 0.67 & 0.67 & 0.04 & 4.850 & $0.122 \times 10^{-7}$ & $.29 \times 10^{5}$ & 0.3 & $.283 \times 10^{-3}$ \\
\hline
\end{tabular}


Table 3.

The Solved Displacement at Each Node

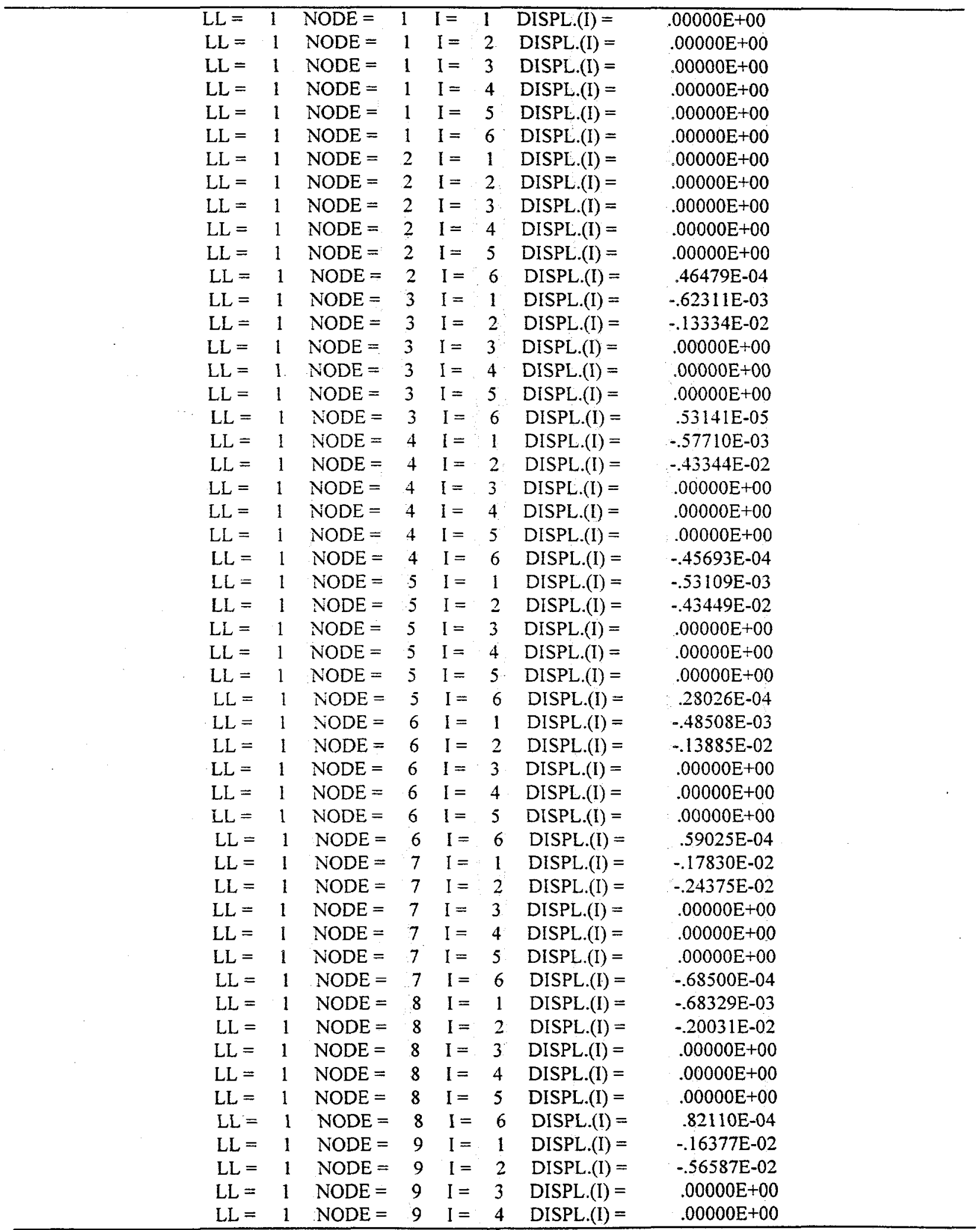




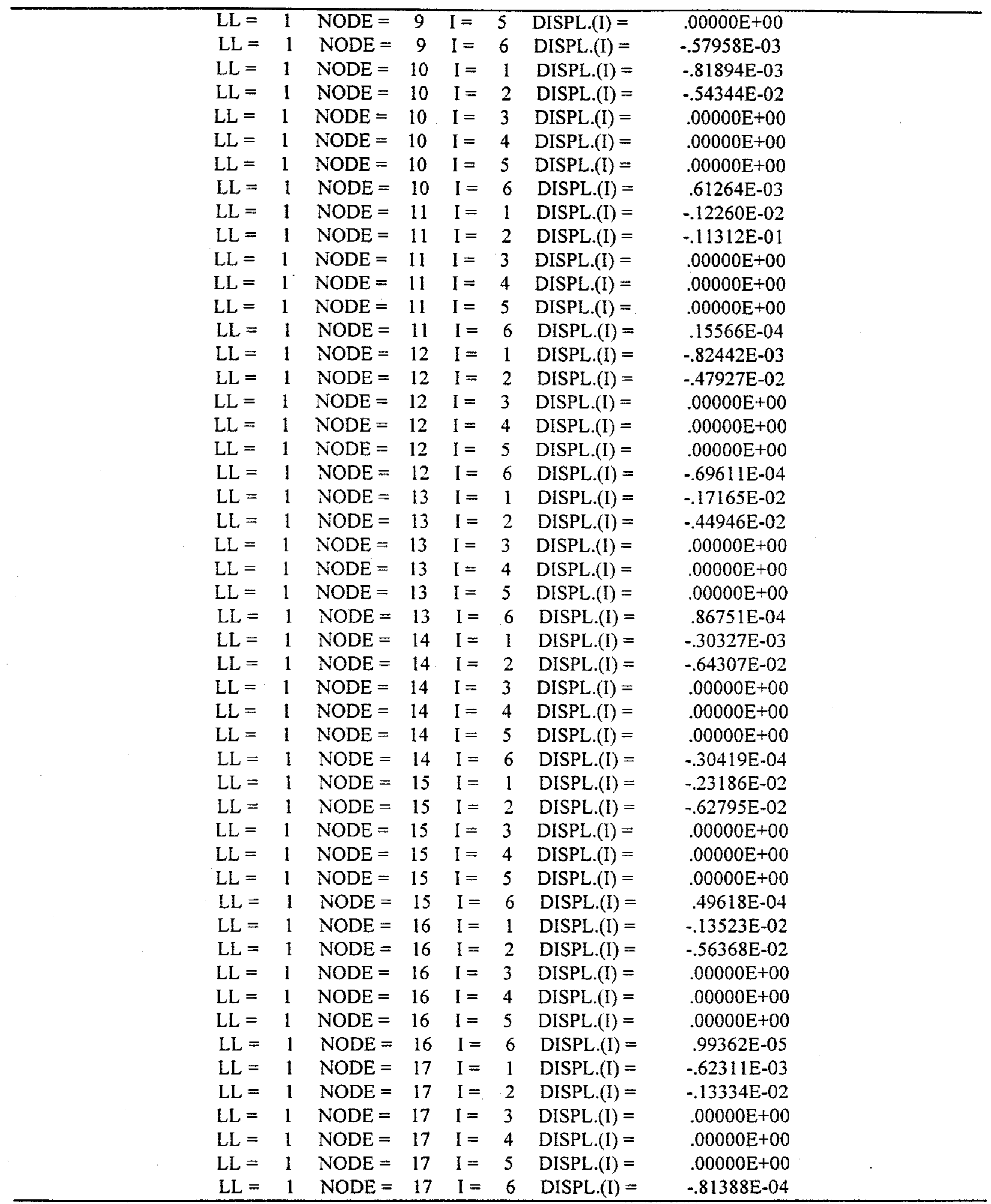

Note: $\quad L L=$ step of solution;

$I=I, \cdots, 6$, six directions of displacement in the 3D space; unit of displacement is in feet. 
Table 4.

The Solved Deterministic Forces of Steel Members

\begin{tabular}{|c|c|c|c|c|c|c|c|}
\hline $\begin{array}{c}\text { ELEM. } \\
\text { No. }\end{array}$ & $\begin{array}{l}\text { JOIN } \\
\text { No. }\end{array}$ & $\begin{array}{c}\text { NT AXIAL } \\
\text { (Kip) }\end{array}$ & $\begin{array}{c}\text { SHEAR-Y } \\
\text { (Kip) }\end{array}$ & $\begin{array}{l}\text { SHEAR-Z } \\
\text { (Kip) }\end{array}$ & $\begin{array}{c}\text { TORSION } \\
\text { (Kip-ft) }\end{array}$ & $\begin{array}{c}\text { MOM-Y } \\
\text { (Kip-ft) }\end{array}$ & $\begin{array}{r}\text { MOM-Z } \\
\text { (Kip-ft) }\end{array}$ \\
\hline \multirow[t]{2}{*}{1} & 1 & $.51235 \mathrm{E}+02$ & $.18173 E+01$ & $.00000 \mathrm{E} \div 00$ & $.00000 \mathrm{E}+00$ & $.00000 \mathrm{E}+00$ & $.25871 \mathrm{E}+02$ \\
\hline & 3 & $-.51235 E+02$ & $3 E+01$ & $.00000 \mathrm{E} \div 00$ & $.00000 \mathrm{E}+00$ & $.00000 \mathrm{E}-00$ & $.10476 \mathrm{E}+02$ \\
\hline \multirow[t]{2}{*}{2} & 3 & $.30737 \mathrm{E}+02$ & $.37787 \mathrm{E}+01$ & $.00000 \mathrm{E} \div 00$ & $.00000 E+00$ & $.00000 \mathrm{E} \div 00$ & $-.10476 E+02$ \\
\hline & 7 & $-.30737 E+02$ & $-.37787 \mathrm{E}+01$ & $.00000 \mathrm{E} \div 00$ & $.00000 \mathrm{E}+00$ & $.00000 \mathrm{E} \div 00$ & $.67157 \mathrm{E}+02$ \\
\hline \multirow[t]{2}{*}{3} & 2 & $.53351 \mathrm{E}+02$ & $.18173 E+01$ & $.00000 \mathrm{E} \div 00$ & $.00000 \mathrm{E}+00$ & $.00000 \mathrm{E}-00$ & $-.59050 \mathrm{E}-14$ \\
\hline & 6 & $-.53351 \mathrm{E}+02$ & $-.18173 \mathrm{E}+01$ & $.00000 \mathrm{E} \div 00$ & $.00000 \mathrm{E}+00$ & $.00000 E \div 00$ & $.36347 \mathrm{E}+02$ \\
\hline \multirow[t]{2}{*}{4} & 6 & $.31488 \mathrm{E}+02$ & $.37787 \mathrm{E}+01$ & $.00000 \mathrm{E}+00$ & $.00000 \mathrm{E}+00$ & $.00000 \mathrm{E}-00$ & $-.16246 \mathrm{E}+02$ \\
\hline & 8 & $-.31488 E+02$ & $-.37787 \mathrm{E}+01$ & $.00000 E+00$ & $.00000 \mathrm{E}+00$ & $.00000 \mathrm{E} \div 00$ & $.72928 \mathrm{E}+02$ \\
\hline \multirow[t]{2}{*}{5} & 4 & $-.19614 \mathrm{E}+01$ & $.20372 \mathrm{E}+02$ & $.00000 \mathrm{E} \div 00$ & $.00000 \mathrm{E}+00$ & $.00000 \mathrm{E} \div 00$ & $.20372 E+03$ \\
\hline & 17 & $.19614 \mathrm{E}+01$ & $-.20372 \mathrm{E}+02$ & $.00000 \mathrm{E} \div 00$ & $.00000 \mathrm{E}+00$ & $.00000 \mathrm{E} \div 00$ & $.68889 \mathrm{E}-13$ \\
\hline \multirow[t]{2}{*}{6} & 4 & $-.19614 E+01$ & $.6700 \mathrm{IE}+00$ & $.00000 \mathrm{E} \div 00$ & $.00000 \mathrm{E}+00$ & $.00000 E \div 00$ & $.21372 E+03$ \\
\hline & 5 & $.19614 \mathrm{E}+01$ & $-.67001 \mathrm{E}+00$ & $.00000 \mathrm{E} \div 00$ & $.00000 \mathrm{E}+00$ & $.00000 E-00$ & $-.20702 \mathrm{E}+03$ \\
\hline \multirow[t]{2}{*}{7} & 5 & $-.19614 E+01$ & $.21712 \mathrm{E}+02$ & $.00000 \mathrm{E} \div 00$ & $.00000 \mathrm{E}+00$ & $.00000 E-00$ & $.19702 \mathrm{E}+03$ \\
\hline & 6 & $.19614 \mathrm{E}+01$ & $-.21712 \mathrm{E}+02$ & $.00000 \mathrm{E} \div 00$ & $.00000 \mathrm{E}+00$ & $.00000 \mathrm{E} \div 00$ & $.20100 \mathrm{E}+02$ \\
\hline \multirow[t]{2}{*}{8} & 7 & $.19968 \mathrm{E} \div 02$ & $-.21193 E+02$ & $.00000 \mathrm{E} \div 00$ & $.00000 E+00$ & $.00000 \mathrm{E} \div 00$ & $-.64607 E+02$ \\
\hline & 12 & $-.19968 E+02$ & $.21193 E+02$ & $.00000 \mathrm{E} \div 00$ & $.00000 \mathrm{E}+00$ & $.00000 E \div 00$ & $-.58968 E+02$ \\
\hline \multirow[t]{2}{*}{9} & 12 & $.20279 E+02$ & $-.13871 \mathrm{E}+02$ & $.00000 E \div 00$ & $.00000 \mathrm{E}+00$ & $.00000 E-00$ & $.58968 \mathrm{E}+02$ \\
\hline & 14 & $-.20279 E+02$ & $.13871 \mathrm{E}+02$ & $.00000 \mathrm{E} \div 00$ & $.00000 \mathrm{E}+00$ & $.00000 \mathrm{E} \div 00$ & $-.13985 E+03$ \\
\hline \multirow[t]{2}{*}{10} & 14 & $.25156 \mathrm{E}+02$ & $.12858 \mathrm{E}+02$ & $.00000 \mathrm{E}+00$ & $.00000 \mathrm{E}+00$ & $.00000 E \div 00$ & $.13985 \mathrm{E}+03$ \\
\hline & 16 & $-.25156 E+02$ & $-.12858 \mathrm{E}+02$ & $.00000 \mathrm{E} \div 00$ & $.00000 \mathrm{E}+00$ & $.00000 \mathrm{E} \div 00$ & $-.64873 E+02$ \\
\hline \multirow[t]{2}{*}{11} & 15 & $.25507 \mathrm{E}+02$ & $.12272 \mathrm{E} \div 02$ & $.00000 E \div 00$ & $.00000 \mathrm{E}+00$ & $.00000 \mathrm{E} \div 00$ & $.13643 \mathrm{E}+03$ \\
\hline & 16 & $-.25507 E+02$ & $-.12272 \mathrm{E} \div 02$ & $.00000 \mathrm{E} \div 00$ & $.00000 \mathrm{E}+00$ & $.00000 E+00$ & $-.64873 E+02$ \\
\hline \multirow[t]{2}{*}{12} & 13 & $.20596 \mathrm{E}+02$ & $-.14490 \mathrm{E}+02$ & $.00000 \mathrm{E} \div 00$ & $.00000 \mathrm{E}+00$ & $.00000 \mathrm{E}+00$ & $.51939 \mathrm{E}+02$ \\
\hline & 15 & $-.20596 \mathrm{E}+02$ & $.14490 \mathrm{E}+02$ & $.00000 \mathrm{E}+00$ & $.00000 \mathrm{E}+00$ & $.00000 \mathrm{E}-00$ & $-.13643 E+03$ \\
\hline \multirow[t]{2}{*}{13} & 8 & $.20279 \mathrm{E}+02$ & $-.21852 \mathrm{E}+02$ & $.00000 E \div 00$ & $.00000 \mathrm{E}+00$ & $.00000 \mathrm{E} \div 00$ & $-.75478 \mathrm{E}+02$ \\
\hline & 13 & $-.20279 \mathrm{E}+02$ & $.21852 E+02$ & $.00000 \mathrm{E}+00$ & $.00000 \mathrm{E}+00$ & $.00000 \mathrm{E} \div 00$ & $-.51939 \mathrm{E}+02$ \\
\hline \multirow[t]{2}{*}{14} & 9 & $-.20835 E+01$ & $-.63067 \mathrm{E}-08$ & $.00000 \mathrm{E} \div 00$ & $.00000 \mathrm{E}+00$ & $.00000 \mathrm{E}-00$ & $-.58517 \mathrm{E}-07$ \\
\hline & 12 & $.20835 \mathrm{E}+01$ & $.63067 \mathrm{E}-08$ & $.00000 \mathrm{E}+00$ & $.00000 \mathrm{E}+00$ & $.00000 \mathrm{E} \div 00$ & $.33888 \mathrm{E}-07$ \\
\hline \multirow[t]{2}{*}{15} & 9 & $.17264 \mathrm{E}+01$ & $-.70154 \mathrm{E}-08$ & $.00000 \mathrm{E}-00$ & $.00000 \mathrm{E}+00$ & $.00000 \mathrm{E} \div 00$ & $-.52691 \mathrm{E}-07$ \\
\hline & 14 & $-.17264 \mathrm{E}+01$ & $.70154 \mathrm{E}-08$ & $.00000 \mathrm{E}-00$ & $.00000 \mathrm{E}+00$ & $.00000 \mathrm{E} \div 00$ & $.70912 \mathrm{E}-08$ \\
\hline \multirow[t]{2}{*}{16} & 11 & $-.22759 \mathrm{E}+02$ & $.33649 \mathrm{E}-07$ & $.00000 \mathrm{E}-00$ & $.00000 \mathrm{E}+00$ & $.00000 \mathrm{E} \div 00$ & $.13349 \mathrm{E}-06$ \\
\hline & 14 & $.22759 \mathrm{E}+02$ & $-.33649 \mathrm{E}-07$ & $.00000 \mathrm{E} \div 00$ & $.00000 \mathrm{E}+00$ & $.00000 \mathrm{E} \div 00$ & $.12932 \mathrm{E}-06$ \\
\hline \multirow[t]{2}{*}{17} & 11 & $-.22812 \mathrm{E}+02$ & $.33924 \mathrm{E}-07$ & $.00000 E+00$ & $.00000 \mathrm{E}+00$ & $.00000 \mathrm{E} \div 00$ & $.13402 \mathrm{E}-06$ \\
\hline & 15 & $.22812 E+02$ & $-.33924 \mathrm{E}-07$ & $.00000 \mathrm{E}+00$ & $.00000 \mathrm{E}+00$ & $.00000 \mathrm{E} \div 00$ & $.13093 \mathrm{E}-06$ \\
\hline \multirow[t]{2}{*}{18} & 10 & $.17595 \mathrm{E}+01$ & $-.68483 \mathrm{E}-08$ & $.00000 \mathrm{E} \div 00$ & $.00000 \mathrm{E}+00$ & $.00000 \mathrm{E} \div 00$ & $-.52903 \mathrm{E}-07$ \\
\hline & 15 & $-.17595 E+01$ & $.68483 \mathrm{E}-08$ & $.00000 \mathrm{E}-00$ & $.00000 \mathrm{E}+00$ & $.00000 \mathrm{E} \div 00$ & $.83888 \mathrm{E}-08$ \\
\hline \multirow[t]{2}{*}{19} & 10 & $-.21233 E+01$ & $-.53029 \mathrm{E}-08$ & $.00000 E \div 00$ & $.00000 \mathrm{E}+00$ & $.00000 E \div 00$ & $-.57999 \mathrm{E}-07$ \\
\hline & 13 & $.21233 \mathrm{E}+01$ & $.53029 \mathrm{E}-08$ & $.00000 E \div 00$ & $.00000 \mathrm{E}+00$ & $.00000 \mathrm{E}+00$ & $.37291 \mathrm{E}-07$ \\
\hline \multirow[t]{2}{*}{20} & 7 & $-.10902 \mathrm{E}+01$ & $-.79595 \mathrm{E}-08$ & $.00000 \mathrm{E}+00$ & $.00000 \mathrm{E}+00$ & $.00000 E+00$ & $-.53957 \mathrm{E}-07$ \\
\hline & 9 & $.10902 \mathrm{E}+01$ & $.79595 \mathrm{E}-08$ & $.00000 \mathrm{E}+00$ & $.00000 \mathrm{E}+00$ & $.00000 \mathrm{E}+00$ & $-.57387 \mathrm{E}-08$ \\
\hline \multirow[t]{2}{*}{21} & 9 & $-.30879 E+01$ & $-.35612 \mathrm{E}-07$ & $.00000 \mathrm{E}+00$ & $.00000 \mathrm{E}+00$ & $.00000 \mathrm{E} \div 00$ & $-.10547 \mathrm{E}-06$ \\
\hline & 11 & $.30879 \mathrm{E}+01$ & $.35612 \mathrm{E}-07$ & $.00000 \mathrm{E}+00$ & $.00000 \mathrm{E}+00$ & $.00000 \mathrm{E}+00$ & $-.16162 \mathrm{E}-06$ \\
\hline \multirow[t]{2}{*}{22} & 10 & $-.30536 \mathrm{E}+01$ & $-.35446 \mathrm{E}-07$ & $.00000 \mathrm{E}+00$ & $.00000 \mathrm{E}+00$ & $.00000 \mathrm{E}+00$ & $-.10476 \mathrm{E}-06$ \\
\hline & 11 & $.30536 \mathrm{E}+01$ & $.35446 \mathrm{E}-07$ & $.00000 \mathrm{E}+00$ & $.00000 \mathrm{E}+00$ & $.00000 \mathrm{E} \div 00$ & $-.16109 \mathrm{E}-06$ \\
\hline 23 & 8 & $-.10176 \mathrm{E}+01$ & $-.83128 \mathrm{E}-08$ & $.00000 \mathrm{E}+00$ & $.00000 \mathrm{E}+00$ & $.00000 \mathrm{E}+00$ & $-.56200 \mathrm{E}-07$ \\
\hline & 10 & $.10176 \mathrm{E}+01$ & $.83128 \mathrm{E}-08$ & $.00000 \mathrm{E} \div 00$ & $.00000 \mathrm{E}+00$ & $.00000 \mathrm{E}+00$ & $-.61459 \mathrm{E}-08$ \\
\hline
\end{tabular}




\subsection{MATERIAL TESTING PLAN}

Because the reliability analysis of a roof system requires statistics information on the basic design variables like modulus of elasticity, area of cross section, moment of inertia, density of weight, and yielding stress, testing methods have been developed to determine the mean value and standard deviation of the material variables.

\subsection{OBJECTIVE}

The reliability analysis of a roof system requires statistical information on the basic design variables. Material testing methods are developed to determine material properties, including the mean and standard deviation:

- Modulus of elasticity $E$

- Area of cross section $A$

- Moment of inertia $I$

- Density of weight $W$

- Yielding stress $[\sigma]$

\subsection{TECHNICAL NOTES}

To obtain enough information for the structural reliability analysis, the material properties of all types of structural members will be measured and a set of 20 specimens for each member type will be tested. The total number of specimens is equal to the number of structural member types multiplied by 20 . The statistics of basic design variables can be obtained based on the test results.

\subsubsection{Data Acquisition}

According to the purpose of the test, three types of tests must be performed: the first one is a simple tension or compression test designed to measure the modulus of elasticity, section area, and yielding stress; the second one is a bending test designed to measure the modulus of elasticity, and moment of inertia; and the last one is designed to measure the weight density. Figure 5 demonstrates a bending test model. Specimens will be selected from the job site and transported to the laboratory.

The specified loading on the roof structure will be performed. For each stop, the data recorded by the strain gauges and measuring equipment will be saved on tape or writable laser disk, and the respective curves will be plotted.

The weight and size of the specimens will be measured, and their density will be calculated. 

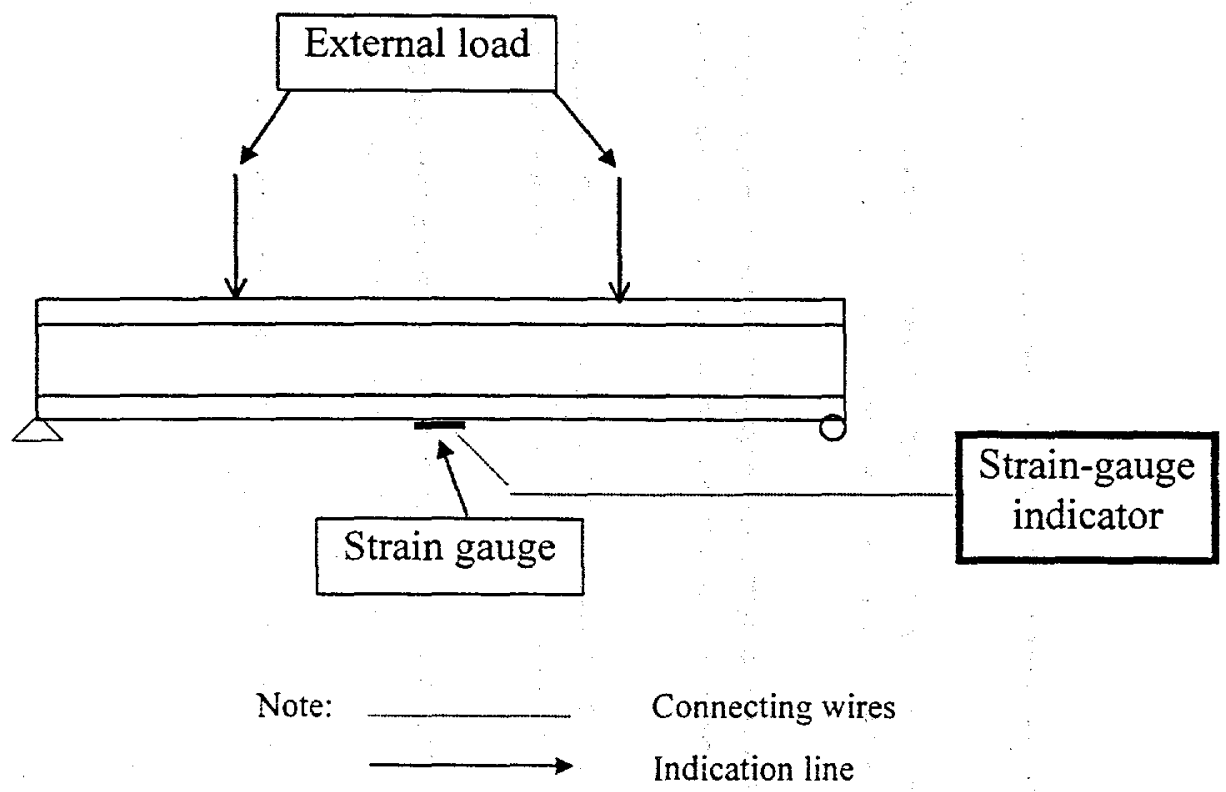

Figure 5. Bending test.

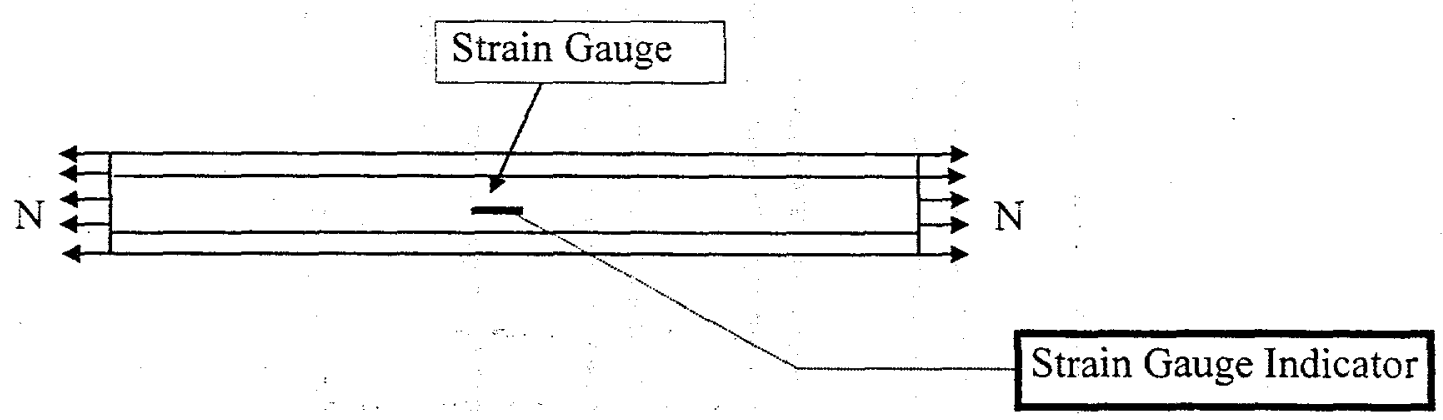

Figure 6. Tension test.

\subsubsection{Data Processing}

For the tension or compression test, we obtain the following according to the mechanics of material

$$
\frac{N L}{E A}=\Delta L
$$

where $N=$ external tension or compression axial load; $L=$ length of steel member; $A=$ section area; $E=$ modulus of elasticity; $\Delta L=$ increment of length of steel member under external axial $\operatorname{load} N$. 
The equation is then rewritten in the following form

$$
\frac{N}{E A}=\varepsilon
$$

Where $\varepsilon=\Delta L / L$, strain of the steel member.

The rigidity of the steel member is the following

$$
E A=\frac{N}{\varepsilon}
$$

For a bending test we obtain, according to mechanics of material

$$
\frac{M}{E I} y=\varepsilon
$$

where $M=$ moment acting on the steel member; $I=$ moment of inertial of section; $y=$ distance from the neutral axis to the extreme fiber; $\varepsilon=$ strain in the extreme fiber.

The rigidity of section is in the following form

$$
E I=\frac{M y}{\varepsilon}
$$

When measuring weight density of structural members, the following formula is used

$$
\rho=\frac{W}{A L}
$$

where $\rho=$ weight density of steel member; $\underline{W}=$ weight of steel member; $A=\operatorname{section}$ area; $L=$ length of steel member.

\subsection{INSTRUMENTATION}

The following instruments are needed for the test:

- The strain gauges, which are 2 in. long, are installed on the specified members

- Portable strain gauge indicator, bridge type, with digital readout

- Signal cables are used to connect the strain gauges and the strain gauge indicator

- Testing machine for bending

- Testing machine for tension or compression

- Lever

- Ruler 
The flowchart for the detailed testing procedure is shown in Figure 7. However, it should be mentioned herein that a large number of sample pieces are needed for the test to obtain sufficient statistics data.

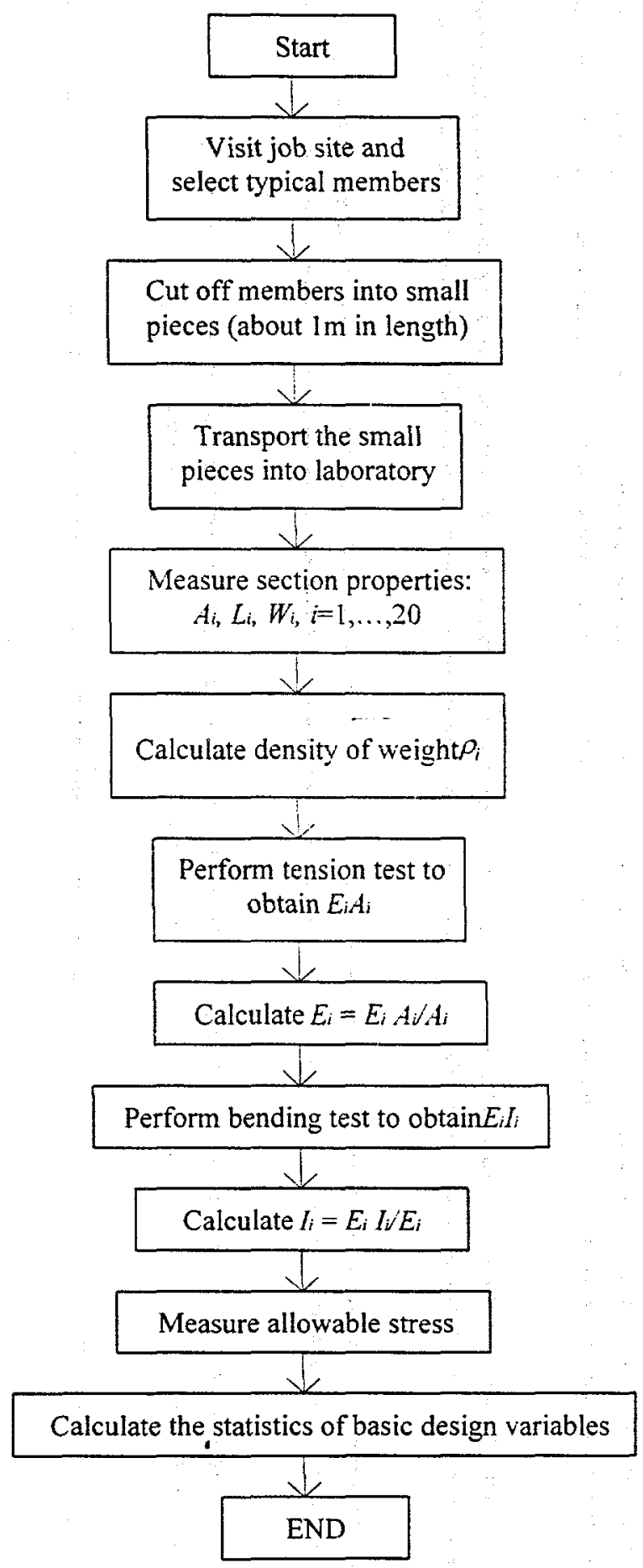

Figure 7. A flowchart for testing. 


\subsection{STATIC RELIABILITY ANALYSIS}

The SFEM has rapidly developed into several algorithms in recent years (Vanmarcke 1983; Der Kiureghian and Liu 1986; Ghanem and Spanos 1991). These algorithms, including Taylor expansion SFEM, perturbation SFEM, and Neumann expansion SFEM exhibit their high efficiency and accuracy. These algorithms have effectively been employed as an alternative tool for structural reliability analysis.

\subsection{BASIC PRINCIPLES OF SFEM}

There are two parts that should be interpreted with the SFEM: random field theory and SFEM algorithms. Random field theory, SFEM algorithms, and FEM constitute the basis of SFEM. These are introduced in the following section.

\subsubsection{Discretization of Random Field}

According to random field theory, randomness of material properties of structural members, and external loads including live load and dead load can be described by meshes of random fields just like the meshes in FEM. There are several approaches to represent the discretization of random fields, such as local averaging method, midpoint method, interpolation method, and series expansion method. In general, the correlated function is approximately expressed in the form of a triangle or exponential type. On the basis of this correlated function, SFEM algorithms converge very quickly with high accuracy. However, the local averaging method is strictly valid only in the case of stationary random fields. In the case of a non-stationary variable field, an alternative discretization method like the midpoint method can be chosen.

In the present analysis, the midpoint method is used to represent random fields of material properties and external loads, i.e., the statistical information at the mid-point of each mesh of random field represents the properties of this whole mesh. Although this method is not highly accurate, it is versatile because:

- it can deal with non-Gaussian variables

- it is easy to write a computer program by this method.

\subsubsection{SFEM Algorithm}

In the research work, perturbation stochastic finite element method (PSFEM) is used to compute the gradient of structural response to basic design variables.

Assume that $\alpha_{i}$ is a small perturbation amount of variable $X_{i}(i=1, \cdots, n)$ at its mean value $\bar{X}_{i}$, i.e., $\alpha_{i}=X_{i}-\bar{X}_{i}$, then one can obtain the following expanded series of structural stiffness $\mathbf{K}$, nodal displacement vector, $\mathbf{U}$, and nodal external load vector, $\mathbf{F}$ on the basis of the first-order perturbation method. 


$$
\begin{aligned}
\mathbf{K} & \approx \overline{\mathbf{K}}+\sum_{i=1}^{n} \alpha_{i} \frac{\partial \mathbf{K}}{\partial \alpha_{i}} \\
\mathbf{U} & \approx \overline{\mathbf{U}}+\sum_{i=1}^{n} \alpha_{i} \frac{\partial \mathbf{U}}{\partial \alpha_{i}} \\
\mathbf{F} & \approx \overline{\mathbf{F}}+\sum_{i=1}^{n} \alpha_{i} \frac{\partial \mathbf{F}}{\partial \alpha_{i}}
\end{aligned}
$$

Substituting the above equations $7-9$ into the structural static equilibrium equation, one obtains the gradients of structural response to basic variables as follows:

$$
\begin{gathered}
\overline{\mathbf{U}}=\overline{\mathbf{K}}^{-1} \overline{\mathbf{F}} \\
\frac{\partial \mathbf{U}}{\partial \alpha_{i}}=-\overline{\mathbf{K}}^{-1}\left(-\frac{\partial \mathbf{F}}{\partial \alpha_{i}}+\overline{\mathbf{U}} \frac{\partial \mathbf{K}}{\partial \alpha_{i}}\right)
\end{gathered}
$$

where $\mathbf{K}=$ the structural stiffness matrix; $\mathbf{U}=$ the vector of displacement; $\overline{\mathbf{K}}, \overline{\mathbf{U}}=$ the mean value matrix and vector of $\mathbf{K}$ and $\mathrm{U}$, respectively; and $\alpha_{i}=$ a set of basic random variables, $i=1, \cdots, n$.

\subsection{RELIABILITY INDEX}

The calculation of reliability index for a roof system under a given limit state should be demonstrated to evaluate the structural safety/failure probability.

According to the advanced first order and second moment approach, one performance criterion of a structural system can be defined as a limit state in the form

$$
g(\mathbf{X})=g(\mathbf{R}(\mathbf{X}), \mathbf{S}(\mathbf{X}))=0
$$

where $\mathbf{X}=\left(X_{1}, X_{2}, \cdots, X_{n}\right)$ is a vector of the basic parameters of the structure; $\mathbf{R}(\mathbf{X})=$ vector of resistance variables; $\mathbf{S}(\mathbf{X})=$ vector of load effects. Usually these parameters are correlated and nonnormal random variables. They are transformed into the space of uncorrelated standard normal variables, $\mathbf{Y}$, as follows

$$
\mathbf{Y}=\mathbf{T X}
$$

and equation 12 becomes

$$
g(\mathbf{X})=g\left[\mathbf{T}^{-1} \mathbf{Y}\right]=G(\mathbf{Y})
$$

where $\mathbf{T}=$ transform matrix from $\mathbf{X}$ to $\mathbf{Y}$. The point $\mathbf{y}^{*}$ on the limit-state surface with the minimum distance to the origin is the most probable failure point or the design point. The 
minimum distance is a measure of reliability, i.e., reliability index denoted by $\beta=\sqrt{\mathbf{y}^{*} \mathbf{y}^{*}}$. The following formula is routinely used to compute the design point:

$$
\mathbf{y}_{i+1}=\left[\mathbf{y}_{i}^{T} \alpha_{\imath}+\frac{G\left(\mathbf{y}_{i}\right)}{\left|\nabla G\left(\mathbf{y}_{i}\right)\right|}\right] \alpha_{\mathfrak{\imath}}
$$

in which $\nabla G\left(\mathbf{y}_{i}\right)=\left\{\partial G\left(\mathbf{y}_{i}\right) / \partial y_{1}, \cdots, \partial G\left(\mathbf{y}_{i}\right) / \partial y_{n}\right\}^{T}$ is the gradient vector of the performance function at $\mathbf{y}_{i} ; \alpha_{i}=-\nabla G\left(\mathbf{y}_{i}\right) /\left|\nabla G\left(\mathbf{y}_{i}\right)\right|$ is the unit vector normal to the limit-state surface away from the origin. In SFEM, the computation of $\nabla G\left(\mathbf{y}^{*}\right)$ is achieved by using the chain rule of differentiation (see Section 5.1.2).

\subsection{STABILITY AND STRENGTH ANALYSIS BASED ON SFEM}

Stability and strength reliability analysis of roof systems based on SFEM can take into account initial manufacturing imperfections, variation in material yield stress, and variation in external loads. The theoretical method for computer modeling of the roof system stability and strength is established according to American Institute of Steel Construction-Load and Resistance Factor Design (AISC-LRFD) specifications. The limit state of stability and the strength of a roof system is determined by these two methods.

The first two steps in SFEM-based reliability analysis are:

1. Definition of the performance function

2. Computation of the derivatives of the performance function with respect to the random variables.

\subsubsection{Definition of the Performance Function}

Member forces obtained from global analysis must be checked against the interaction equations to ensure that they satisfy member strength and stability. According to AISC-LRFD specifications, the performance function (also limit state) of member strength and stability is in the following:

$$
\begin{aligned}
& \frac{P_{u}}{\phi_{c} P_{n}}+\frac{8}{9}\left(\frac{M_{u x}}{\phi_{b} M_{n x}}+\frac{M_{u v}}{\phi_{b} M_{n y}}\right) \leq 1.0 \text { for } \frac{P_{u}}{\phi_{c} P_{n}} \geq 0.2 \\
& \frac{P_{u}}{2 \phi_{c} P_{n}}+\left(\frac{M_{u x}}{\phi_{b} M_{n x}}+\frac{M_{u y}}{\phi_{b} M_{n y}}\right) \leq 1.0 \text { for } \frac{P_{u}}{\phi_{c} P_{n}}<0.2
\end{aligned}
$$

where $P_{u}=$ required axial strength; $P_{n}=$ nominal axial compressive strength evaluated using equation 18; $M_{u x}, M_{u y}=$ required flexural strength about the strong and the weak axes, respectively, within the unbraced length of the member; $M_{n x}, M_{n y}=$ nominal flexural strengths 
about the strong and the weak axes, respectively; $\phi_{c}=$ column resistance factor $(=0.85) ; \phi_{b}=$ beam resistance factor $(=0.90)$.

For the evaluation of $P_{n}$, the LRFD specifications have adopted the following column strength formulas:

$$
P_{n}=\left\{\begin{array}{l}
P_{y}\left(0.685^{\lambda_{c}^{2}}\right) \text { for } \lambda_{c} \leq 1.5 \\
P_{y}\left(\frac{0.877}{\lambda_{c}^{2}}\right) \text { for } \lambda_{c}>1.5
\end{array}\right.
$$

where $P_{y}=$ yield strength; $\lambda_{c}=$ column slenderness ratio $=\frac{K L}{\pi r} \sqrt{\frac{F_{y}}{E}} ; K=$ the effective length factor; $L=$ the length of column; $r=$ the governing radius of gyration; $E=$ the modulus of elasticity; $F_{y}=$ the yield stress.

\subsubsection{Computation of the Derivatives of the Performance Function with Respect to the Random Variables}

In SFEM, the computation of gradients of the performance function with respect to the random variables is achieved by using the chain rule of differentiation (see Section 5.1.2).

\subsection{RELIABILITY-BASED OPTIMIZATION DESIGN}

In Sections 5.1, 5.2 and 5.3, we have already established the computer model for reliability analysis of roof structures and have given several numerical examples under both strength limit state and serviceability limit state. The model constitutes a basis of the reliability-based optimization design method for roof systems.

Any optimization procedure has three aspects: objective function, constraints, and the algorithm to search for the optimum solution. All the constraints to be considered here are related to the reliability of the structure. Two types of reliability constraints can be used: element reliability and system reliability.

The element reliability constraints are written as

$$
\beta_{i}^{\prime} \leq \beta_{i} \leq \beta_{i}^{u} \quad \mathrm{i}=1,2, \cdots, \mathrm{m}
$$

where the lower bound $\beta_{i}^{l}$ specifies the minimum required safety level for the $i^{\text {th }}$ limit state, while the upper bound $\beta_{i}^{u}$ indicates the desired range of $\beta_{i}$, and $m$ is the number of limit states. The optimum design is reached if all the $\beta_{i}$, values fall within the desired range.

Some element-level reliability constraints may simply require the satisfaction of the limit state equation at the nominal values, as in the case of code-specified serviceability criteria. Such constraints may be written as 


$$
g_{j} \geq 0.0 \quad \mathrm{j}=1,2, \cdots, 1
$$

where $g_{j}$ is the performance function for the $j^{\text {th }}$ limit state and $l$ is the number of limit states.

The system reliability constraints are written as

$$
p_{f} \leq p_{f}^{0}
$$

where $p_{f}$ is the overall failure probability of the structural system, which is required to be less than an acceptable value $p_{f}^{0}$.

The reliability indices corresponding to all the element-level limit states are obtained using the SFEM-based reliability analysis described earlier. The system reliability constraints may be evaluated using Cornell's upper bound method.

The following is an optimum design procedure intended to achieve minimum weight of the roof structure:

1. Start with a feasible trial structure.

2. Search using decreasing $\beta$ values.

3. Examine only those configurations whose component sizes are less than those of the trial structure.

4. The new design is accepted if it still satisfies the lower bounds of equations 19,20 and 21 ; otherwise it is rejected and the size reduction is halved until no significant improvement is possible.

\subsection{NUMERICAL EXAMPLES}

Figure 8 is a numerical example of a steel frame $\left(L_{1}=30 f t, L_{2}=15 f t\right)$ with random stiffness and uniform external load $W$. The statistics data of random variables are shown in Table 5. Their correlation function can be described as the exponential form:

$$
\rho(\Delta x)=\exp (-|\Delta x| / a L)
$$

where $\Delta x=$ the distance between two random correlated variables; $a=$ the coefficient of correlation; $L=$ the total length.

\subsubsection{The Stability and Strength Limit State}

The stability and strength criterion is chosen in the following form:

$$
g(\mathbf{R}, \mathbf{S})=1.0-\frac{P}{P_{y}}-\frac{M}{1.18 M_{p}}=0
$$


in which $P=$ applied axial load on the beam-column member; $M=$ applied bending moment; $P_{y}=A F_{y}$, where $F_{y}$ is the yield strength; $M_{p}=$ plastic moment capacity. The relationship between reliability index $\beta$ and coefficient of correlation $a$ is shown in Figure 9. The corresponding variation of structural safety probability with coefficient of correlation $a$ is shown in Figure 10. It shows that the correlation length has a significant effect on the reliability index.

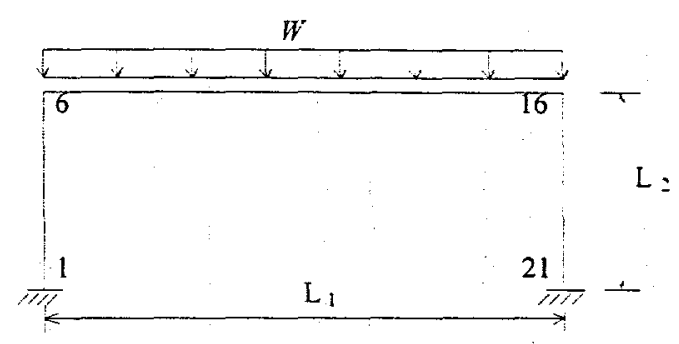

Figure 8. A steel frame with random stiffness and uniform load.

Table 5.

Statistics Data for Steel Frame

\begin{tabular}{cccc}
\hline \multicolumn{1}{c}{ Type } & Mean value & COV $^{*}$ & Type of distribution \\
\hline$W \mathrm{kip} / \mathrm{ft}$ & 5.36 & 0.1 & Gaussian \\
$E \mathrm{kip} / \mathrm{ft}^{2}$ & $4.176 \times 10^{6}$ & 0.06 & Gaussian \\
$A \mathrm{ft}^{2}$ & 0.1368 & 0.0 & - \\
$I \mathrm{ft}^{5}$ & 0.046 & 0.0 & - \\
$F_{\mathrm{y}} \mathrm{ksi}$ & 36.0 & 0.1 & Gaussian \\
\hline
\end{tabular}

Note: ${ }^{*} \mathrm{COV}=$ Coefficient of variation.

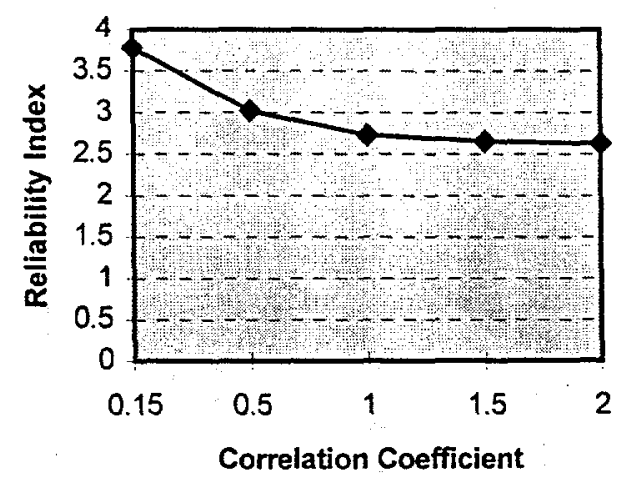

Figure 9. Reliability index versus coefficient of correlation 


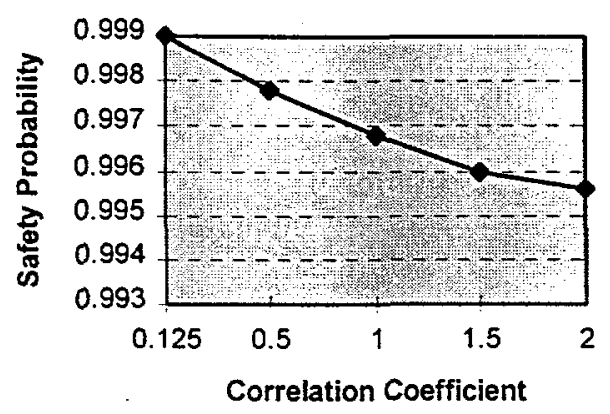

Figure 10. Safety probability versus coefficient of correlation $a$.

\subsubsection{The Serviceability Limit State}

\section{Example I}

The same numerical example in Figure 8 with random stiffness and uniform external load is used to calculate the reliability index under serviceability limit state. The statistics data of random variables are shown in Table 6.

Table 6.

Statistics Data for Steel Frame

\begin{tabular}{cccc}
\hline Type & Mean value & COV $^{\star}$ & Type of distribution \\
\hline$W, \mathrm{kip} / \mathrm{ft}$ & 3.3 & 0.1 & Gaussian \\
$E, \mathrm{~N} / \mathrm{m}^{2}$ & $4.176 \times 10^{6}$ & 0.06 & Gaussian \\
$A, \mathrm{~m}^{2}$ & 0.1368 & 0.0 & - \\
$I, \mathrm{~m}^{4}$ & 0.046 & 0.0 & - \\
\hline
\end{tabular}

${ }^{*} \mathrm{COV}=$ Coefficient of variation.

The serviceability limit state is determined in the following form:

$$
g(\mathbf{R}, \mathbf{S})=v_{\text {midspan }}-L_{1} / 360=0
$$

in which $v_{\text {midspan }}=$ vertical displacement at the mid-span point.

The relationship between the reliability index, $\beta$, and the coefficient of correlation, $a$, is shown in Figure 11. The corresponding variation of structural safety probability with coefficient of 
correlation $a$ is shown in Figure 12. These graphs show that the degree of correlation has a significant effect on the reliability index.

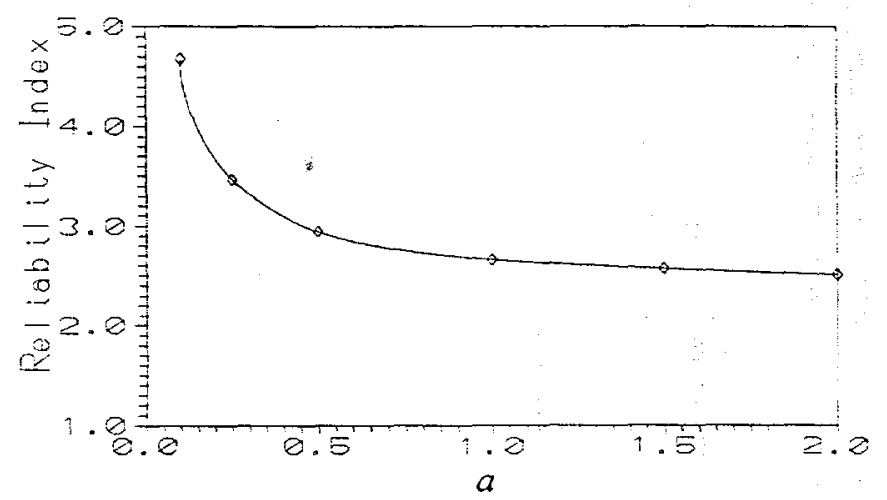

Figure 11. Reliability index $\beta$ versus coefficient of correlation $a$.

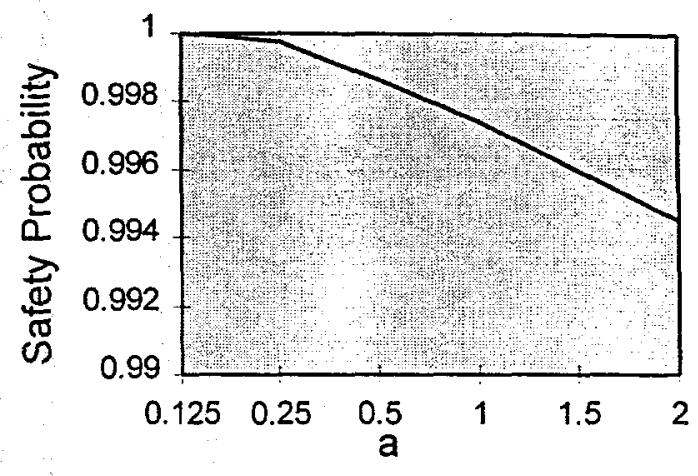

Figure 12. Safety probability versus coefficient of correlation $a$.

\section{Example II}

As another example for SFEM, a steel frame with a roof structure shown in Figure 3 is calculated by the present approach. In this example, the modulus of elasticity of every structural member and external load is assumed to be random and Gaussian variables. The correlation between these variables is expressed in the same form in equation 22 and the total length $L$ is selected as $(15 \mathrm{ft}+20 \mathrm{ft}+2 \times 15 \mathrm{ft})=65 \mathrm{ft}$. The meshes of random field are chosen as the same size of finite elements. Other data are based on the example in Section 3.2.

The serviceability limit state requires the displacement at midspan point should not exceed 1/360 of the span under all live loads. The calculated reliability index is 4.75 when a correlation coefficient of 2.0 basic elasticity modulus variables with $\mathrm{COV}=0.2$ and 4.0 between basic load variables with $\mathrm{COV}=0.15$ are given. 


\subsection{DYNAMIC RELIABILITY ANALYSIS}

Certain parts of roof structures will be locally damaged by long-term dynamic loads such as wind and earthquake. The local damage caused by wind, earthquake or other natural forces will decrease the whole structural safety of a roof over time. When the structural safety probability reaches a specified target safety index, it is dangerous to live and work in such structures.

Usually, fatigue analysis is necessary to evaluate dynamic reliability of a structure. This kind of analysis depends mainly on fatigue testing results to obtain accurate information of existing accumulative structural damage. It is a very expensive method to evaluate the fatigue status of existing structures. Therefore, in this report we establish a theoretical method without any detailed example. If possible, typical roof structures will be analyzed as examples using the present method in the next phase of the project.

\subsection{THEORETICAL PROCEDURE}

The fatigue failure model for a part of a structure can be described as follows:

$$
N S^{m}=C
$$

where $S$ denotes amplitude or range of stress cycles; and $N$ represents the cycle number when fatigue failure occurs at stress level $S$, and $N$ can be assumed to be distributed as Weibull's density function or Lognormal density function according to random fatigue test with $m$ and $C$ representing corresponding coefficients in the test. By using the linear cumulative damage model, one can reach a decision as to whether the structure is damaged due to fatigue.

It is assumed at the present analysis that $N$ is distributed as a Lognormal density function as follows:

$$
P_{N}(n)=\frac{1}{n \sqrt{2 \pi D_{Y}}} \exp \left\{-\frac{\left(\ln (n)-M_{Y}\right)^{2}}{2 \sqrt{D_{Y}}}\right\}
$$

where

$$
\begin{aligned}
& Y=\ln (N) \\
& M_{Y}=\ln \left(M_{N}\right)-\frac{1}{2} \ln \left(1+V_{N}^{2}\right) \\
& D_{Y}=\ln \left(1+V_{N}^{2}\right)
\end{aligned}
$$

in which $M$ represents mean value; $D$ represents variance; and $V_{N}=\frac{\sqrt{D_{N}}}{M_{N}}$ is the coefficient of variation. 
Using the linear cumulative damage model, the index for structural fatigue cumulative damage is expressed as the following:

$$
G=\sum_{i} \frac{n_{i}}{N\left(s_{i}\right)} \quad \text { or } \quad G=\int_{\infty}^{\infty} \frac{n(s)}{N(s)} d s
$$

where $n_{i}=$ the number of cycle at stress amplitude $s_{i}$ and $N_{i}\left(S_{i}\right)=$ the allowable number of cycles at stress amplitude $s_{i}$. In the case of $G=1$, it is assumed that the structure fails due to fatigue.

To estimate structural fatigue life and cumulative damage, $n(s)$ can be expressed as following within time period $[O, T]$ :

$$
n(s)=n_{0}^{+} T P_{S}(s)
$$

where $P_{s}(s)=$ probability distribution function of stress peak $s$ and $n_{0}^{+}=$peak expected number per unit time.

Let $G=1$, the average structural fatigue life can be written in the following form:

$$
\begin{gathered}
T_{S}=\frac{C}{n_{0}^{+}} \cdot \frac{1}{\zeta} \\
\zeta=\int_{0}^{\infty} s^{m} P_{S}(s) d s
\end{gathered}
$$

Fatigue reliability within a design life span, $T_{p}$, can be defined as follows:

$$
P_{S F}\left(T_{p}\right)=P\left\{N_{T_{p}} \leq N\right\}
$$

where $N_{T_{p}}$ is the total number of peaks within the time period $\left[O, T_{p}\right]$ and $N$ is the number of cycles when fatigue failure occurs at stress level $S$. In fact, $N_{T_{p}}$ and $N$ can be described approximately in the form of a Lognormal distribution. Thus, fatigue reliability can be calculated within a time period, $[O, T]$.

\subsection{EXPERIMENTAL SETUP AND TEST SPECIMENS}

Figure 13 shows an experimental setup of cantilever-type test specimens in which a beam is connected to the flange of $3.66-\mathrm{m}$-long pin-ended column. Cyclic loads are applied to the beam at a distance of $2.44 \mathrm{~m}$ from the column face. A beam lateral support is provided near the hydraulic ram.

Usually, a set of specimens is used to conduct a fatigue test. Figure 14 demonstrates the detailed connection of a testing specimen. 


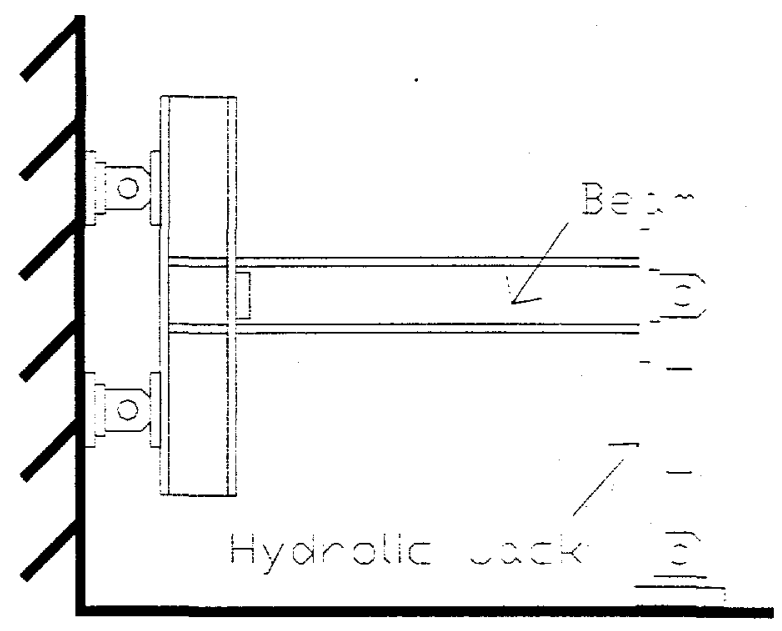

Figure 13. Experimental setup.

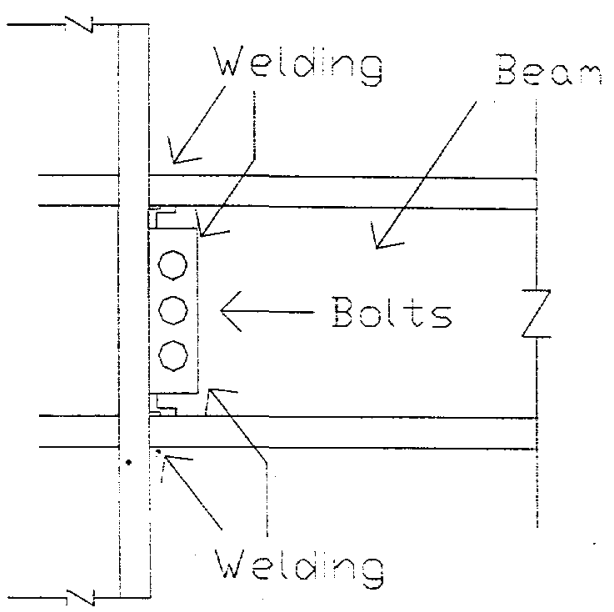

Figure 14. Connection details for specimen. 


\subsection{RECOMMENDATION OF COMMONLY USED ROOF MATERIALS}

In this section, a few individual roof materials which are commonly used nowadays are reviewed and their characteristics are summarized. Detailed research work on roofing materials will be conducted in Phase II next year.

\subsection{TYPICAL ROOF MATERIALS}

\subsubsection{Single-ply roofing}

The single-ply membrane roofing system was first introduced in the United States in the mid 1960s by European manufacturers, partially in response to difficulties being experienced at the time in obtaining asphaltic materials for conventional roofing systems. Single-ply membranes are flexible sheets of compounded synthetic materials that are manufactured in a factory to strict quality control requirements. The prefabricated sheets are inherently flexible, can be used with a variety of attachment methods, and are compounded for watertight integrity for years of life. These various factors are the reason for the popularity of single-ply systems that account for up to $40 \%$ of the commercial roofing market. Figure 15 shows workers installing single-ply roofing material.

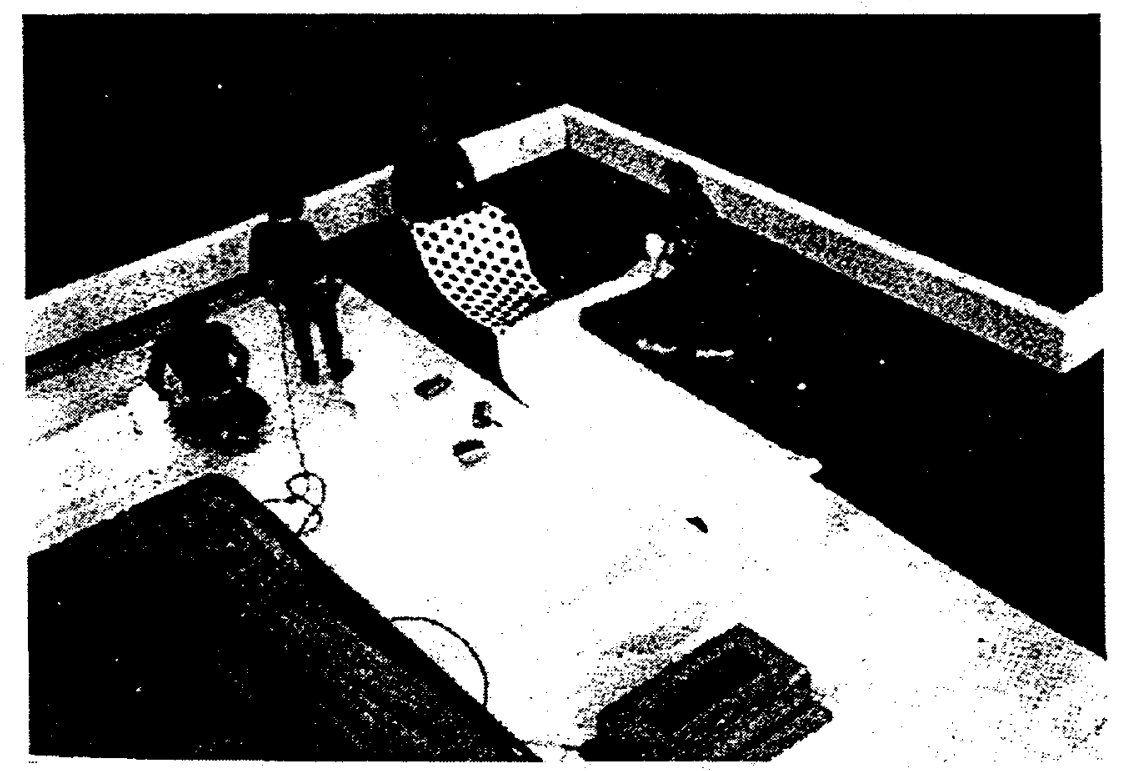

Figure 15. A Single-ply installation (6-1).

\subsubsection{Asphalt roofing}

Asphalt materials are the most commonly used low- and high-slope roofing material for both residential and commercial buildings. The surfacing is available in a wide range of colors and 
color blends, which improves the adaptability of asphalt roofing materials to different types of buildings and provides a greater variety of design possibilities. Asphalt roofing materials can be classified into three groups: roll roofing, shingles, and underlayment.

- Roll roofing is an outer roof covering. It is exposed to the weather and designed to withstand the elements. Roll roofing is sometimes used for low-cost housing and utility buildings such as sheds, garages, and barns in place of asphalt shingles. It comes in rolls that are 36 to $38 \mathrm{ft}$ long and 36 in. wide. This covering is accompanied by an underlying cover of lesser resistance referred to as the underlayment.

- Shingles are the most common roofing material used today (See Figure 10). They are manufactured as strip shingles, interlocking shingles, and large individual shingles in a variety of colors and weights. Strip shingles are rectangular. They measure about $12 \mathrm{in}$. wide by 36 in. long. Cutouts are separate from the shingle's tabs, which are exposed to the weather and give the roof the appearance of being comprised of a larger number of individual shingles.

- Underlayment: This type of asphalt roofing product consists of a dry felt impregnated with an asphalt saturant. It is primarily placed under asphalt shingles, roll roofing, and other types of roofing materials like sheathing paper (See Figure 15).

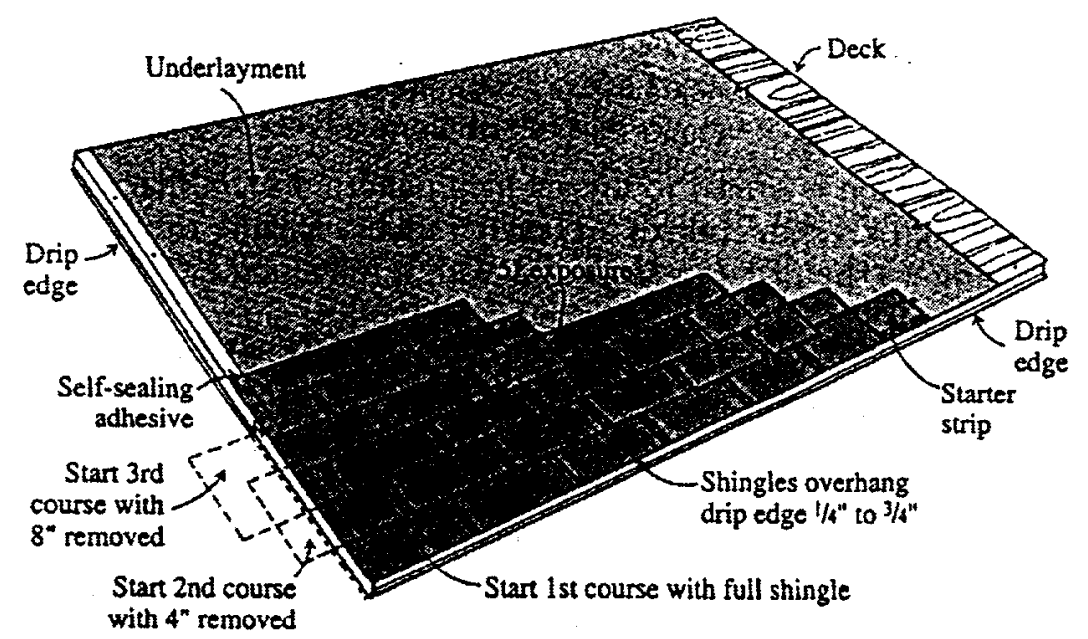

Figure 16. Shingle with Underlayment.

\subsubsection{Slate shingles (See Figure 17)}

A slate roof is really a custom job and its use gives character to a building unlike that of any other roofing material. Slate quarried for roofing is of dense, sound rock, and is exceedingly tough and durable. The minerals that constitute slate were deposited in bodies of water. Erosion and deposition account for the different compositions of successive beds. Other materials were 
then deposited over the clays, and the pressure of the superimposed material gradually united the clays into shale.

Huge holes are dug into the ground to find the first beds of slate. Often, the top layers of slate, which usually are brown or gold, are very soft. The top-layer slates are not recommended for roofing use because they do not afford the same quality offered by the deeper beds. Only the best quality slate can be used to make roofing slate.

The production of roofing slate is truly an art. Because these slates are a natural stone product, each piece has its own unique qualities. Roofing slate comes in thickness from $1 / 4$ to 1 in. and offers roof appearances that range from smooth and uniform to rough and textured. Slate roofs have a life service from 75 to 100 years.
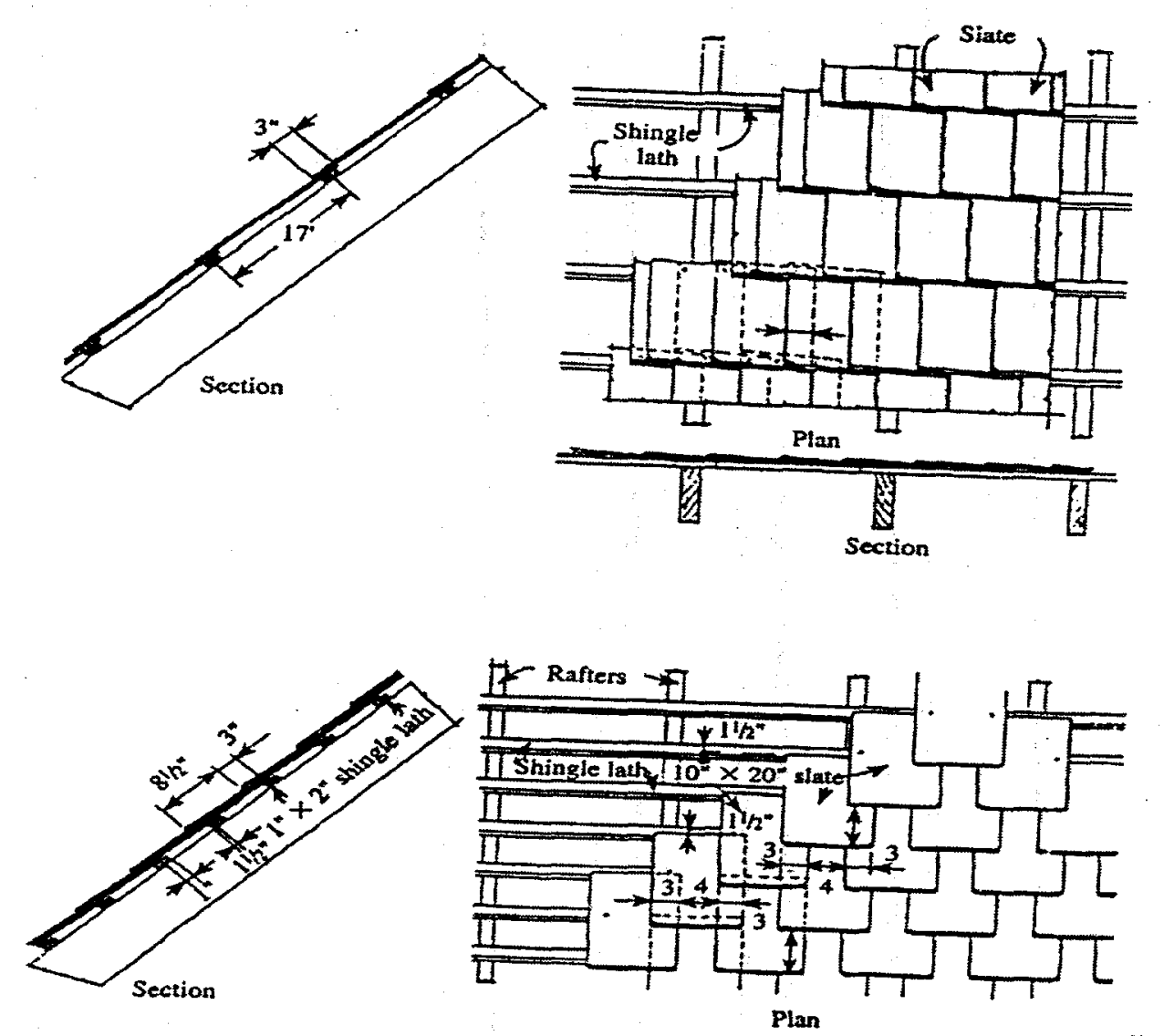

Figure 17. Designs of Slate Roofs.

\subsubsection{Clay and concrete tiles}

Clay tiles (See Figure 18) offer the roofing contractor numerous advantages:

- Tile roofs typically last 50 years or longer and do not rust or otherwise deteriorate. 
- The color and texture of most tiles is integral and of natural materials that do not fade.

- Tile roofs are more insulating. Clay and concrete tiles resist the passage of heat gain from summer sun and winter heat loss.

- The mass of tile roofing provides superior insulation from sound.

- Tile roofs are noncombustible and protect the structure from burning embers without suffering irreparable damage. Tile and cement roof products carry Class A fire ratings.

Concrete tiles are relatively new compared to clay tiles. Concrete tiles are composed of portland cement, sand and water, mixed in varying proportions. These materials are mixed and extruded on individual molds under high pressure to form the tile product.

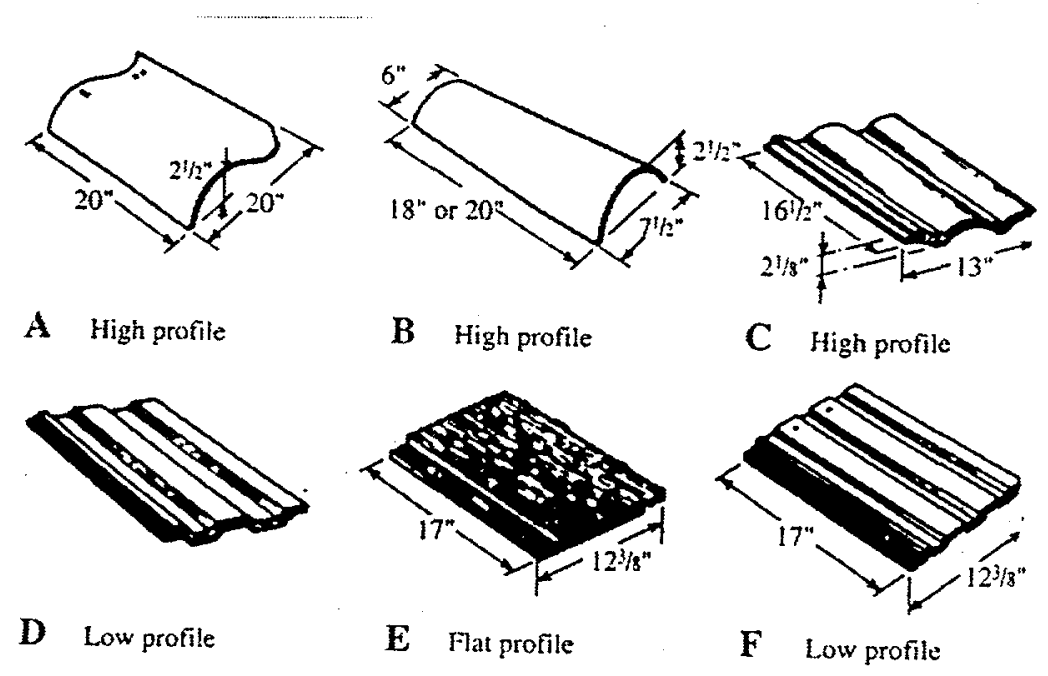

Figure 18. Special clay tile shapes.

\subsubsection{Metal roofing}

Many technical improvements have been made in the basic, venerable metal roof system. Advances in metal coatings, treatments, and forming technologies, as well as major improvements in systems for seaming and anchoring, have combined with a renewed interest in historic architectural styles to make metal roofing systems a leading choice once again. These improvements, while bringing many benefits, require greater attention to detail and proper field practices.

There are a number of good reasons to use metal on building roofs. First, metal is a predictable and stable product. Unlike other single-ply technologies like rubber, a metal panel (see Figure 19) is not affected by ultraviolet (UV) rays, which is one of the leading sources of roof degradation. Second, advances in metal coating and finishing technologies have significantly improved the life cycle of metal roofs, and the related cost benefits. 
Metal roofing also is extremely puncture-resistant, which is a real benefit to today's building owner who is looking for long-term, low-maintenance solutions. Actually, durability is one reason for metal's growing popularity.

Metal roofing also offers the roofing contractor the following advantages:

- Metal roofs are lightweight, yet extremely durable and cost effective over the long term.

- They install easily and quickly, yet are flexible enough to overcome unique or difficult situations (see Figure 20).

- They are readily available in the United States.

- Metal roofing systems can be applied at low slopes.

- The standard panel free-span is five feet.
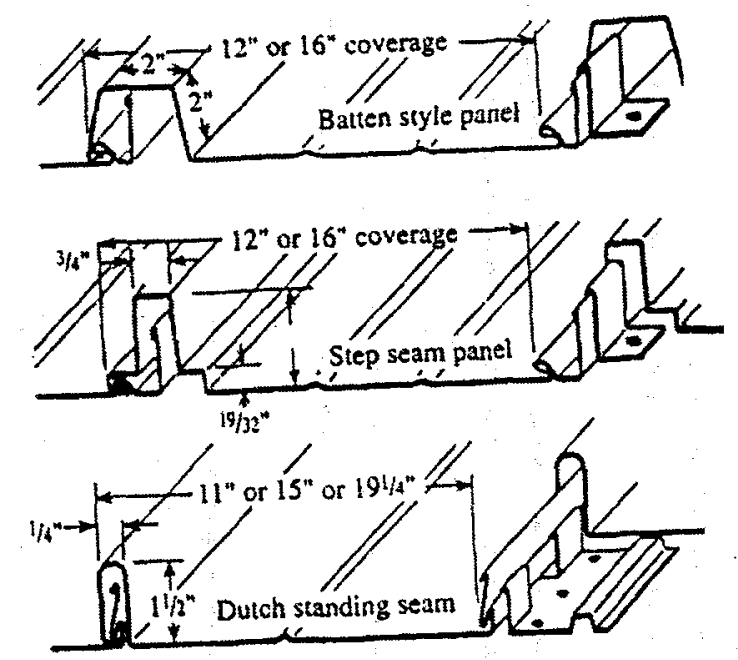

Figure 19. Basic Metal Panel Configurations. 


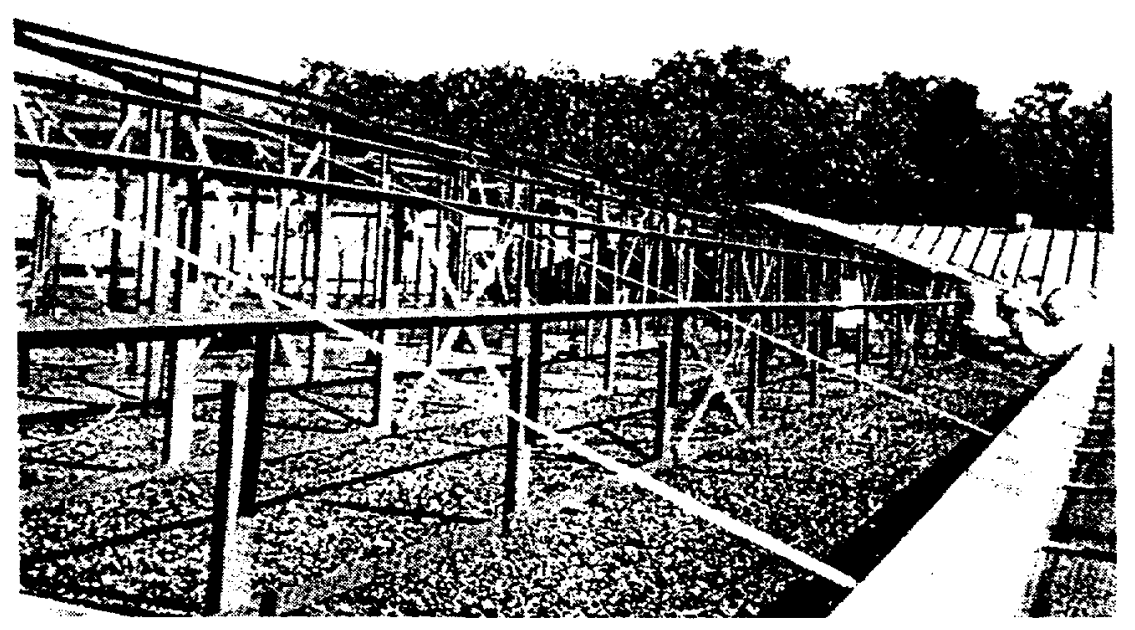

Figure 20. Creating a siope/subassembly system roof frame.

\subsection{MISCELLANEOUS ROOF WORK}

\subsubsection{Putting in Roof Drainage Systems}

More and more roofing contractors are installing roof drainage systems. The area on the roof where the drainage system is placed is the single most vulnerable place for leaks to form. The architect usually designs the drainage system by taking into account such factors as the area to be drained, size of gutters, downspouts and outlets, the slope of the roof, type of building, and desired appearance. The design capacity for a roof-drainage system depends on the quantity of water that needs to be handled. The quantity of water, in turn, depends on the roof area, slope, and rainfall intensity.

\subsubsection{Performing Nondestructive Testing}

Millions of dollars are spent each year to make roof repairs because of leaks. This creates an ever-increasing demand for more accurate moisture damage assessment. Roofs leaks that result in wet insulation, yet cannot be seen as a drip, cause real problems for roofers. A successful moisture analysis can significantly reduce overall repair costs while developing and securing mutually beneficial relationships between roofing professionals and their customers.

Nondestructive testing (NDT) is designed to locate the presence of moisture in roofing systems, including interply and substrate moisture, without causing physical damage to the roof's surface or substrate. Wet insulation in roofing systems is often compared to a cancer. NDT acts as an Xray or biopsy of the roof to determine the location of the cancer. If left untreated, this cancer deteriorates the roof membrane, fastener system, and structural deck.

The most popular NDT methods are listed below. 
- Using infrared instruments

- Operating nuclear equipment

- Testing with the impedance method

\subsubsection{Providing Preventive Maintenance}

The life span and energy saving performance of a roofing system is greatly influenced by the presence or absence of a roof maintenance program. For this reason, nondestructive testing is becoming increasingly popular among roofing professionals. These cost-effective diagnostic methods provide vital information that can expand business opportunities and ensure long-term profit potential.

Many roofers agree that more than one method is necessary if roofs are to be properly surveyed for leaks. Each system complements the other and can be used for verification. Anything that does not show up using one method usually shows up with another method. There is no substitute, however, for know-how and roofing knowledge. No machine can replace the experience and the knowledge the roofing contractor has about the many different roofing systems.

\subsubsection{Promoting Roof Accessories}

There are several roof accessories that roofing contractors can install in their normal work operations to help their profit picture. These accessories like curbs and walkways help prevent damage to a metal roof when a curb is used to distribute the weight of a rooftop unit, or prevent damage from foot traffic when the installation of a roof walkway is specified between equipment located on the roof (see Figure 21).

Other roof accessories that enhance safety and protect a building owner's investment are access hatches, smoke hatches, and gravity ventilators. Access hatches allow workers to safely get onto the roof to install or repair rooftop equipment.

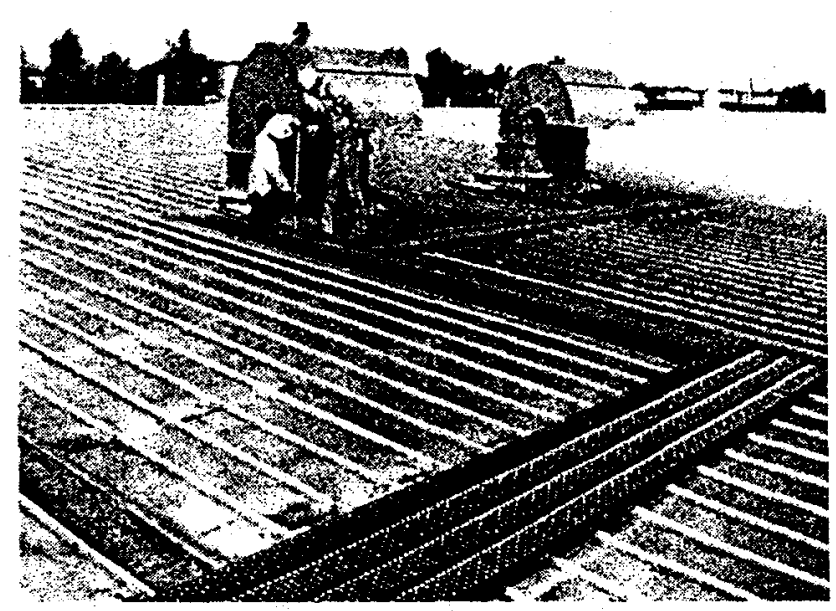

Figure 21. Roof accessories/walkways. 


\subsubsection{Future of Roofing}

New ideas and materials are on the way, although the conventional roofing practices described in this report are by no way on the way out. One new concept is fabric roofing. Permanent fabric roof structures are past the experimental stage. They are undergoing the technological evolution that takes place in every segment of this industry.

When a clear-span exceeds 100 to $150 \mathrm{ft}$, fabric structures generally cost less than traditional structures. Proponents of the fabric structures cite the fact that the weight and cost of the supporting structure per unit plan area do not increase with the roof's clear-span, as they do in conventional construction. Furthermore, the cost advantage occurs because the fabric envelope performs the function of several conventional building components, including roofing materials, roof deck, insulation, structure, wall cladding, waterproofing, acoustical absorber, interior finish, and daytime light source.

\subsection{WIND-RESISTANT CONSIDERATIONS}

In the past years, low-rise buildings particularly in the tropics suffered severely from the high winds of hurricanes and storms. There is very little engineering input into the design and construction of low-rise buildings as there is for tall buildings (Mahendran 1995).

\subsubsection{Roof claddings}

Wind damage investigations have shown that in buildings it is the uplift load path that often has the weakest links, and in fact, this weakest link is very often in the form of connections. Very rarely were the actual roof members found to have initiated the failure. The connection between metal roof cladding/tiles and battens/purlins has been one of the common problems. Loss of tiles or metal sheeting has been a common sight during high wind events. This often leads to the collapse of the entire building. Uplift loading on the roof is a randomly fluctuating loading, and thus causes fatigue failures of roofing to the batten connections. Low cycle fatigue cracking of thin metal roofing causes extensive damage to buildings. Valley-fixed metal claddings appear to perform better under cyclic wind loading. Therefore, the following areas should be strengthened and inspected routinely:

- the connections in the metal roof claddings

- the connections of roof sheeting and the fastener heads

- the connections of steel battens or timber and the fasteners

- the eaves, ridges, hips, and edges of the buildings.

\subsubsection{Roof structure}

Battens are immediately under the roof claddings. Battens may also suffer from fatigue under such wind fluctuating loading. It is suggested that light gauge metal straps be used to improve the strength of these connections.

Rafters or trusses are connected to the top plates of the wall frame by metal straps or anchor grips. These connections usually fail due to the fluctuations inherent in wind loading. 


\subsection{CONCLUDING REMARKS}

The accomplishments of the project to date can be summarized as follows:

- From the viewpoint of structural safety, one basic evaluation method for roof structures has been established by combining theoretical and experimental means. In experiments some example roof systems were evaluated.

- Deterministic FEM has been reviewed, and a computer program has been developed to calculate the static displacements of nodes and forces of structural members. Numerical example has been demonstrated and results have been compared with those from the well known software STAAD-III, which was developed for the application of the LRFD method.

- An experimental plan to obtain statistics data that constitute the basis of the static reliability evaluation model has been developed in the project. In this plan, a number of specimens from job sites will be needed to obtain information on design variables, such as the area and inertial moment of section, yielding strength, and modulus of elasticity, etc.

- An analytical model for static reliability analysis, which is based on SFEM, has been developed in Phase I of this project. A Fortran program has been written to put this idea to practical use. Numerical examples have been given to demonstrate the versatility of this model.

Numerical results show that the correlation between basic design variables has significant effect on reliability index, i.e., it has apparent effect on structural safety level. Actually, it is easy to obtain the first order and second order of statistics of variables through testing on specimens. However, it is difficult to get the information on the correlation between variables. To do so, a huge amount of work will be needed to acquire accurate information. This point is worth further research work in the future.

- Based on the SFEM mentioned above, a flowchart for optimization design of roof systems has been suggested. This kind of optimization design can ensure the uniform safety level within the whole structure.

- Fatigue cracks that occur in the structural members are usually caused by cyclic dynamic loads, such as live loads, wind loads, and earthquake loads. We have suggested a method to estimate the remaining life of existing roof structures.

- During the visit to SRS conducted by DOE and FIU-HCET, we found several typical roofs with severe material problems. Structural stabilization problems have rarely occurred within the job site; however, this does not mean that such problems will never happen because potential structural deterioration are not visible in most cases. In the final section, we present several most commonly used roof materials and briefly discuss them. The future of roofing materials is discussed to familiarize decision-makers with possible new roof systems for new buildings within DOE.

Overall, this proposed reliability-based analytical method for roof systems include two functions: static section and dynamic section. In practice, the one section that is less safe will be considered 
and corresponding measures will be taken to ensure the safety of the whole roof system. If possible, the blueprints of buildings in specific job-sites will be collected and structural analysis will be performed using this model in the next year.

The major reason roofs leak is that the roof covering materials develop problems and fail, generally because of age. In the next phase of this project the properties of commonly used roof materials will be evaluated. One goal of the project is to look for better roofing materials to use to stabilize the DOE building roof systems so that D\&D personnel can work in a safer environment. 


\section{REFERENCES}

Ang, A.H-S. and Tang, W.H., 1984, Probability Concepts in Engineering Planning and Design, Volume II: Decision, Risk, and Reliability, John Wiley \& Sons, New York.

Bickford, William B., 1990, A First Course in the Finite Element Method, Richard D. Irwin, Inc., Homewood, IL.

Engelhardt, M.D. and Husain, A.S., 1993, "Cyclic-Loading Performance of Welded FlangeBolted Web Connections", Journal of Structural Engineering, ASCE, Vol. 119, No. 12, pp. 3537-3550.

Ghanem, R.G. and Spanos, P.D., 1991, Stochastic Finite Elements: A Spectral Approach, Berlin Springer-Veriag, Berlin.

Harr, M.E., 1987, Reliability-Based Design in Civil Engineering, McGraw-Hill, New York.

Karamchandani, A. and Bjerager, P., 1992, "Systems Reliability Approach to Fatigue of Structures," Journal of Structural Engineering, ASCE, Vol. 118, No. 3, pp. 684-770.

Kleiber, M. and Hien, T.D., 1992, The Stochastic Finite Element Method, Basic Perturbation Technique and Computer Implementation, John Wiley \& Sons, New York.

Liu, C.H. and Qin, Q., 1996, "Reliability Analysis of Steel Frame Structures Based on SFEM," Proceedings, International Conference on Advances in Steel Structures, Hong Kong.

Mahadevan, S. and Haldar, A., 1990, "Reliability-based Optimization Using SFEM," Proceedings, Reliability and Optimization of Structural System Conference.

Mahadevan, S. and Haldar, A., 1991, "Stochastic FEM-based Validation of LRFD," Journal of Structural Engineering, ASCE, Vol. 117, No. 5, pp. 1393-1412.

Mahendran, Mahen, 1995, "Wind-Resistant Low-Rise Buildings in the Tropics," Journal of Performance of Constructed Facilities, ASCE, Vol. 9, No. 4, pp. 330-346.

Martin, Harold C. and Carey, Graham F., 1973, Introduction to Finite Element Analysis, Theory and Application, McGraw-Hill Book Company, New York.

Rahman, S. and Grigoriu, M., 1993, "Markov Model for Seismic Reliability Analysis of Degrading Structures", Journal of Structural Engineering, ASCE, Vol. 111, No. 4, pp. 1844-1865.

Roeder, C.W., Foutch, D.A., 1996, "Experimental Results for Seismic Resistant Steel Moment Frame Connections", Journal of Structural Engineering, ASCE, Vol. 122, No. 6, pp. 581588.

Scharff, R., Roofing Handbook, 1st ed., McGraw Hill, N.Y., 1996

South Florida Building Code, Dade County, FL, 1994 
SriVidya, A. and Ranganathan, R., 1995, "Reliability Based Optimal Design of Reinforced Concrete Frames", Journal of Computer and Structures, Vol. 57, No. 4, pp. 651-661.

Surahman, A. and Rojiani, K.B., 1983, "Reliability Based Optimum Design of Concrete Frames", Journal of Structural Engineering, ASCE, Vol. 109, No. 3, pp. 741-757.

Tamboli, Akbar R., 1997, Steel Design Handbook, LRFD Method, McGraw-Hill, New York. 
USER'S MANUAL FOR PROGRAM OF

DETERMINISTIC AND RELIABILITY ANALYSIS OF ROOF STRUCTURES 


\section{USER'S MANUAL \\ FOR PROGRAM OF DETERMINISTIC AND RELIABILITY ANALYSIS OF ROOF STRUCTURES}

Presented by:

Ton-Lo Wang, Ph.D., P.E.

and

Chunhua Liu, Ph.D.

January 1998 


\subsection{INTRODUCTION}

This computer program is compiles by Fortran language. The objective is to perform static deterministic and reliability analysis. This user's manual includes four parts:

- PART I Sample Example

- PART II Sample Input Data

- PART III Sample Output Files

- PART IV Explanations for Input Data

Part I provides a numerical example for this computer program. Part II and Part III demonstrate the input and output file of this example. Part IV gives an explanation of format and variables of the input data in Part II. 
As a numerical example, a steel frame with a roof structure as shown in Figure 1 is calculated by using the FORTRAN program developed in the project. The dividing of nodes and finite elements is shown in Figure 2. This plane steel frame example is designed according to the LRFD (Load and Resistance Factor Design) specifications. The analytical results are in accordance with those in the reference.

The section properties of this frame are shown in Table 1. The deterministic displacements at every node and the deterministic forces of steel members under dead load and live loads are calculated, respectively.

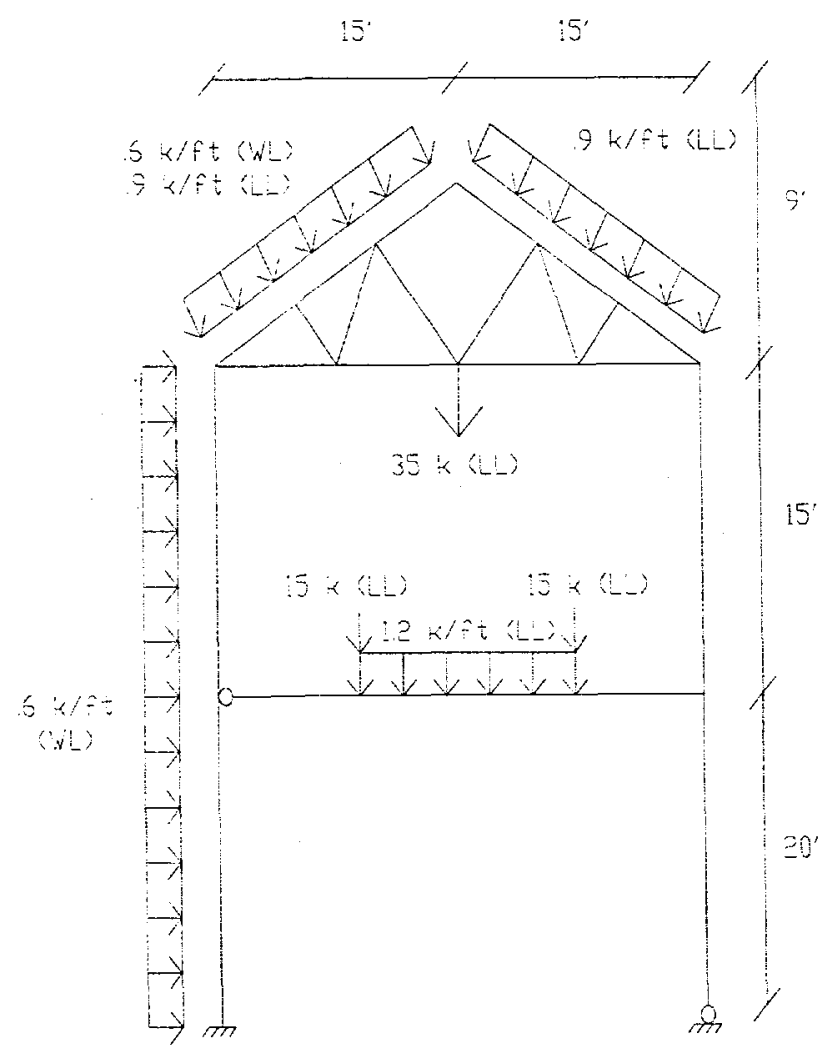

Note: LL: Live Load WL: Wind Load

Figure 1. A steel frame designed by LRFD method. 


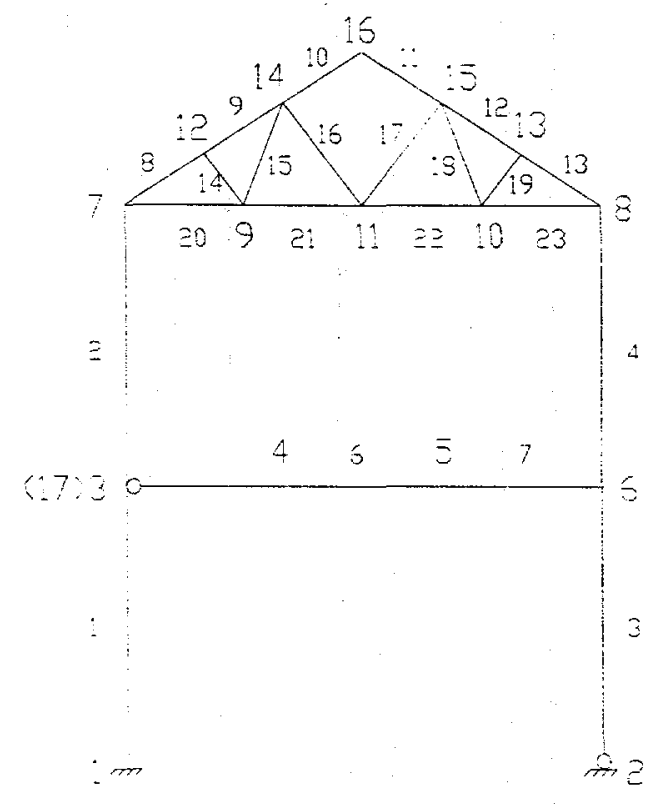

Note: Large size number represents the number of nodes; Small size number represents the number of elements.

Figure 2. The divided nodes and finite elements.

Table 1.

The Properties of Cross Section

\begin{tabular}{|c|c|c|c|c|c|c|c|c|c|}
\hline Element No. & $\begin{array}{c}d_{x} \\
\left(\text { in. }^{2}\right)\end{array}$ & $\begin{array}{c}A_{y} \\
\left(\text { in. }^{2}\right)\end{array}$ & $\begin{array}{c}A= \\
\left(\text { in. }^{2}\right)\end{array}$ & $\begin{array}{c}I_{x} \\
\left(\text { in. }{ }^{4}\right)\end{array}$ & $\begin{array}{c}I_{x} \\
\left(\text { in. }{ }^{+}\right)\end{array}$ & $\begin{array}{c}I_{x} \\
\left(\text { in. }^{4}\right)\end{array}$ & $\begin{array}{c}E \\
\text { (psi) }\end{array}$ & $\mu$ & $\begin{array}{c}\rho \\
\left.\left(\mathrm{kip} / \mathrm{in}^{3}\right)^{3}\right)\end{array}$ \\
\hline $1,3,4$ & 26.5 & 6.17 & 13.75 & 4.06 & 362.0 & 999.0 & $.29 \times 10^{5}$ & 0.3 & $.283 \times 10^{-3}$ \\
\hline 2 & 14.4 & 3.39 & 7.47 & 1.39 & 93.40 & 272.0 & $.29 \times 10^{5}$ & 0.3 & $.283 \times 10^{-3}$ \\
\hline $5,6,7$ & 14.7 & 7.92 & 4.66 & 1.14 & 24.90 & .984 .0 & $.29 \times 10^{5}$ & 0.3 & $.283 \times 10^{-3}$ \\
\hline $8,9,10,11,12,13$ & 10.3 & 5.31 & 3.4 & 0.51 & 15.30 & 510.0 & $.29 \times 10^{5}$ & 0.3 & $.283 \times 10^{-3}$ \\
\hline $\begin{array}{c}14,15,16,17,18,19,20 \\
21,22,23\end{array}$ & 1.9 & 0.67 & 0.67 & 0.04 & 4.850 & $0.122 \times 10^{-7}$ & $.29 \times 10^{5}$ & 0.3 & $.283 \times 10^{-3}$ \\
\hline
\end{tabular}

In this example, the modulus of elasticity of every structural member and external loads are assumed to be random and Gaussian variables. The correlation between these variables is expressed in the exponential form and the total length, $L$, is selected as $\left(15^{\prime}+20^{\prime}+2 \times 15^{\prime}\right)=65$ feet. The meshes of random field are chosen as the same size of finite elements. 
The serviceability limit state requires the displacement at the midspan point should not exceed $1 / 360$ of the span under all live loads. The correspondent reliability index is calculated as an example. 
$* * * * * * * * * * * * * * * * * * * * * * * * * * * * * * * * * * * * * * * * * * * * * * * * * * * * * * * * * * * * * * * *$

This is a plane steel frame problem designed by LRFD (FEASIBLE PROJECT)

$$
\begin{aligned}
& 23,17,17,5,0,0,10,0,-2 \\
& 1,1,3,2,1,1 \\
& 2,3,7,2,2,2 \\
& 3,2,6,1,1,3 \\
& 4,6,8,1,1,4 \\
& 5,4,17,1,3,5 \\
& 6,4,5,1,3,6 \\
& 7,5,6,1,3,7 \\
& 8,7,12,11,4,8 \\
& 9,12,14,11,4,9 \\
& 10,14,16,11,4,10 \\
& 11,15,16,11,4,11 \\
& 12,13,15,11,4,12 \\
& 13,8,13,11,4,13 \\
& 14,9,12,7,5,14 \\
& 15,9,14,7,5,15 \\
& 16,11,14,7,5,16 \\
& 17,11,15,8,5,17 \\
& 18,10,15,8,5,18 \\
& 19,10,13,8,5,19 \\
& 20,7,9,1,5,20 \\
& 21,9,11,1,5,21 \\
& 22,10,11,1,5,22 \\
& 23,8,10,1,5,23 \\
& 1,0.0,0.0,0.0 \\
& 2,30.0,0.0,0.0 \\
& 3,0.0,20.0,0.0 \\
& 4,10.0,20.0,0.0 \\
& 5,20.0,20.0,0.0 \\
& 6,30.0,20.0,0.0 \\
& 7,0.0,35.0,0.0 \\
& 8,30.0,35.0,0.0 \\
& 9,7.5,35.0,0.0 \\
& 10,22.5,35.0,0.0 \\
& 11,15.0,35.0,0.0 \\
& 12,5.0,38.0,0.0 \\
& 13,25.0,38.0,0.0 \\
&
\end{aligned}
$$


$14,10.0,41.0,0.0$

$15,20.0,41 \cdot 0,0.0$

$16,15.0,44.0,0.0$

$17,0.0,20.0,0.0$

$4,0.0,-21.0,0.0,0.0,0.0,-10.0$

$5,0.0,-21.0,0.0,0.0,0.0,10.0$

$7,1.35,-2.25,0.0,0.0,0.0,-2.55$

$8,-1.35,-2.25,0.0,0.0,0.0,-2.55$

$11,0.0,-35.0,0.0,0.0,0.0,0.0$

$12,2.7,-4.50,0.0,0.0,0.0,0.0$

$13,-2.7,-4.50,0.0,0.0,0.0,0.0$

$14,2.7,-4.50,0.0,0.0,0.0,0.0$

$15,-2.7,-4.50,0.0,0.0,0.0,0.0$

$16,0.0,-4.50,0.0,0.0,0.0,0.0$

$1,1,1,1,1,1,1,0.0,0.0,0.0,0.0,0.0,0.0$

$2,1,1,1,1,1,0,0.0,0.0,0.0,0.0,0.0,0.0$

$3,0,0,1,1,1,0,0.0,0.0,0.0,0.0,0.0,0.0$

$4,0,0,1,1,1,0,0.0,0.0,0.0,0.0,0.0,0.0$

$5,0,0,1,1,1,0,0.0,0.0,0.0,0.0,0.0,0.0$

$6,0,0,1,1,1,0,0.0,0.0,0.0,0.0,0.0,0.0$

$7,0,0,1,1,1,0,0.0,0.0,0.0,0.0,0.0,0.0$

$8,0,0,1,1,1,0,0.0,0.0,0.0,0.0,0.0,0.0$

$9,0,0,1,1,1,0,0.0,0.0,0.0,0.0,0.0,0.0$

$10,0,0,1,1,1,0,0.0,0.0,0.0,0.0,0.0,0.0$

$11,0,0,1,1,1,0,0.0,0.0,0.0,0.0,0.0,0.0$

$12,0,0,1,1,1,0,0.0,0.0,0.0,0.0,0.0,0.0$

$13,0,0,1,1,1,0,0.0,0.0,0.0,0.0,0.0,0.0$

$14,0,0,1,1,1,0,0.0,0.0,0.0,0.0,0.0,0.0$

$15,0,0,1,1,1,0,0.0,0.0,0.0,0.0,0.0,0.0$

$16,0,0,1,1,1,0,0.0,0.0,0.0,0.0,0.0,0.0$

$17,3,3,1,1,1,0,0.0,0.0,0.0,0.0,0.0,0.0$

$1,26.50,6.17,13.75,4.06,362.0,999.0,29000.0,0.3,0.000283$

$2,14.40,3.39,7.47,1.39,93.40,272.0,29000.0,0.3,0.000283$

$3,14.70,7.92,4.66,1.14,24.90,984.0,29000.0,0.3,0.000283$

$4,10.30,5.31,3.40,0.51,15.30,510.00,29000.0,0.3,0.000283$

$5,1.94,0.67,0.67,0.04,4.85,1.22 \mathrm{E}-8,29000.0,0.3,0.000283$

$0.04,0.0,0.0,0.01,0.0,0.0,0.0,0.0,0.0,0.0,0.0,0.0,0.0,0.0,0.0$

$10.0,0.0,0.0,0.0,0.0,0.0,0.0,0.0,0.0,0.0,0.0,0.0,0.0,0.0,0.0$, $0.0,0.0,0.0,0.0,0.0,0.0,0.0,0.0,0.0,0.0,0.0,0.0,0.0,0.0,0.0$

$23,10,0,0,0$

$1,1,0,0$

$2,1,0,0$ 
$3,0,0,0$

$4,0,0,0$

$5,0,0,0$

$1,1,3,1$

$2,3,7,1$

$3,2,6,1$

$4,6,8,1$

$5,4,17,1$

$6,4,5,1$

$7,5,6,1$.

$8,7,12,1$

$9,12,14,1$

$10,14,16,1$

$11,15,16,1$

$12,13,15,1$

$13,8,13,1$

$14,9,12,1$

$15,9,14,1$

$16,11,14,1$

$17,11,15,1$

$18,10,15,1$

$19,10,13,1$

$20,7,9,1$

$21,9,11,1$

$22,10,11,1$

$23,8,10,1$

$24,4,4,2$

$25,5,5,2$

$26,7,7,2$

$27,8,8,2$

$28,11,11,2$

$29,12,12,2$

$30,13,13,2$

$31,14,14,2$

$32,15,15,2$

$33,16,16,2$

$11,2,0.083333$ 


\section{PART III. SAMPLE OUTPUT FILES}

There are two parts for output results: one for deterministic analysis and the other for reliability analysis. When one runs the program, the screen prompts:

PLEASE ENTER THE NUMBER (0 OR 1):

0 IS FOR DETERMINISTIC ANALYSIS;

1 IS FOR RELIABILITY ANALYSIS

1. Deterministic Analysis Results:

$* * * * * * * * * * * * * * * * * * * * * * * * * * * * * * * * * * * * * * * * * * * * * * * * * * * * * * * * * * * * * * * * *$

THIS IS A PLANE STEEL FRAME PROBLEM DESIGNED BY LRFD (FEASIBLE PROJECT)

TOTAL NUMBER OF ELEMENTS $=23$

TOTAL NUMBER OF NODES $=17$

TOTAL NODAL NUMBER OF FIXTIES $=17$

TOTAL NUMBER OF MATERIALS $=5$

TOTAL GEOMETRIC NUMBER ELEMENT $=0$

NONLINEARITY MARK $=0$

NODAL LOADS $=10$

NON-NODAL LOADS $=0$

SELF-WEIGHT NO. $=-2$

ELEMENT DEFINITIONS

ELEMENT NODE1 NODE2 NODE3

$\begin{array}{llllll}1 & 1 & 3 & 2 & 1 & 1 \\ 2 & 3 & 7 & 2 & 2 & 2 \\ 3 & 2 & 6 & 1 & 1 & 3 \\ 4 & 6 & 8 & 1 & 1 & 4 \\ 5 & 4 & 17 & 1 & 3 & 5 \\ 6 & 4 & 5 & 1 & 3 & 6 \\ 7 & 5 & 6 & 1 & 3 & 7 \\ 8 & 7 & 12 & 11 & 4 & 8 \\ 9 & 12 & 14 & 11 & 4 & 9 \\ 10 & 14 & 16 & 11 & 4 & 10 \\ 11 & 15 & 16 & 11 & 4 & 11 \\ 12 & 13 & 15 & 11 & 4 & 12 \\ 13 & 8 & 13 & 11 & 4 & 13 \\ 14 & 9 & 12 & 7 & 5 & 14 \\ 15 & 9 & 14 & 7 & 5 & 15 \\ 16 & 11 & 14 & 7 & 5 & 16 \\ 17 & 11 & 15 & 8 & 5 & 17 \\ 18 & 10 & 15 & 8 & 5 & 18 \\ 19 & 10 & 13 & 8 & 5 & 19 \\ 20 & 7 & 9 & 1 & 5 & 20 \\ 21 & 9 & 11 & 1 & 5 & 21 \\ 22 & 10 & 11 & 1 & 5 & 22 \\ 23 & 8 & 10 & 1 & 5 & 23\end{array}$




\begin{tabular}{clll}
\multicolumn{4}{c}{ NODAL COORDINATES } \\
NODE & \multicolumn{1}{c}{$X$} & $Y$ & $Z$ \\
& & & \\
1 & .000 & .000 & .000 \\
2 & 30.000 & .000 & .000 \\
3 & .000 & 20.000 & .000 \\
4 & 10.000 & 20.000 & .000 \\
5 & 20.000 & 20.000 & .000 \\
6 & 30.000 & 20.000 & .000 \\
7 & .000 & 35.000 & .000 \\
8 & 30.000 & 35.000 & .000 \\
9 & 7.500 & 35.000 & .000 \\
10 & 22.500 & 35.000 & .000 \\
11 & 15.000 & 35.000 & .000 \\
12 & 5.000 & 38.000 & .000 \\
13 & 25.000 & 38.000 & .000 \\
14 & 10.000 & 41.000 & .000 \\
15 & 20.000 & 41.000 & .000 \\
16 & 15.000 & 44.000 & .000 \\
17 & .000 & 20.000 & .000
\end{tabular}

$\begin{array}{ccccccc}\text { NODAL LOADS } & & & & \\ \text { NODE } & \text { X-FORCE } & \text { Y-FORCE } & \text { Z-FORCE } & \text { X-MOMENT } & \text { Y-MOMENT } & \text { Z-MOMENT } \\ 4 & .000 E+00 & -.210 E+02 & .000 E+00 & .000 E+00 & .000 E+00 & -.100 E+02 \\ 5 & .000 E+00 & -.210 E+02 & .000 E+00 & .000 E+00 & .000 E+00 & .100 E+02 \\ 7 & .135 E+01 & -.225 E+01 & .000 E+00 & .000 E+00 & .000 E+00 & -.255 E+01 \\ 8 & -.135 E+01 & -.225 E+01 & .000 E+00 & .000 E+00 & .000 E+00 & -.255 E+01 \\ 11 & .000 E+00 & -.350 E+02 & .000 E+00 & .000 E+00 & .000 E+00 & .000 E+00 \\ 12 & .270 E+01 & -.450 E+01 & .000 E+00 & .000 E+00 & .000 E+00 & .000 E+00 \\ 13 & -.270 E+01 & -.450 E+01 & .000 E+00 & .000 E+00 & .000 E+00 & .000 E+00 \\ 14 & .270 E+01 & -.450 E+01 & .000 E+00 & .000 E+00 & .000 E+00 & .000+00 \\ 15 & -.270 E+01 & -.450 E+01 & .000 E+00 & .000 E+00 & .000 E+00 & .000 E+00 \\ 16 & .000 E+00 & -.450 E+01 & .000 E+00 & .000 E+00 & .000 E+00 & .000 E+00\end{array}$

BOUNDARY CONDITIONS

NODE X-DIREC. Y-DIREC. Z-DIREC. X-X Y Y-Y Z Z-Z

$\begin{array}{lllllllllllll}1 & 1 & 1 & 1 & 1 & 1 & 1 & .0000 & .0000 & .0000 & .0000 & .0000 & .0000 \\ 2 & 1 & 1 & 1 & 1 & 1 & 0 & .0000 & .0000 & .0000 & .0000 & .0000 & .0000 \\ 3 & 0 & 0 & 1 & 1 & 1 & 0 & .0000 & .0000 & .0000 & .0000 & .0000 & .0000 \\ 4 & 0 & 0 & 1 & 1 & 1 & 0 & .0000 & .0000 & .0000 & .0000 & .0000 & .0000 \\ 5 & 0 & 0 & 1 & 1 & 1 & 0 & .0000 & .0000 & .0000 & .0000 & .0000 & .0000 \\ 6 & 0 & 0 & 1 & 1 & 1 & 0 & .0000 & .0000 & .0000 & .0000 & .0000 & .0000 \\ 7 & 0 & 0 & 1 & 1 & 1 & 0 & .0000 & .0000 & .0000 & .0000 & .0000 & .0000 \\ 8 & 0 & 0 & 1 & 1 & 1 & 0 & .0000 & .0000 & .0000 & .0000 & .0000 & .0000 \\ 9 & 0 & 0 & 1 & 1 & 1 & 0 & .0000 & .0000 & .0000 & .0000 & .0000 & .0000 \\ 10 & 0 & 0 & 1 & 1 & 1 & 0 & .0000 & .0000 & .0000 & .0000 & .0000 & .0000 \\ 11 & 0 & 0 & 1 & 1 & 1 & 0 & .0000 & .0000 & .0000 & .0000 & .0000 & .0000 \\ 12 & 0 & 0 & 1 & 1 & 1 & 0 & .0000 & .0000 & .0000 & .0000 & .0000 & .0000 \\ 13 & 0 & 0 & 1 & 1 & 1 & 0 & .0000 & .0000 & .0000 & .0000 & .0000 & .0000 \\ 14 & 0 & 0 & 1 & 1 & 1 & 0 & .0000 & .0000 & .0000 & .0000 & .0000 & .0000 \\ 15 & 0 & 0 & 1 & 1 & 1 & 0 & .0000 & .0000 & .0000 & .0000 & .0000 & .0000 \\ 16 & 0 & 0 & 1 & 1 & 1 & 0 & .0000 & .0000 & .0000 & .0000 & .0000 & .0000 \\ 17 & 3 & 3 & 1 & 1 & 1 & 0 & .0000 & .0000 & .0000 & .0000 & .0000 & .0000\end{array}$


THE PROPERTIES OF CROSS SECTION

\begin{tabular}{|c|c|c|c|c|c|c|c|c|c|}
\hline 1 & $.2650 E+02$ & $.6170 E+01$ & $.1375 E+02$ & $.4060 E+01$ & $.3620 E+03$ & $.9990 E+03$ & $.2900 E+05$ & $.3000 E+00$ & .283 \\
\hline 2 & $.1440 E+02$ & $.3390 \mathrm{E}+01$ & $.7470 E+01$ & $.1390 \mathrm{E}+01$ & $.9340 E+02$ & $.2720 E+03$ & $.2900 E+05$ & $.3000 E+00$ & $.2830 \mathrm{E}-03$ \\
\hline 3 & $.1470 \mathrm{E}+02$ & $.7920 E+01$ & $.4660 E+01$ & $.1140 E+01$ & $.2490 E+02$ & $.9840 \mathrm{E}+03$ & $.2900 E+05$ & $.3000 E+00$ & $.2830 \mathrm{E}-03$ \\
\hline 4 & $.1030 E+02$ & $.5310 E+01$ & $.3400 E+01$ & $.5100 E+00$ & $.1530 \mathrm{E}+02$ & $.5100 \mathrm{E}+03$ & $.2900 E+05$ & $.3000 E+00$ & $.2830 \mathrm{E}-03$ \\
\hline 5 & $.1940 E+01$ & $.6700 E+00$ & $.6700 E+00$ & $.4000 \mathrm{E}-01$ & $.4850 E+01$ & $.1220 \mathrm{E}-07$ & $.2900 E+05$ & $.3000 E+00$ & $.2830 \mathrm{E}-03$ \\
\hline
\end{tabular}

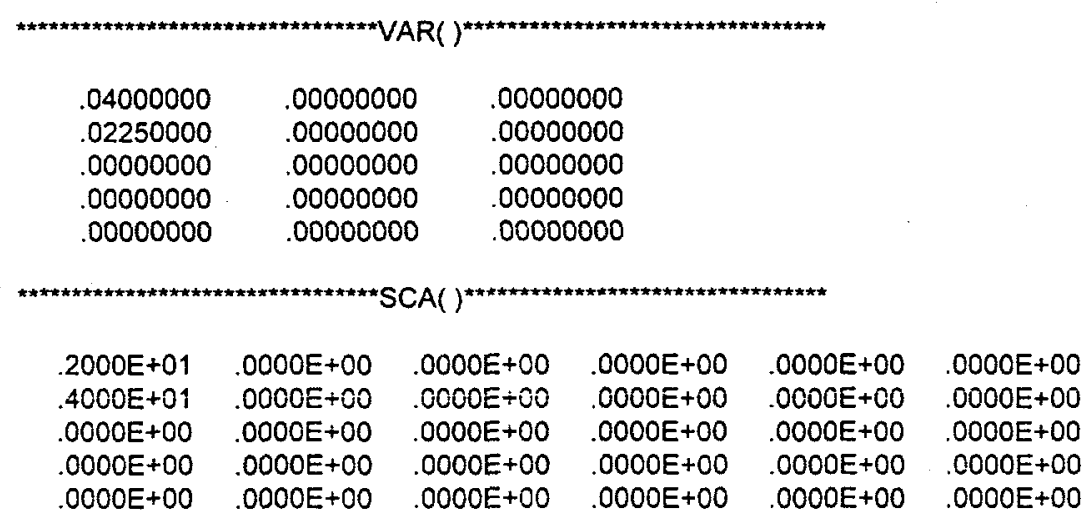

INPUT THE LOCAL AVAERAGE ELEMENT NUMBER: NEAD(I)

MATERIAL 1\# LOCAL AVERAGE MESH NUMBER = 23

MATERIAL 2\# LOCAL AVERAGE MESH NUMBER $=10$

MATERIAL 3\# LOCAL AVERAGE MESH NUMBER = 0

MATERIAL 4\# LOCAL AVERAGE MESH NUMBER = 0

MATERIAL 5\# LOCAL AVERAGE MESH NUMBER $=0$

INPUT THE RANDOMNESS MARK OF EVERY FIELD: MY $(1, J)$

$\begin{array}{llll}1 & 1 & 0 & 0 \\ 2 & 1 & 0 & 0 \\ 3 & 0 & 0 & 0 \\ 4 & 0 & 0 & 0 \\ 5 & 0 & 0 & 0\end{array}$

** LOCAL AVERAGE ELEMENTS AMOUNT $=33^{* * *}$

INEA

$\begin{array}{cccc}1 & 1 & 3 & 1 \\ 2 & 3 & 7 & 1 \\ 3 & 2 & 6 & 1 \\ 4 & 6 & 8 & 1 \\ 5 & 4 & 17 & 1 \\ 6 & 4 & 5 & 1 \\ 7 & 5 & 6 & 1 \\ 8 & 7 & 12 & 1 \\ 9 & 12 & 14 & 1 \\ 10 & 14 & 16 & 1 \\ 11 & 15 & 16 & 1 \\ 12 & 13 & 15 & 1 \\ 13 & 8 & 13 & 1 \\ 14 & 9 & 12 & 1 \\ 15 & 9 & 14 & 1 \\ 16 & 11 & 14 & 1 \\ 17 & 11 & 15 & 1\end{array}$




$\begin{array}{cccc}18 & 10 & 15 & 1 \\ 19 & 10 & 13 & 1 \\ 20 & 7 & 9 & 1 \\ 21 & 9 & 11 & 1 \\ 22 & 10 & 11 & 1 \\ 23 & 8 & 10 & 1 \\ 24 & 4 & 4 & 2 \\ 25 & 5 & 5 & 2 \\ 26 & 7 & 7 & 2 \\ 27 & 8 & 8 & 2 \\ 28 & 11 & 11 & 2 \\ 29 & 12 & 12 & 2 \\ 30 & 13 & 13 & 2 \\ 31 & 14 & 14 & 2 \\ 32 & 15 & 15 & 2 \\ 33 & 16 & 16 & 2\end{array}$

NODE OF DISPLACEMENT $=11$

NO OF DIPLACEMENT $=2$

LIMIT OF DISPLACEMENT $\quad$ AT MIDSPAN POINT =

.08333

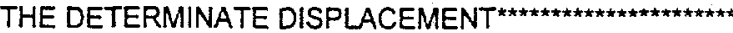

\begin{tabular}{|c|c|c|c|c|c|c|c|}
\hline$L L=$ & 1 & NODE = & 1 & $1=$ & 1 & DISPL.(I) $=$ & $.00000 E+00$ \\
\hline $\mathrm{LL}=$ & 1 & NODE $=$ & 1 & $i=$ & 2 & DISPL. $(1)=$ & $.00000 E+00$ \\
\hline $\mathrm{LL}=$ & 1 & NODE $=$ & 1 & $1=$ & 3 & DISPL.(I) $=$ & $.00000 E+00$ \\
\hline $\mathrm{LL}=$ & 1 & NODE = & 1 & $1=$ & 4 & DISPL.(I) $=$ & $.00000 E+00$ \\
\hline$L L=$ & 1 & NODE $=$ & 1 & $1=$ & 5 & DISPL. $(1)=$ & $.00000 E+00$ \\
\hline$L L=$ & 1 & NODE $=$ & 1 & $1=$ & 6 & DISPL.(I) $=$ & $.00000 E+00$ \\
\hline $\mathrm{LL}=$ & 1 & NODE $=$ & 2 & $1=$ & 1 & DISPL.(1) = & $.00000 E+00$ \\
\hline$L L=$ & 1 & NODE $=$ & 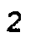 & $1=$ & 2 & DISPL.(1) = & $.00000 E+00$ \\
\hline$L=$ & 1 & NODE $=$ & 0 & $1=$ & 3 & DISPL.(I) = & $O E+00$ \\
\hline $\mathrm{L}=$ & 1 & $E=$ & 0 & $1=$ & 4 & DISPL.(1) $=$ & $.00000 E+00$ \\
\hline$L L=$ & 1 & $=$ & 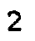 & $1=$ & 5 & DISPL. $(1)=$ & $.00000 E+00$ \\
\hline$L=$ & 1 & $=$ & 2 & $1=$ & 6 & DISPL. $(1)=$ & -04 \\
\hline$L=$ & 1 & $=$ & 3 & $1=$ & 1 & DISPL. $(I)=$ & -03 \\
\hline$L L=$ & 1 & $=$ & 3 & $1=$ & 2 & DISP & -02 \\
\hline$L L=$ & 1 & NOI & 3 & $1=$ & 3 & $=$ & $E+00$ \\
\hline$L=$ & 1 & $=$ & 3 & $1=$ & 4 & $=$ & $+\infty$ \\
\hline$L L=$ & 1 & $=$ & 3 & $1=$ & 5 & $=$ & $E+\infty$ \\
\hline $\mathrm{LL}=$ & 1 & $=$ & 3 & $1=$ & 6 & $=$ & .05 \\
\hline $\mathrm{LL}=$ & 1 & NOS & 4 & $1=$ & & $=$ & -03 \\
\hline $\mathrm{LL}=$ & 1 & NOC & 4 & $1=$ & 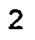 & $=$ & -02 \\
\hline$L L=$ & 1 & NOI & 4 & $1=$ & 3 & DIS & $+\infty$ \\
\hline$L L=$ & 1 & $=$ & 4 & $1=$ & 4 & DIS & $.00000 \mathrm{E}+00$ \\
\hline $\mathrm{LL}=$ & 1 & $=$ & 4 & $1=$ & 5 & $=$ & $.00000 E+00$ \\
\hline$L L=$ & 1 & $=$ & 4 & $1=$ & 6 & DISP & $-.45693 E-04$ \\
\hline $\mathrm{LL}=$ & 1 & $=$ & 5 & $1=$ & 1 & $=$ & $9 E-03$ \\
\hline $\mathrm{LL}=$ & 1 & NO & 5 & $1=$ & 2 & DIS & E-02 \\
\hline $\mathrm{LL}=$ & 1 & $=$ & 5 & $1=$ & 3 & $=$ & $E+\infty$ \\
\hline $\mathrm{LL}=$ & 1 & $=$ & 5 & $1=$ & 4 & DIS & $.00000 E+00$ \\
\hline $\mathrm{LL}=$ & 1 & NO & 5 & $1=$ & 5 & DIS & $E+\infty$ \\
\hline$L L=$ & 1 & $=$ & 5 & $1=$ & 6 & DIS & $6 E-04$ \\
\hline$L L=$ & 1 & NC & 6 & $1=$ & 1 & DIS & $3 E-03$ \\
\hline$L L=$ & 1 & NC & 6 & $1=$ & 2 & DIS & 5E-02 \\
\hline$L L=$ & 1 & NO & 6 & $1=$ & 3 & DISF & $.00000 E+00$ \\
\hline $\mathrm{LL}=$ & 1 & NC & 6 & $1=$ & 4 & DISP & $.00000 E+00$ \\
\hline $\mathrm{LL}=$ & 1 & NO & 6 & $1=$ & 5 & DIS & $.00000 E \div 00$ \\
\hline$L=$ & 1 & & 6 & $1=$ & 6 & DIS & EE-04 \\
\hline LL & 1 & NO & 7 & $1=$ & 1 & DIS & -.17830 E-02 \\
\hline$L=$ & 1 & $E=$ & 7 & $I=$ & 2 & DIS & -.243 \\
\hline$L$ & 1 & NC & 7 & $1=$ & 3 & DISPL.(I) = & $.00000 E+00$ \\
\hline $\mathrm{LL}=$ & 1 & & 7 & $1=$ & 4 & DISPL. $(1)=$ & $.00000 E+0$ \\
\hline $1=$ & 1 & $E=$ & 7 & $1=$ & 5 & DISPL.(I) = & $.00000 E+00$ \\
\hline
\end{tabular}




\begin{tabular}{|c|c|c|c|c|c|c|c|}
\hline$L L=$ & 1 & NODE $=$ & 7 & $1=$ & 6 & DISPL. $(I)=$ & $-.68500 \mathrm{E}-04$ \\
\hline$L L=$ & 1 & NODE $=$ & 8 & $1=$ & 1 & DISPL. $(I)=$ & $-.68329 E-03$ \\
\hline $\mathrm{LL}=$ & 1 & NODE $=$ & 8 & $1=$ & 2 & DISPL.(I) = & $-.20031 E-02$ \\
\hline$L=$ & 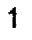 & NODE $=$ & 8 & $1=$ & 3 & DISPL.(I) = & $.00000 E+00$ \\
\hline$L L=$ & 1 & NODE $=$ & 8 & $1=$ & 4 & DISPL.(I) = & $.00000 E+00$ \\
\hline$L=$ & 1 & NODE = & 8 & $1=$ & 5 & DISPL.(I) = & $.00000 E+00$ \\
\hline$L=$ & 1 & NODE $=$ & 8 & $1=$ & 6 & DISPL.(I) = & $.82110 \mathrm{E}-04$ \\
\hline$L=$ & 1 & NODE $=$ & 9 & $1=$ & 1 & DISPL.(I) = & $-.16377 E-02$ \\
\hline$=$ & 1 & NODE = & 9 & $1=$ & 2 & DISPL. $(1)=$ & $-.56587 E-02$ \\
\hline$L L=$ & 1 & NODE $=$ & 9 & $1=$ & 3 & DISPL.(I) = & $.00000 E+00$ \\
\hline$L L=$ & 1 & NODE $=$ & 9 & $1=$ & 4 & DISPL.(I) = & $.00000 E+00$ \\
\hline$L L=$ & 1 & NODE = & 9 & $1=$ & 5 & DISPL.(I) = & $.00000 E+00$ \\
\hline $\mathrm{LL}=$ & 1 & NODE $=$ & 9 & $1=$ & 6 & DISPL.(I) = & $-.57958 E-03$ \\
\hline$L L=$ & 1 & NODE $=$ & 10 & $I=$ & 1 & DISPL.(I) = & $-.81894 E-03$ \\
\hline $\mathrm{LL}=$ & 1 & NODE $=$ & 10 & $1=$ & 2 & DISPL.(I) = & $-.54344 E-02$ \\
\hline$L L=$ & 1 & NODE $=$ & 10 & $I=$ & 3 & DISPL.(I) = & $.00000 E+00$ \\
\hline$L L=$ & 1 & NODE $=$ & 10 & $1=$ & 4 & DISPL.(I) = & $.00000 E+00$ \\
\hline$L L=$ & 1 & NODE $=$ & 10 & $1=$ & 5 & DISPL.(I) = & $.00000 E+00$ \\
\hline$L L=$ & 1 & NODE $=$ & 10 & $1=$ & 6 & DISPL.(I) = & $.61264 E-03$ \\
\hline$L L=$ & 1 & NODE = & 11 & $1=$ & 1 & DISPL.(I) = & $-.12260 E-02$ \\
\hline$L L=$ & 1 & NODE $=$ & $1 !$ & $1=$ & 2 & DISPL.(I) = & $-.11312 E-01$ \\
\hline$L L=$ & 1 & NODE $=$ & 11 & $1=$ & 3 & DISPL.(I) = & $.00000 E+00$ \\
\hline$L L=$ & 1 & NODE = & 11 & $1=$ & 4 & DISPL.(I) = & $00 E+00$ \\
\hline$L L=$ & 1 & NODE = & 11 & $I=$ & 5 & DISPL.(I) = & $10 E+\infty 0$ \\
\hline$L L=$ & 1 & NODE = & 11 & $1=$ & 6 & DISPL.(I) = & $E-04$ \\
\hline$L L=$ & 1 & NOL & 12 & $1=$ & 1 & DISPL.(I) = & $2 E-03$ \\
\hline$L L=$ & 1 & NO & 12 & $1=$ & 2 & DISPL.(1) = & $-.47927 \mathrm{E}-02$ \\
\hline$L L=$ & 1 & NO & 12 & $1=$ & 3 & DISP & $O E+00$ \\
\hline$L L=$ & 1 & NODE = & 12 & $1=$ & 4 & DISPL.(I) = & $.00000 E+00$ \\
\hline$L L=$ & 1 & NODE $=$ & 12 & $1=$ & 5 & DISPL.(I) $=$ & $.00000 E+00$ \\
\hline$L L=$ & 1 & NODE $=$ & 12 & $1=$ & 6 & DISPL.(I) = & $-.69611 \mathrm{E}-04$ \\
\hline $\mathrm{LL}=$ & 1 & NODE = & 13 & $1=$ & 1 & DISPL.(l) = & $-.17165 \mathrm{E}-02$ \\
\hline $\mathrm{LL}=$ & 1 & NODE $=$ & 13 & $1=$ & 2 & DISPL.(I) = & $-.44946 E-02$ \\
\hline $\mathrm{LL}=$ & 1 & NODE $=$ & 13 & $1=$ & 3 & DISPL.(I) = & $.00000 E+00$ \\
\hline$L L=$ & 1 & NODE $=$ & 13 & $1=$ & 4 & DISPL.(I) = & $.00000 E+00$ \\
\hline $\mathrm{LL}=$ & 1 & NODE $=$ & 13 & $1=$ & 5 & DISPL.(I) = & $.00000 E+00$ \\
\hline $\mathrm{LL}=$ & 1 & NODE $=$ & 13 & $1=$ & 6 & DISPL. $(I)=$ & $.86751 E-04$ \\
\hline$L L=$ & 1 & NODE $=$ & 14 & $1=$ & 1 & DISPL.(I) = & $-.30327 E-03$ \\
\hline $\mathrm{LL}=$ & 1 & NODE $=$ & 14 & $1=$ & 2 & DISPL.(I) = & $-.64307 \mathrm{E}-02$ \\
\hline $\mathrm{LL}=$ & 1 & NODE $=$ & 14 & $1=$ & 3 & DISPL.(I) = & $.00000 \mathrm{E}+00$ \\
\hline $\mathrm{LL}=$ & 1 & NODE $=$ & 14 & $1=$ & 4 & DISPL.(I) = & $.00000 E+00$ \\
\hline $\mathrm{LL}=$ & 1 & NODE $=$ & 14 & $1=$ & 5 & DISPL.(I) = & $.00000 E+00$ \\
\hline $\mathrm{LL}=$ & 1 & $E=$ & 14 & $1=$ & 6 & DISPL.(I) = & $-.30419 E-04$ \\
\hline $\mathrm{LL}=$ & 1 & NO & 15 & $1=$ & 1 & DISPL. $(I)=$ & $-.23186 \mathrm{E}-02$ \\
\hline $\mathrm{LL}=$ & 1 & NODE $=$ & 15 & $1=$ & 2 & DISPL.(I) = & $-.62795 \mathrm{E}-02$ \\
\hline $\mathrm{LL}=$ & 1 & NODE $=$ & 15 & $1=$ & 3 & DISPL.(I) = & $.00000 E+00$ \\
\hline $\mathrm{LL}=$ & 1 & NODE $=$ & 15 & $1=$ & 4 & DISPL. $(I)=$ & $.00000 E+00$ \\
\hline $\mathrm{LL}=$ & 1 & NODE $=$ & 15 & $1=$ & 5 & DISPL.(I) = & $.00000 E+00$ \\
\hline $\mathrm{LL}=$ & 1 & NODE $=$ & 15 & $1=$ & 6 & DISPL.(I) = & $.49618 E-04$ \\
\hline $\mathrm{LL}=$ & 1 & NODE $=$ & 16 & $1=$ & 1 & DISPL.(I) = & $-.13523 E-02$ \\
\hline $\mathrm{LL}=$ & 1 & NO & 16 & $1=$ & 2 & DISPL. $(1)=$ & $-.56368 \mathrm{E}-02$ \\
\hline $\mathrm{LL}=$ & 1 & NODE $=$ & 16 & $1=$ & 3 & DISPL.(I) = & $.00000 E+00$ \\
\hline $\mathrm{LL}=$ & 1 & NOI & 16 & $\mathrm{I}=$ & 4 & DISPL.(1) = & $.00000 E+00$ \\
\hline $\mathrm{LL}=$ & 1 & NO & 16 & $1=$ & 5 & DISPL.(I) = & $.00000 E+00$ \\
\hline$L L=$ & 1 & NO & 16 & $1=$ & 6 & DISPL.(I) = & S2E-05 \\
\hline $\mathrm{LL}=$ & 1 & NO & 17 & $1=$ & 1 & DISPL. $(I)=$ & $-.62311 E-03$ \\
\hline $\mathrm{LL}=$ & 1 & NO & 17 & $\mathbf{I}=$ & 2 & DISPL.(I) = & $-.13334 \mathrm{E}-02$ \\
\hline$L L=$ & 1 & NODE = & 17 & $I=$ & 3 & DISPL.(I) = & $.00000 E+00$ \\
\hline$L L=$ & 1 & NODE $=$ & 17 & $1=$ & 4 & DISPL.(l) = & $.00000 E+00$ \\
\hline $\mathrm{LL}=$ & 1 & NODE $=$ & 17 & $1=$ & 5 & DISPL.(I) = & $.00000 E+00$ \\
\hline $\mathrm{LL}=$ & 1 & NODE $=$ & 17 & $\mathbf{I}=$ & 6 & DISPL.(I) = & $-.81388 E-04$ \\
\hline
\end{tabular}




\begin{tabular}{|c|c|c|c|c|c|c|c|c|}
\hline \multicolumn{2}{|c|}{ ELEMENT } & 3 & AXIAL & EAR-Y & $<$ & SiUTN & MOM-Y & $\angle$ \\
\hline 1 & 1 & & $5 E+02$ & $E+01$ & $E \div 00$ & 00 & $E+\infty$ & $E+0$ \\
\hline & 3 & & & $E+01$ & & .0 & 10 & $E+02$ \\
\hline 2 & 3 & & $7 E+02$ & $7 E+01$ & $O E+D O$ & +00 & & +02 \\
\hline & 7 & -.30 & $7 E+02$ & $E+01$ & +00 & .00 & 00 & .67 \\
\hline 3 & $\begin{array}{l}2 \\
6\end{array}$ & $\begin{array}{r}.53 \\
-.53\end{array}$ & $\begin{array}{l}1 E+02 \\
1 E+02\end{array}$ & $\begin{array}{r}.18173 E+01 \\
-.18173 E+01\end{array}$ & $\begin{array}{l}.00000 E+00 \\
.00000 E+00\end{array}$ & $\begin{array}{l}.00 \\
.00\end{array}$ & -00 & $\begin{array}{l}-.59 \\
.36\end{array}$ \\
\hline 4 & $\begin{array}{l}6 \\
8\end{array}$ & $\begin{array}{r}.31 \\
-.31\end{array}$ & $\begin{array}{l}8 E+02 \\
8 E+02\end{array}$ & $\begin{array}{r}.37787 E+01 \\
-.37787 E+01\end{array}$ & $\begin{array}{l}.00000 E+00 \\
.00000 E+00\end{array}$ & $\begin{array}{l}.00 \\
.000\end{array}$ & .00 & $\begin{array}{l}-.16246 \mathrm{E}+02 \\
.72928 \mathrm{E}+02\end{array}$ \\
\hline 5 & 4 & -.19 & $4 E+01$ & $72 E+02$ & $00 E+00$ & $+\infty$ & +00 & $.20372 E+03$ \\
\hline & 17 & & $4 E+01$ & $72 E+02$ & $100 E+00$ & $+\infty$ & $000 E+00$ & $89 E-13$ \\
\hline 6 & 4 & -.1 & $4 E+01$ & $1 E+00$ & DOE +00 & $+\infty 0$ & +00 & $E+03$ \\
\hline & 5 & .19 & $4 E+01$ & $1 E+00$ & $00 \mathrm{E}+00$ & .00 & +00 & $-.20702 E+03$ \\
\hline 7 & 5 & -.19 & $4 E+01$ & $2 E+02$ & J00E+00 & +00 & 100 & $E+03$ \\
\hline & 6 & .196 & $4 E+01$ & $2 E+02$ & DOE +00 & 00 & & +02 \\
\hline 8 & 7 & .19 & $8 E+02$ & $3 E+02$ & $+\infty$ & +00 & -00 & +02 \\
\hline & 12 & -.19 & $8 E+02$ & $33 E+02$ & $00 E+00$ & $+\infty$ & -00 & -.58 \\
\hline 9 & 12 & & $79 E+02$ & $E+02$ & $:+\infty$ & $+\infty 0$ & $+\infty 0$ & $+U<$ \\
\hline & 14 & -.20 & $9 \mathrm{E}+02$ & $71 E+02$ & $00 E+00$ & +00 & -00 & -.139 \\
\hline 10 & 14 & & $56 \mathrm{E}+02$ & +02 & $E+00$ & +00 & $+\infty$ & $: 0$ \\
\hline & 16 & -.25 & $6 E+02$ & +02 & -00 & .00 & 00 & -.6 \\
\hline 11 & 15 & & $07 E+02$ & +02 & $+\infty$ & +00 & +00 & $E+0$ \\
\hline & 16 & -.25 & $78+02$ & -.12 & 00 & .00 & .0 & -.6 \\
\hline 12 & 13 & & $96 \mathrm{E}+02$ & +02 & +00 & $+\infty$ & $+\infty$ & $:+\infty$ \\
\hline & 15 & -.20 & $6 E+02$ & 02 & & & .0 & -.1 \\
\hline 13 & 8 & & +02 & -02 & .00 & +00 & 00 & 02 \\
\hline & 13 & -.20 & 02 & & & & 00 & -.5 \\
\hline 14 & 9 & -.2 & +01 & 08 & 00 & 00 & 00 & -07 \\
\hline & 12 & & .01 & & & & & \\
\hline 15 & 9 & & 01 & & 00 & .0 & 0 & -07 \\
\hline & 14 & -.17 & 01 & & & & & \\
\hline 16 & 11 & -.2 & +02 & & 0 & .0 & 0 & -06 \\
\hline & 14 & .22 & $99 E$ & & & .0 & & \\
\hline 17 & 11 & & +02 & & & & & 6 \\
\hline & 15 & .22 & 02 & .3 & .00 & .00 & & .1 \\
\hline 18 & $\begin{array}{c}10 \\
15\end{array}$ & -.17 & & & & & & \\
\hline 19 & 10 & -.2 & $E+c$ & & 30 & $+\infty 0$ & $+\infty$ & -.5 \\
\hline & 13 & .21 & & & & & & \\
\hline 20 & 7 & -.1 & +01 & -08 & $+\infty$ & $+\infty$ & $:+\infty$ & -.53 \\
\hline & 9 & .10 & 01 & .79 & .00 & .00 & .00 & -.57 \\
\hline 21 & 9 & -.30 & $79 E+01$ & $2 E-07$ & $E+\infty$ & $+\infty$ & $O E+00$ & E-06 \\
\hline & 11 & .30 & $E+01$ & & .00 & .00 & .00 & -.16 \\
\hline 22 & 10 & & $536 E+0$ & $-.35446 \mathrm{E}-07$ & $E+\infty$ & $E+00$ & $.00000 \mathrm{E}+00$ & -.1 \\
\hline & 11 & .30 & $36 \mathrm{E}+01$ & .35 & .0000 & .00 & & -.1 \\
\hline 23 & 8 & -1 & $76 \mathrm{E}+01$ & 8E-08 & $E+\infty$ & $E+\infty$ & $.00000 E+00$ & $-.56200 \mathrm{E}-07$ \\
\hline & 10 & & $76 \mathrm{E}+01$ & 3E-08 & .00 & .0 & $.00000 \mathrm{E}+00$ & \\
\hline
\end{tabular}




\section{RELIABILITY ANALYSIS RESULTS}

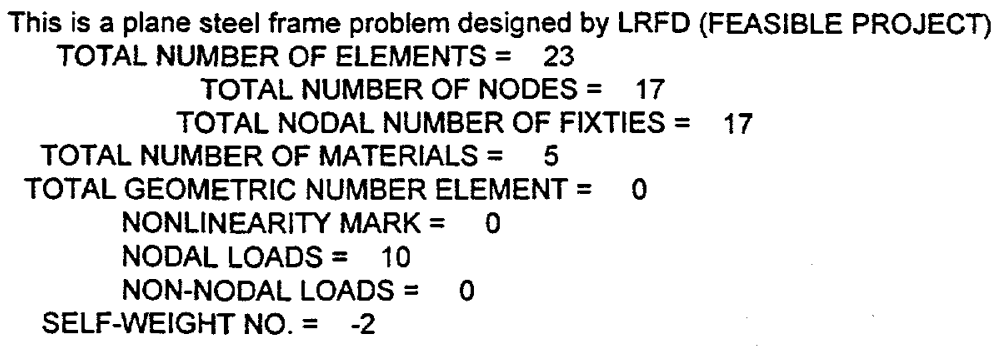

\section{ELEMENT DEFINITIONS \\ ELEMENT NODE1 NODE2 NODE3}

$\begin{array}{cccccc}1 & 1 & 3 & 2 & 1 & 1 \\ 2 & 3 & 7 & 2 & 2 & 2 \\ 3 & 2 & 6 & 1 & 1 & 3 \\ 4 & 6 & 8 & 1 & 1 & 4 \\ 5 & 4 & 17 & 1 & 3 & 5 \\ 6 & 4 & 5 & 1 & 3 & 6 \\ 7 & 5 & 6 & 1 & 3 & 7 \\ 8 & 7 & 12 & 11 & 4 & 8 \\ 9 & 12 & 14 & 11 & 4 & 9 \\ 10 & 14 & 16 & 11 & 4 & 10 \\ 11 & 15 & 16 & 11 & 4 & 11 \\ 12 & 13 & 15 & 11 & 4 & 12 \\ 13 & 8 & 13 & 11 & 4 & 13 \\ 14 & 9 & 12 & 7 & 5 & 14 \\ 15 & 9 & 14 & 7 & 5 & 15 \\ 16 & 11 & 14 & 7 & 5 & 16 \\ 17 & 11 & 15 & 8 & 5 & 17 \\ 18 & 10 & 15 & 8 & 5 & 18 \\ 19 & 10 & 13 & 8 & 5 & 19 \\ 20 & 7 & 9 & 1 & 5 & 20 \\ 21 & 9 & 11 & 1 & 5 & 21 \\ 22 & 10 & 11 & 1 & 5 & 22 \\ 23 & 8 & 10 & 1 & 5 & 23\end{array}$

NODAL COORDINATES

\begin{tabular}{llll} 
NODE & \multicolumn{1}{c}{$X$} & $Y$ & $Z$ \\
& & & \\
1 & .000 & .000 & .000 \\
2 & 30.000 & .000 & .000 \\
3 & .000 & 20.000 & .000 \\
4 & 10.000 & 20.000 & .000 \\
5 & 20.000 & 20.000 & .000 \\
6 & 30.000 & 20.000 & .000 \\
7 & .000 & 35.000 & .000 \\
8 & 30.000 & 35.000 & .000 \\
9 & 7.500 & 35.000 & .000 \\
10 & 22.500 & 35.000 & .000 \\
11 & 15.000 & 35.000 & .000 \\
12 & 5.000 & 38.000 & .000 \\
13 & 25.000 & 38.000 & .000 \\
14 & 10.000 & 41.000 & .000 \\
15 & 20.000 & 41.000 & .000 \\
16 & 15.000 & 44.000 & .000 \\
17 & .000 & 20.000 & .000
\end{tabular}




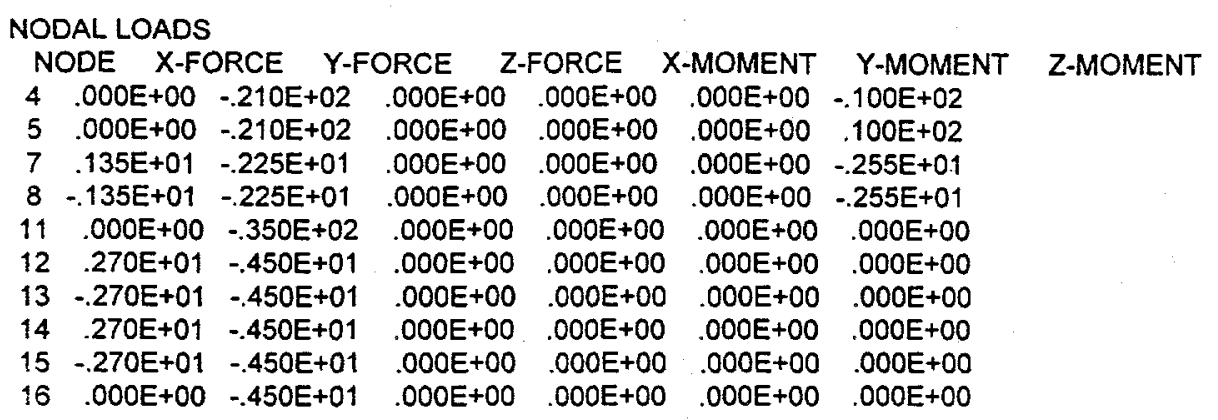

\section{BOUNDARY CONDITIONS}

$\begin{array}{ccccccccccccc}\text { NODE } & X \text {-DIREC. } & Y \text {-DIREC. } & \text { Z-DIREC. } X-X & Y-Y & Z-Z \\ 1 & 1 & 1 & 1 & 1 & 1 & 1 & .0000 & .0000 & .0000 & .0000 & .0000 & .0000 \\ 2 & 1 & 1 & 1 & 1 & 1 & 0 & .0000 & .0000 & .0000 & .0000 & .0000 & .0000 \\ 3 & 0 & 0 & 1 & 1 & 1 & 0 & .0000 & .0000 & .0000 & .0000 & .0000 & .0000 \\ 4 & 0 & 0 & 1 & 1 & 1 & 0 & .0000 & .0000 & .0000 & .0000 & .0000 & .0000 \\ 5 & 0 & 0 & 1 & 1 & 1 & 0 & .0000 & .0000 & .0000 & .0000 & .0000 & .0000 \\ 6 & 0 & 0 & 1 & 1 & 1 & 0 & .0000 & .0000 & .0000 & .0000 & .0000 & .0000 \\ 7 & 0 & 0 & 1 & 1 & 1 & 0 & .0000 & .0000 & .0000 & .0000 & .0000 & .0000 \\ 8 & 0 & 0 & 1 & 1 & 1 & 0 & .0000 & .0000 & .0000 & .0000 & .0000 & .0000 \\ 9 & 0 & 0 & 1 & 1 & 1 & 0 & .0000 & .0000 & .0000 & .0000 & .0000 & .0000 \\ 10 & 0 & 0 & 1 & 1 & 1 & 0 & .0000 & .0000 & .0000 & .0000 & .0000 & .0000 \\ 11 & 0 & 0 & 1 & 1 & 1 & 0 & .0000 & .0000 & .0000 & .0000 & .0000 & .0000 \\ 12 & 0 & 0 & 1 & 1 & 1 & 0 & .0000 & .0000 & .0000 & .0000 & .0000 & .0000 \\ 13 & 0 & 0 & 1 & 1 & 1 & 0 & .0000 & .0000 & .0000 & .0000 & .0000 & .0000 \\ 14 & 0 & 0 & 1 & 1 & 1 & 0 & .0000 & .0000 & .0000 & .0000 & .0000 & .0000 \\ 15 & 0 & 0 & 1 & 1 & 1 & 0 & .0000 & .0000 & .0000 & .0000 & .0000 & .0000 \\ 16 & 0 & 0 & 1 & 1 & 1 & 0 & .0000 & .0000 & .0000 & .0000 & .0000 & .0000 \\ 17 & 3 & 3 & 1 & 1 & 1 & 0 & .0000 & .0000 & .0000 & .0000 & .0000 & .0000\end{array}$

\begin{tabular}{|c|c|c|c|c|c|c|c|c|c|}
\hline \multicolumn{10}{|c|}{ THE PROPERTIES OF CROSS SECTION } \\
\hline & EM. Ax & $A z$ & Iy & E & $\mathbf{p}$ & & & & \\
\hline 1 & $.2650 \mathrm{E}+02$ & $.6170 E+01$ & $.1375 E+02$ & $.4060 E+01$ & $.3620 E+03$ & $.9990 E+03$ & $.2900 E+05$ & $.3000 E+00$ & $.2830 E-03$ \\
\hline 2 & $.1440 E+02$ & $.3390 \mathrm{E}+01$ & $.7470 E+01$ & $.1390 E+01$ & $.9340 \mathrm{E}+02$ & $.2720 E+03$ & $.2900 E+05$ & $.3000 E+00$ & .2830 E-03 \\
\hline 3 & $.1470 E+02$ & $.7920 \mathrm{E}+01$ & $.4660 E+01$ & $.1140 E+01$ & .2490E+02 & $.9840 E+03$ & $.2900 E+05$ & $.3000 E+00$ & $.2830 \mathrm{E}-03$ \\
\hline 4 & $.1030 E+02$ & $.5310 E+01$ & $.3400 E+01$ & $.5100 E+00$ & $.1530 \mathrm{E}+02$ & $.5100 E+03$ & $.2900 E+05$ & $.3000 E+00$ & $.2830 E-03$ \\
\hline 5 & $.1940 E+01$ & $.6700 E+00$ & $.6700 \mathrm{E}+00$ & $.4000 \mathrm{E}-01$ & $.4850 E+01$ & $.1220 E-07$ & $.2900 E+05$ & $.3000 \mathrm{E}+00$ & $.2830 \mathrm{E}-03$ \\
\hline
\end{tabular}

\begin{tabular}{lll} 
& \multicolumn{2}{c}{. } \\
.04000000 & .00000000 & .00000000 \\
.02250000 & .00000000 & .00000000 \\
.00000000 & .00000000 & .00000000 \\
.00000000 & .00000000 & .00000000 \\
.00000000 & .00000000 & .00000000
\end{tabular}




$\begin{array}{llllll}.2000 E+01 & .0000 E+00 & .0000 E+00 & .0000 E+00 & .0000 E+00 & .0000 E+00 \\ .4000 E+01 & .0000 E+00 & .0000 E+00 & .0000 E+00 & .0000 E+00 & .0000 E+00 \\ .0000 E+00 & .0000 E+00 & .0000 E+00 & .0000 E+00 & .0000 E+00 & .0000 E+00 \\ .0000 E+00 & .0000 E+00 & .0000 E+00 & .0000 E+00 & .0000 E+00 & .0000 E+00 \\ .0000 E+00 & .0000 E+00 & .0000 E+00 & .0000 E+00 & .0000 E+00 & .0000 E+00\end{array}$

INPUT THE LOCAL AVAERAGE ELEMENT NUMBER: NEAD(I)

MATERIAL 1 \# LOCAL AVERAGE MESH NUMBER $=23$

MATERIAL 2\# LOCAL AVERAGE MESH NUMBER $=10$

MATERIAL 3\# LOCAL AVERAGE MESH NUMBER = 0

MATERIAL 4\# LOCAL AVERAGE MESH NUMBER = 0.

MATERIAL 5\# LOCAL AVERAGE MESH NUMBER = 0

INPUT THE RANDONINESS MARK OF EVERY FIELD: MY(1,J)

$\begin{array}{llll}1 & 1 & 0 & 0 \\ 2 & 1 & 0 & 0 \\ 3 & 0 & 0 & 0 \\ 4 & 0 & 0 & 0 \\ 5 & 0 & 0 & 0\end{array}$

$* *$ LOCAL AVERAGE ELEMENTS AMOUNT $=33^{\star * \star}$

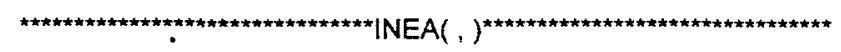

$\begin{array}{cccc}1 & 1 & 3 & 1 \\ 2 & 3 & 7 & 1 \\ 3 & 2 & 6 & 1 \\ 4 & 6 & 8 & 1 \\ 5 & 4 & 17 & 1 \\ 6 & 4 & 5 & 1 \\ 7 & 5 & 6 & 1 \\ 8 & 7 & 12 & 1 \\ 9 & 12 & 14 & 1 \\ 10 & 14 & 16 & 1 \\ 11 & 15 & 16 & 1 \\ 12 & 13 & 15 & 1 \\ 13 & 8 & 13 & 1 \\ 14 & 9 & 12 & 1 \\ 15 & 9 & 14 & 1 \\ 16 & 11 & 14 & 1 \\ 17 & 11 & 15 & 1 \\ 18 & 10 & 15 & 1 \\ 19 & 10 & 13 & 1 \\ 20 & 7 & 9 & 1 \\ 21 & 9 & 11 & 1 \\ 22 & 10 & 11 & 1 \\ 23 & 8 & 10 & 1 \\ 24 & 4 & 4 & 2 \\ 25 & 5 & 5 & 2 \\ 26 & 7 & 7 & 2 \\ 27 & 8 & 8 & 2 \\ 28 & 11 & 11 & 2 \\ 29 & 12 & 12 & 2 \\ 30 & 13 & 13 & 2 \\ 31 & 14 & 14 & 2 \\ 32 & 15 & 15 & 2 \\ 33 & 16 & 16 & 2 \\ & & & \end{array}$


NODE OF DISPLACEMENT = NO OF DIPLACEMENT $=2$ LIMIT OF DISPLACEMENT

\begin{tabular}{|c|c|c|}
\hline 1 & 1 & $.00000 E+00$ \\
\hline 1 & 2 & $.00000 E+00$ \\
\hline 1 & 3 & $.00000 E+00$ \\
\hline 1 & 4 & $.00000 E+00$ \\
\hline 1 & 5 & $.00000 E+00$ \\
\hline 1 & 6 & $.00000 E+00$ \\
\hline 0 & 1 & $.00000 E+00$ \\
\hline ก & 2 & $.00000 E+00$ \\
\hline ? & 3 & $.00000 E+00$ \\
\hline 2 & 4 & $.00000 E+00$ \\
\hline 2 & 5 & $.00000 E+00$ \\
\hline O & 6 & $.46479 E-04$ \\
\hline 0 & 1 & $-.62311 E-03$ \\
\hline 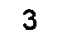 & 2 & $-.13334 \mathrm{E}-02$ \\
\hline 0 & 3 & $.00000 E+00$ \\
\hline 0 & 4 & $.00000 E+00$ \\
\hline 3 & 5 & $.00000 E+00$ \\
\hline 3 & 6 & $.53141 \mathrm{E}-05$ \\
\hline 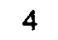 & 1 & $-.57710 \mathrm{E}-03$ \\
\hline 4 & 2 & $-.43344 E-02$ \\
\hline 4 & 3 & $.00000 E+00$ \\
\hline 4 & 4 & $.00000 E+00$ \\
\hline 4 & 5 & $.00000 E+00$ \\
\hline 4 & 6 & $-.45693 \mathrm{E}-04$ \\
\hline 5 & 1 & $-.53109 \mathrm{E}-03$ \\
\hline 5 & 2 & $-.43449 \mathrm{E}-02$ \\
\hline 5 & 3 & $.00000 E+00$ \\
\hline 5 & 4 & $.00000 E+0$ \\
\hline 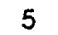 & 5 & $.00000 E+0$ \\
\hline 5 & 6 & $.28026 \mathrm{E}-04$ \\
\hline 6 & 1 & $-.48508 \mathrm{E}-03$ \\
\hline 6 & 2 & $-.13885 E-02$ \\
\hline 6 & 3 & $.00000 \mathrm{E}+0$ \\
\hline 6 & 4 & $.00000 E+00$ \\
\hline 6 & 5 & $.00000 E+0 C$ \\
\hline 6 & 6 & $.59025 E-04$ \\
\hline 7 & 1 & -.17830 E-02 \\
\hline 7 & 2 & $-.24375 E-02$ \\
\hline 7 & 3 & $.00000 E+00$ \\
\hline 7 & 4 & $.00000 E+00$ \\
\hline 7 & 5 & $.00000 E+00$ \\
\hline 7 & 6 & $-.68500 E-04$ \\
\hline 8 & 1 & $-.68329 E-03$ \\
\hline 8 & 2 & $-.20031 E-02$ \\
\hline 8 & 3 & $.00000 E+00$ \\
\hline 8 & 4 & $.00000 E+00$ \\
\hline 8 & 5 & $.00000 E+00$ \\
\hline 8 & 6 & $.82110 \mathrm{E}-04$ \\
\hline 9 & 1 & $-.16377 \mathrm{E}-02$ \\
\hline 9 & 2 & $-.56587 E-02$ \\
\hline 9 & 3 & $.00000 E+00$ \\
\hline 9 & 4 & $.00000 E+00$ \\
\hline 9 & 5 & $.00000 E+00$ \\
\hline 9 & 6 & $-.57958 \mathrm{E}-03$ \\
\hline 10 & 1 & $-.81894 E-0$ \\
\hline 10 & 2 & $-.54344 \mathrm{E}-0$ \\
\hline 10 & 3 & $.00000 \mathrm{E}+0$ \\
\hline 10 & 4 & $.00000 \mathrm{E}+0$ \\
\hline 10 & 5 & $.00000 \mathrm{E}+0$ \\
\hline 10 & 6 & $.61264 E-0$ \\
\hline 1 & 1 & $-.12260 \mathrm{E}-0$ \\
\hline & 2 & $-.11312 E-0$ \\
\hline
\end{tabular}

11

AT MIDSPAN POINT =

.08333 

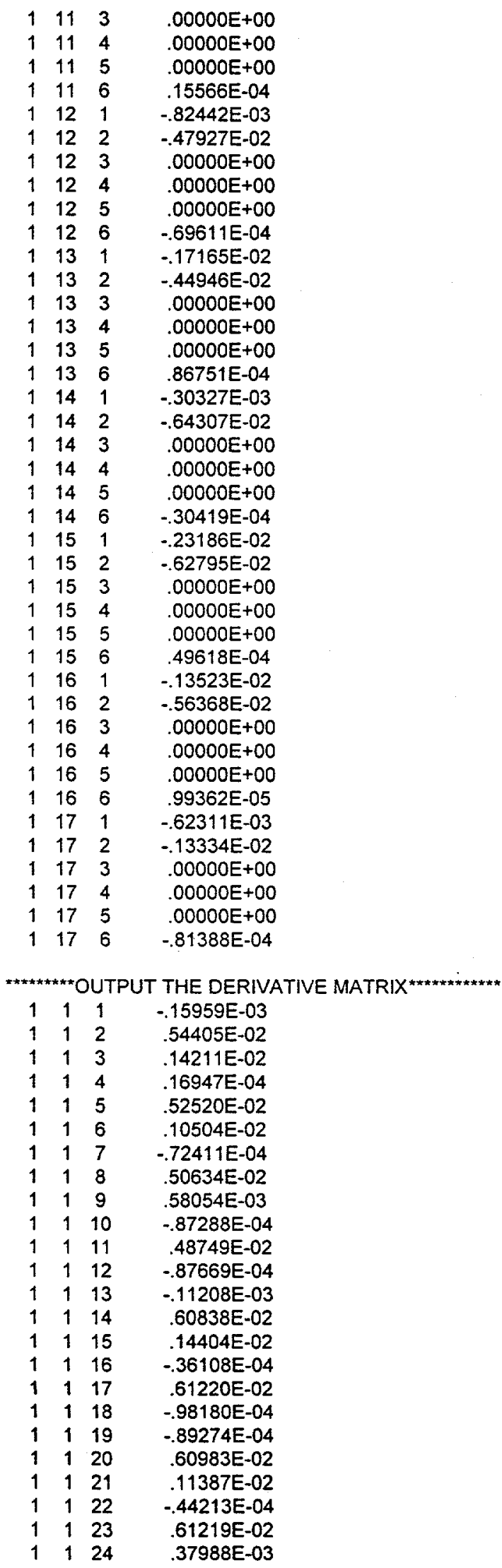


$\begin{array}{llll}1 & 1 & 25 & -.52261 \mathrm{E}-04 \\ 1 & 1 & 26 & .61135 \mathrm{E}-02 \\ 1 & 1 & 27 & .79076 \mathrm{E}-03 \\ 1 & 1 & 28 & -.49672 \mathrm{E}-04 \\ 1 & 1 & 29 & .62270 \mathrm{E}-02 \\ 1 & 1 & 30 & .12464 \mathrm{E}-02 \\ 1 & 1 & 31 & -.43603 \mathrm{E}-04 \\ 1 & 1 & 32 & .63047 \mathrm{E}-02 \\ 1 & 1 & 33 & .23336 \mathrm{E}-03 \\ 1 & 1 & 34 & -.76535 \mathrm{E}-04 \\ 1 & 1 & 35 & .63921 \mathrm{E}-02 \\ 1 & 1 & 36 & .10157 \mathrm{E}-02 \\ 1 & 1 & 37 & -.50927 \mathrm{E}-04 \\ 1 & 1 & 38 & .64561 \mathrm{E}-02 \\ 1 & 1 & 39 & .51244 \mathrm{E}-03 \\ 1 & 1 & 40 & -.66151 \mathrm{E}-04 \\ 1 & 1 & 41 & .65810 \mathrm{E}-02 \\ 1 & 1 & 42 & .74542 \mathrm{E}-03 \\ 1 & 1 & 43 & -.58038 \mathrm{E}-04 \\ 1 & 1 & 44 & -.67452 \mathrm{E}-04\end{array}$

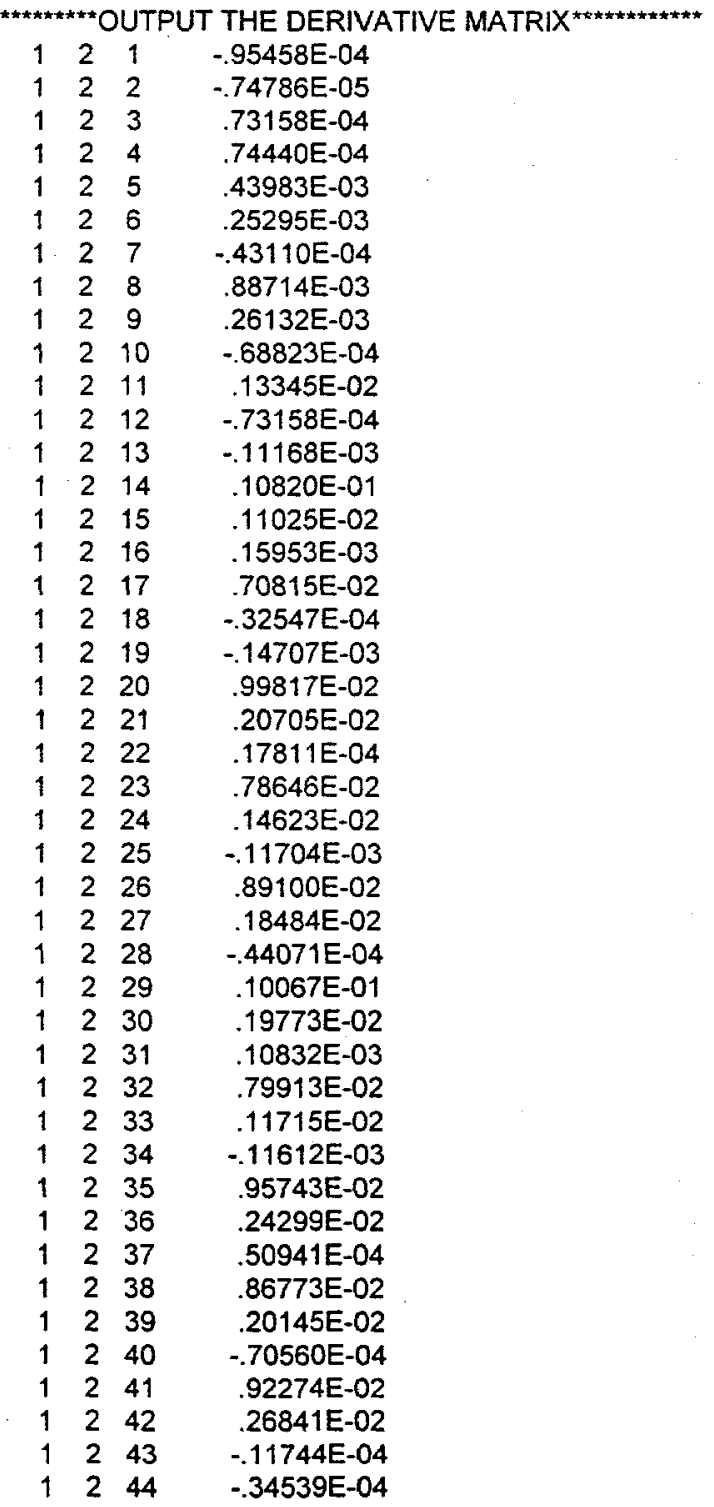




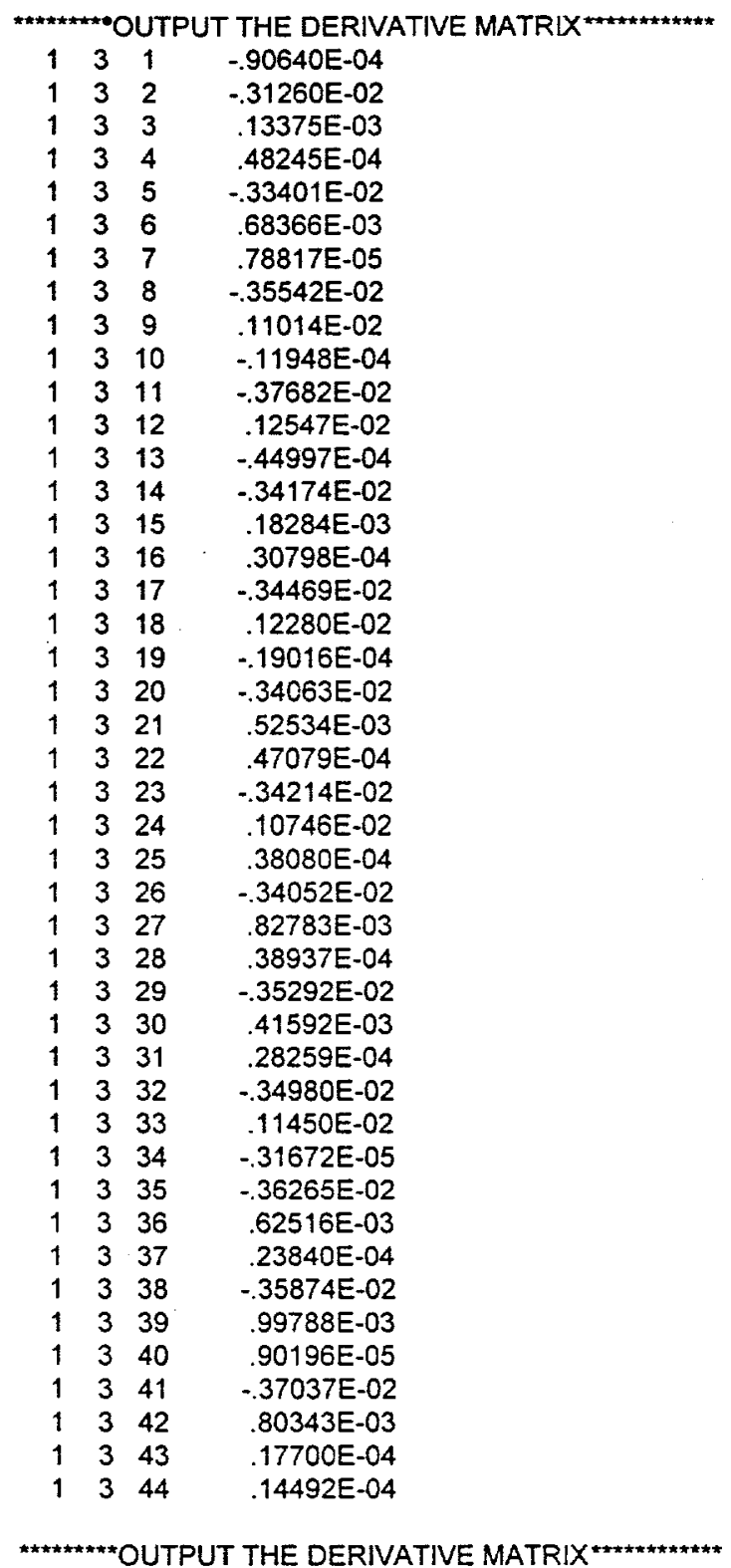

********* OUTPUT THE DERIVATIVE MATRIX************
$\begin{array}{lll}1 & 33 & 1\end{array}$
33280E-06
$\begin{array}{llll}1 & 33 & 2 & -.23397 \mathrm{E}-04\end{array}$
$\begin{array}{llll}1 & 33 & 3 & -.57260 E-04\end{array}$
$\begin{array}{llll}1 & 33 & 4 & .66190 E-06\end{array}$
$1 \quad 33 \quad 5 \quad-.13455 E-04$
$1336 \quad-.59811 \mathrm{E}-04$
$\begin{array}{llll}1 & 33 & 7 & .19587 E-06\end{array}$
$\begin{array}{llll}1 & 33 & 8 & -.35132 \mathrm{E}-05\end{array}$
$13390 \quad-.61097$ E-04
$\begin{array}{llll}1 & 33 & 10 & .38571 E-06\end{array}$
$\begin{array}{lllll}1 & 33 & 11 & .64285 E-05\end{array}$
$\begin{array}{llll}1 & 33 & 12 & -.59851 E-04\end{array}$
$\begin{array}{llll}1 & 33 & 13 & .70210 E-06\end{array}$
$\begin{array}{llll}1 & 33 & 14 & -.19468 \mathrm{E}-03\end{array}$
$133 \quad 15 \quad-.13499 E-03$ 


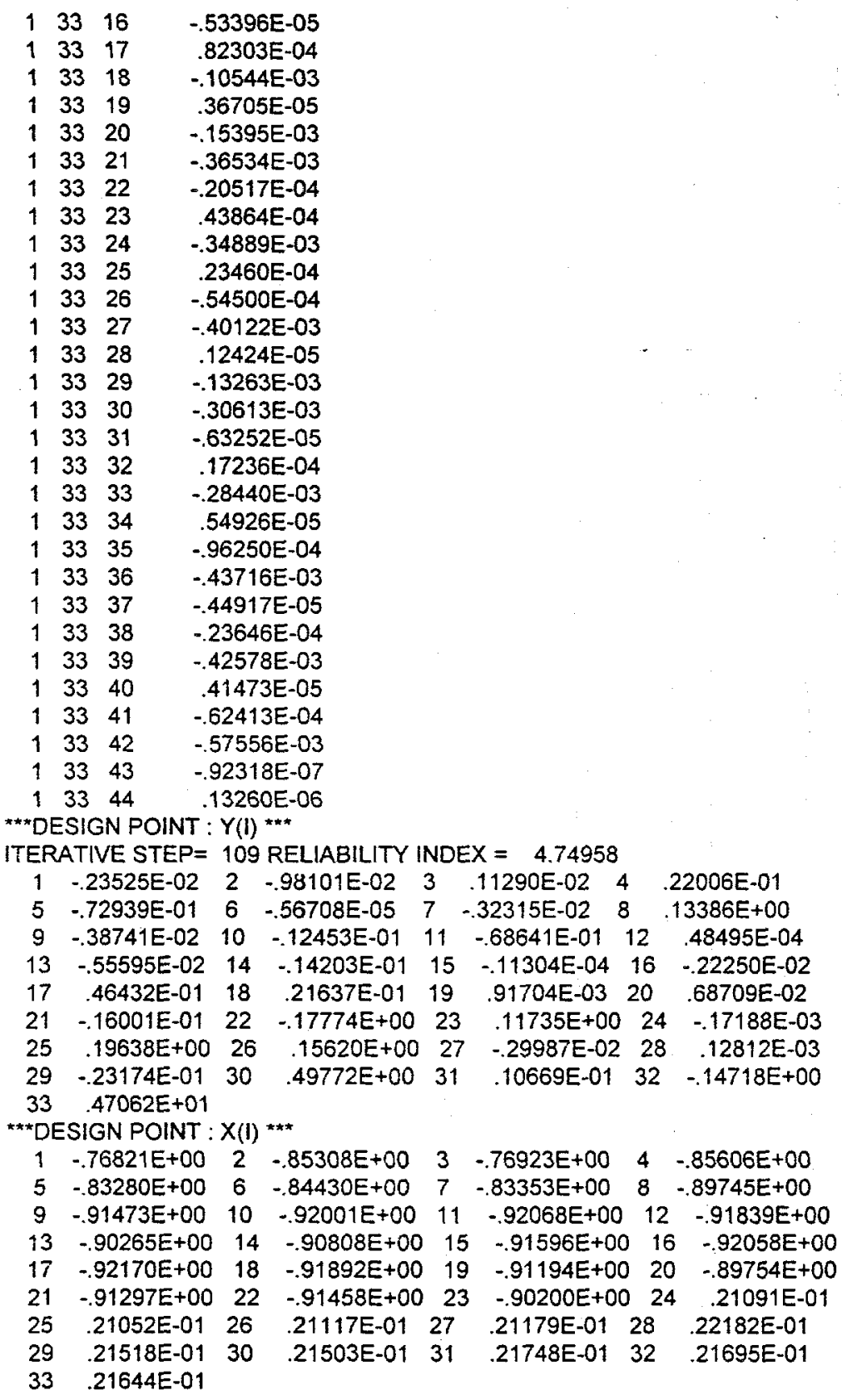

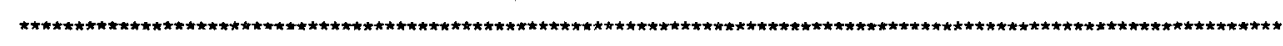




\section{PART IV. EXPLANATIONS FOR INPUT DATA}

\section{CONTROL VARIABLES}

Format:

DESCRIPTION OF CURRENT WORK MXNEL,MXNOD,MXFIX,MXMAT,MXGEO,NLGEO,MXLOD,MXNLD, NWEIGHT

MXNEL: $\quad$ Maximum number of finite elements

MXNOD: $\quad$ Maximum number of nodes

MXFIX: $\quad$ Maximum number of restraints

MXMAT: $\quad$ Maximum number of material types

MXGEO: Maximum number of elements with initial geometrical stiffness

NLGEO: $\quad$ Sign of structural geometrical nonlinearity

0 : without structural geometrical nonlinearity

1: with structural geometrical nonlinearity

MXLOD: $\quad$ Maximum number of external nodal loads

MXNLD: $\quad$ Maximum number of external non-nodal loads

NWEIGHT: $\quad$ Sign of self-weight

0 : No self-weight load

-1 : Self-weight load along negative $\mathrm{X}$-axis direction

-2 : Self-weight load along negative $\mathrm{Y}$-axis direction

-3: Self-weight load along negative Z-axis direction

\section{INFORMATION ON ELEMENTS}

Format:

No of element, Joint I, Joint J, Joint K, Number of material, Number of mesh of random field

\section{INFORMATION ON NODAL COORDINATES}

Format:

Number of node. X-coordinate, Y-coordinate, Z-coordinate

4. READING NODAL LOADS .

Format:

Number of node, X-component, Y-component, Z-component, X-X component, Y-Y component, $\mathrm{Z}-\mathrm{Z}$ component 


\section{READING NON-NODAL LOADS \\ Format:}

Number of non-nodal load, magnitude of load, Distribution length on the finite element, Number of the finite element, Type of non-nodal load

\section{READING BOUNDARY CONDITIONS}

Format:

Number of node, $\mathrm{X}$-axis boundary, $\mathrm{Y}$-axis boundary, Z-axis boundary, $\mathrm{X}-\mathrm{X}$ axis boundary, $\mathrm{Y}-\mathrm{Y}$ axis boundary, $Z-Z$ axis boundary, initial deflection along $X$-axis, initial deflection along $Y$-axis, initial deflection along $Z$-axis, initial deflection along $\mathrm{X}-\mathrm{X}$ axis, initial deflection along $\mathrm{Y}-\mathrm{Y}$ axis, initial deflection along $\mathrm{Z}-\mathrm{Z}$ axis

Note:

0 : free

1: fixed

7. READING MATERIAL PROPERTIES

Format:

Number of material, section area of $X$-axis, section area of $Y$-axis, section area of $Z$-axis, Inertial moment along X-X, Inertial moment along Y-Y, Inertial moment along Z-Z, Modulus of elasticity, Poisson's ratio, Density of self-weight

\section{READING GEOMETRICAL STIFFNESS}

This card is effective only in the case of geometrical nonlinearity.

Format:

Number of finite element, Internal force component along X-axis, Internal force component along Y-axis, Internal force component along Z-axis*

Note: ${ }^{*}$ Of the three internal force components, only one is needed to input.

\section{READING VARIATION OF RANDOM VARIABLES}

In this program, there are five random fields that are independent to each other. In every random field, there are three random variables: modulus of elasticity, modulus of shear, and length of element.

Format:

$\operatorname{Var}(\mathrm{E} 1), \operatorname{Var}(\mathrm{G} 1), \operatorname{Var}(\mathrm{L} 1)$,

$\operatorname{Var}(\mathrm{E} 2), \operatorname{Var}(\mathrm{G} 2), \operatorname{Var}(\mathrm{L} 2)$,

$\operatorname{Var}(\mathrm{E} 3), \operatorname{Var}(\mathrm{G} 3), \operatorname{Var}(\mathrm{L} 3)$,

$\operatorname{Var}(\mathrm{E} 4), \operatorname{Var}(\mathrm{G} 4), \operatorname{Var}(\mathrm{L} 4)$, 
$\operatorname{Var}(\mathrm{E} 5), \operatorname{Var}(\mathrm{G} 5), \operatorname{Var}(\mathrm{L} 5)$

Note:

E denotes modulus of elasticity;

$\mathrm{G}$ denotes modulus of shear;

$\mathrm{L}$ denotes length of element;

Number 1,2,3,4, or 5 represents the number of five random fields, respectively; and

Var denotes variation of random variables.

\section{READING CORRELATION LENGTH BETWEEN RANDOM VARIABLES}

Let $\theta$ denote the correlation length between random variables, then the information is arranged in the following queue:

Format:

$$
\begin{aligned}
& \theta_{E 1 E 1}, \theta_{E 1 G 1}, \theta_{E 1 L 1}, \theta_{G 1 G 1}, \theta_{G 1 L 1}, \theta_{L 1 L 1}, \\
& \theta_{E 2 E 2}, \theta_{E 2 G 2}, \theta_{E 2 L 2}, \theta_{G 2 G 2}, \theta_{G 2 L 2}, \theta_{L 2 L 2}, \\
& \theta_{E 3 E 3}, \theta_{E 3 G 3}, \theta_{E 3 L 3}, \theta_{G 3 G 3}, \theta_{G 3 L 3}, \theta_{L 3 L 3}, \\
& \theta_{E 4 E 4}, \theta_{E 4 G 4}, \theta_{E 4 L 4}, \theta_{G 4 G 4}, \theta_{G 4 L 4}, \theta_{L+L 4}, \\
& \theta_{E 5 E 5}, \theta_{E S G 5}, \theta_{E 5 L 5}, \theta_{G S G 5}, \theta_{G 5 L 5}, \theta_{L 5 L 5}
\end{aligned}
$$

\section{READING MESH NUMBER OF EVERY RANDOM FIELD}

\section{Format:}

Number of mesh in No. 1 random field, Number of mesh in No. 2 random field, Number of mesh in No. 3 random field, Number of mesh in No. 4 random field, Number of mesh in No. 5 random field

\section{READING INFORMATION ON VARIABLE IN USE}

Format:

Number, Sign of variable No. 1, Sign of variable No. 2, Sign of variable No. 3

Note:

Variable No. 1: denotes modulus of elasticity;

Variable No. 2: denotes modulus of shear;

Variable No. 3: denotes length of element;

0 : deterministic

1: random 


\section{READING MESHES OF RANDOM FIELD}

Format:

Number, Node I, Node J, Sign of mesh shape *

Note:

* 0 for horizontal or vertical case; 1 for arbitrary shape

\section{READING LIMIT STATE OF SERVICEABILITY}

Format:

Node. Direction component *, Limit of displacement **

Note:

* $\quad$ 1: X-axis; 2 : $Y$-axis; 3: Z-axis

** It is decided according to the current design code. 